\title{
A Multi-Dimensional Finite Element Code for the Analysis of Coupled Fluid, Energy and Solute Transport (CFEST)
}

\section{August 1982}

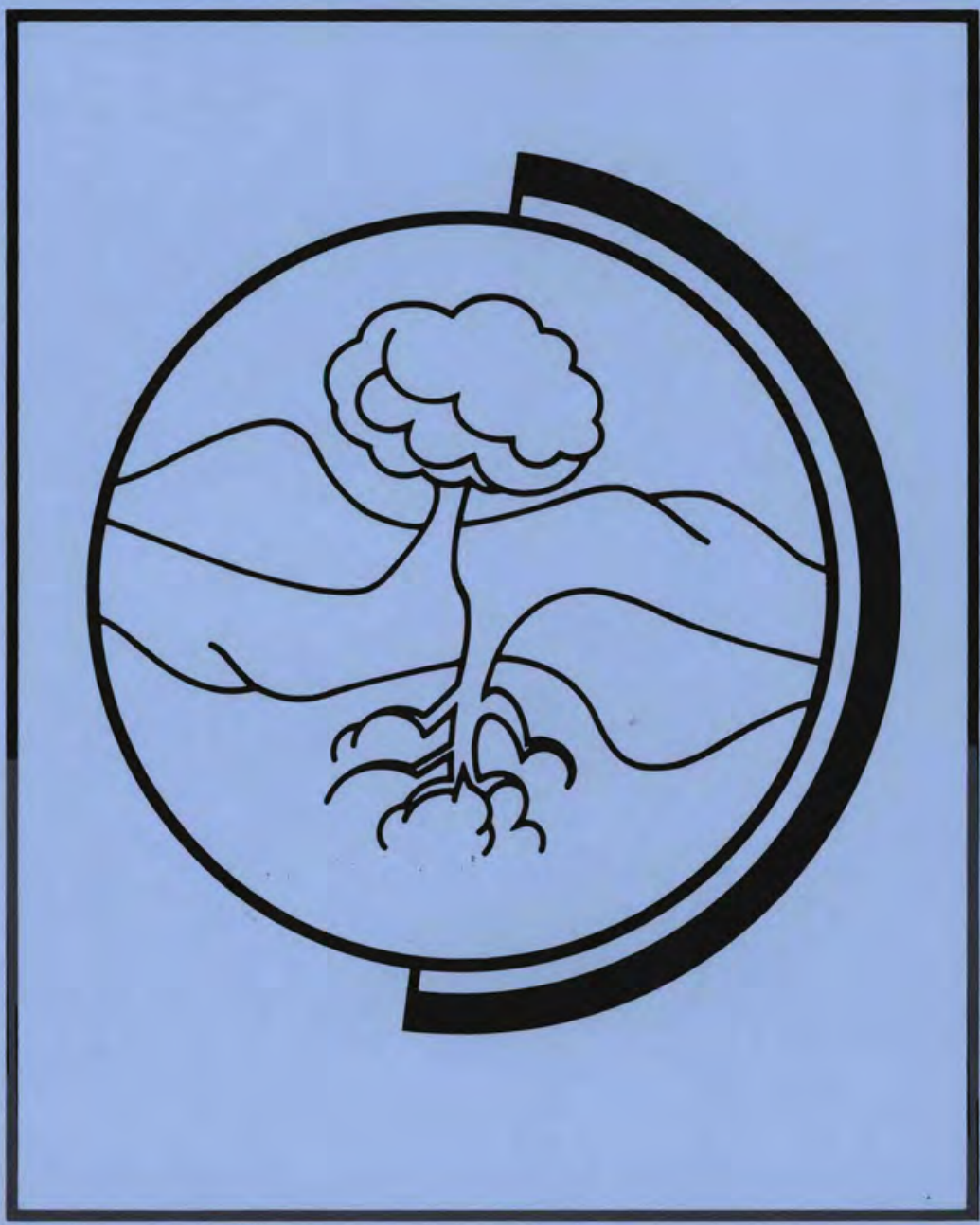

Prepared for the U.S. Department of Energy under Contract DE-AC06-76RLO 1830

Pacific Northwest Laboratory

Operated for the U.S Department of Energy by Battelle Memorial Institute 


\title{
DISCLAIMER
}

This report was prepared as an account of work sponsored by an agency of the United States Government. Neither the United States Government nor any agency thereof, nor any of their employees, makes any warranty, express or implied, or assumes any legal liability or responsibility for the accuracy, completeness, or usefulness of any information, apparatus, product, or process disclosed, or represents that its use would not infringe privately owned rights. Reference herein to any specific commercial product, process, or service by trade name, trademark, manufacturer, or otherwise, does not necessarily constitute or imply its endorsement, recommeridation, or favoring by the United States Government or any agency thereof. The views and opinions of authors expressed herein do not necessarily state or reflect those of the United States Government or any agency thereof.

\author{
PACIFIC NORTHWEST LABORATORY \\ operated by \\ BATTELLE \\ for the \\ UNITED STATES DEPARTMENT OF ENERGY \\ under Contract DE-AC06-76RLO 1830
}

\begin{tabular}{|c|c|}
\hline \multicolumn{2}{|c|}{ Printed in the United States of America } \\
\hline \multicolumn{2}{|c|}{ Available from } \\
\hline \multicolumn{2}{|c|}{ National Technical Information Service } \\
\hline \multirow{3}{*}{\multicolumn{2}{|c|}{$\begin{array}{c}\text { United States Department of Commerce } \\
5285 \text { Port Royal Road } \\
\text { Springfield, Virginia } 22151\end{array}$}} \\
\hline & \\
\hline & \\
\hline \multirow{2}{*}{\multicolumn{2}{|c|}{$\begin{array}{l}\text { NTIS Price Codes } \\
\text { Microfiche A01 }\end{array}$}} \\
\hline & \\
\hline \multicolumn{2}{|c|}{ Printed Copy } \\
\hline & Price \\
\hline Pages & Codes \\
\hline $001-025$ & $\mathrm{~A} 02$ \\
\hline $026-050$ & $\mathrm{~A} 03$ \\
\hline 051-075 & A04 \\
\hline $076-100$ & A05 \\
\hline $101-125$ & A06 \\
\hline $126-150$ & A07 \\
\hline $151-175$ & $\mathrm{~A} 08$ \\
\hline $176-200$ & A09 \\
\hline $201-225$ & A010 \\
\hline $226-250$ & $\mathrm{~A} 011$ \\
\hline $251-275$ & $\mathrm{~A} 012$ \\
\hline $276-300$ & $\mathrm{~A} 013$ \\
\hline
\end{tabular}


A MULTI-DIMENSIONAL FINITE ELEMENT CODE FOR THE ANALYSIS OF COUPLED FLUID, ENERGY AND SOLUTE TRANSPORT (CFEST)
S. K. Gupta
C. T. Kincaid
$P$. R. Meyer
C. A. Newbill
C. R. Cole

August 1982

Prepared for the U.S. Department of Energy under Contract DE-AC06-76RLO 1830

Pacific Northwest Laboratory

Richland, Washington 99352 

SUMMARY

Since 1979 the Pacific Northwest Laboratory has directed the Seasonal Thermal Energy Storage (STES) Program for the Department of Energy. Initially designed as a demonstration program, it was revamped in calendar year 1981 to address the technology adaptation and development needs of the seasonal storage concept. At the beginning of fiscal year 1982, STES was combined with the Compressed Air Energy Storage (CAES) Program under the Underground Energy Storage (UES) Program. While a variety of host media are being studied under the present program, aquifers remain the media of greatest potential for seasonal energy storage within the United States. One technology area of the Seasonal Thermal Energy Storage Program is the numerical modeling of an aquifer's response to nonisothermal flows. The primary objective of the numerical modeling subtask has been to provide the program with the best available technology for the design and evaluation of experimental field studies.

In light of the program's original scope (i.e., demonstration) a major goal of the numerical modeling task was the establishment of a responsive simulation capability. This report provides the primary documentation for a multidimensional analysis of coupled fluid, energy and solute transport. The code employs a standard Galerkin finite element methodology and is known by its acronym, CFEST. Presented herein are the basic physics and numerical methodology, the input requirements, and the verifications completed to date against published solutions. This document is not intended to be a user's manual. Detailed instructions for the operation of CFEST will be issued under separate cover for specific computing hardware.

Publication of these verification studies completes the first phase of the establishment of a responsive simulation capability for the program. Validation against recorded field data sets is the next step for the CFEST code. Following validation studies, CFEST will be employed in the evaluation of ongoing field studies of the Seasonal Thermal Energy Storage Program. 



\section{ABSTRACT}

The Seasonal Thermal Energy Storage Program is being conducted for the Department of Energy by Pacific Northwest Laboratory. A major thrust of this program has been the study of natural aquifers as hosts for thermal energy storage and retrieval. Numerical simulation of the nonisothermal response of the host media is fundamental to the evaluation of proposed experimental designs and field test results. This report represents the primary documentation for the coupled fluid, energy and solute transport (CFEST) code. Sections of this document are devoted to the conservation equations and their numerical analogues, the input data requirements, and the verification studies completed to date. 



\section{LIST OF SYMBOLS}

$a_{1}$

a2

$a_{3}$

$C_{p}^{\prime}$

$\mathrm{C}_{\text {pw }}$

$\left(\rho C_{p}\right)_{B}$

$\left(\rho C_{p}\right)_{r}$

$\mathrm{C}_{r}$

$\mathrm{C}_{\mathrm{T}}$

$C_{W}$

C

$c_{C}$

$C^{\prime}$

$D_{L}$

$\mathrm{D}_{\mathrm{T}}$

$\mathrm{D}_{\mathrm{m}}$

$D_{\alpha_{\beta}}$

$E_{\alpha B}$
= Partial derivative of density with respect to pressure

= Partial derivative of density with respect to temperature

= Partial derivative of density with respect to concentration

= Specific heat of injected fluid

$=$ Specific heat of water

= Overburden/underburden rock heat capacity

$=$ Rock. heat capacity per unit volume

= Compressibility of porous media

= Coefficient of thermal expansion of fluid aquifer fluid

= Compressibility of aquifer fluid

= Concentration of solute, mass fraction

= Rate of change of density per unit change in concentration

= Concentration of injected solute, mass fraction

= Longitudinal hydrodynamic dispersivity

= Transverse hydrodynamic dispersivity

= Molecular dispersion properties of medium including affects of tortuosity

= Homogeneous, isotropic dispersion tensor for 3-D flow inclusive of molecular diffusion

= Apparent (both hydrodynamic and molecular) heat conductivity tensor, analogous to $D_{\alpha \beta}$, i.e., homogeneous, isotropic
${ }_{0} C_{W}$

${ }_{0}{ }_{0} C_{T}$

$\rho_{0} C_{C}$

$E M-1 T-1$

$E M-1 T-1$

$E L-3 T-1$

$E L-3 T-1$

$L-1$

$T^{-1}$

$L-1$

ppm or $\%$

$\%$

ppm or $\%$

$L^{2} t-1$

$L \dot{L}^{\mathrm{t}-1}$

$L^{2} t-1$

$L^{2} t-1$

$E(L T t)^{-1}$ 


\section{LIST OF SYMBOLS (contd)}

Definitions

= Longitudinal hydrodynamic heat conductivity

= Transverse hydrodynamic heat conductivity

= Molecular thermal heat conductivity of medium and fluid

$\mathrm{E}_{0} \quad=$ Reference pressure, temperature and concentration conditions for po

$E_{Z}$

g

$h$

$h_{p}$

$h_{0}$

$n_{\theta}$

$$
\mathrm{h}
$$

$\mathrm{H}$

$\mathrm{H}_{\mathrm{E}}$

$H_{L}$

$k_{\alpha \beta}$

$K_{\alpha \beta}$

m

n

N

$p$

$q_{0}, q_{i}$
= Vertical heat conductivity of confining media

$$
E(L T t)-1
$$

= Acceleration due to gravity

= Equivalent hydraulic head $=z+p / g_{0}$

= Pressure head component of $h$

= Reference pressure head for aquifer density $=$ Reference pressure head at which $\theta_{0}$ is
defined

$=$ Pressure head of withdrawal, injection

= Simulated hydraulic head

$=$ Internal heat energy $=C_{p w}{ }^{\top}$

= Rate of heat loss gain at boundary of domain

= Intrinsic permeability of media

$=$ Hydraulic conductivity (collinear) $=\rho g k_{\alpha \beta} / \mu$

= Iteration counter also used for number of wells in source/sink functions

$=$ Number of global degrees of freedom

= Number of Gaussian quadrature points

= Pressure

= Mass rate of withdrawal and injection of fluid
$L t-2$

$E M-1$

$E L-2 t-1$

$L^{2}$

$L t-1$

$M t-1_{L}-3$

Units

$E(L T t)^{-1}$

$E(L T t)^{-1}$

$E(L T t)^{-1}$

L

L

L

L

L

$M t-1_{L}-3$ 


\section{LIST OF SYMBOLS (contd)}

= Strength of source or sink

$$
=q_{i}+\frac{d q_{i}}{d h_{p}}\left(h_{p_{i n}}-h_{p}\right)
$$

$=q_{o}-\frac{d q_{o}}{d h_{p}}\left(h_{p_{\text {out }}}-h_{p}\right)$

S

$\mathrm{t}$

$\mathrm{T}$

$T^{\prime}$

$T_{B}$

$T_{0}$

$T_{u}$

$u_{\alpha}$

u

U

V

$x$

z

Greek

$\alpha, \beta$

$\delta_{\alpha \beta}$

= Number of space dimensions

= Time

$\mathrm{T}$

= Temperature T T

$=$ Injection fluid temperature

T

= Vertical temperature distribution in confining media

= Reference temperature for density and internal energy

$=$ Reference temperature at which $U_{0}$ specified

= Components of the Darcy fluid velocity

$L t-1$

= Absolute Darcy fluid velocity

$L^{-1}$

$=$ Internal energy $=U_{0}+C_{p w}\left(T-T_{u}\right)$

$E M-1$

= Trial function (also called shape or basis function

\section{$E M-1$}

= Cartesian coordinate vector

L

= Elevation above datum

$L$

$=$ Cartesian component indices; i.e., 1, 2, and 3

$=$ Kronecker delta 
LIST OF SYMBOLS (contd)

Definitions

Units

$\theta$

$\theta_{0}$

$\mu$

$\rho$

$\rho 0$

$\varepsilon L$

$\epsilon T$
$=$ Porosity of aquifer at $h_{p}$

$=$ Porosity of aquifer at $h_{\theta}$

= Absolute viscosity

$=$ Density

$=$ Reference density at $h_{p}, T_{0}, C_{0}$

$M(L t)-1$

$M L-3$

$M L-3$

$=$ Bounded region

= Longitudinal dispersivity length of an isotropic porous medium

$=$ Transverse dispersivity length of an isotropic porous medium
L 


\section{CONTENTS}

SUMMARY

ABSTRACT .

LIST OF SYMBOLS.

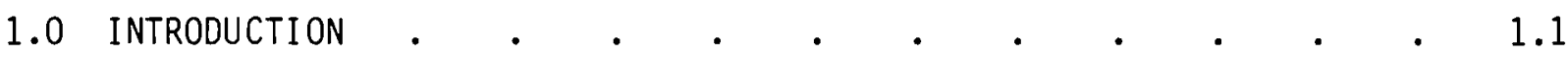

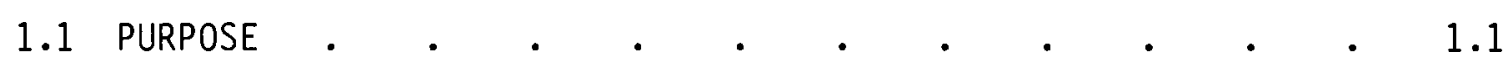

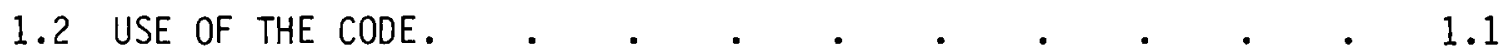

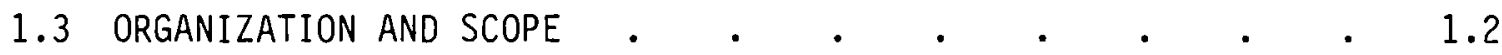

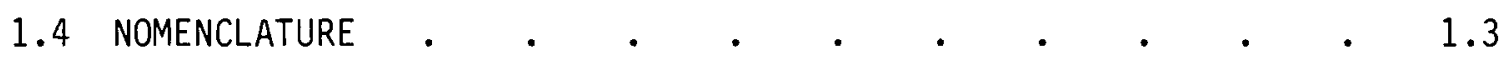

2.0 GOVERNING PARTIAL DIFFERENTIAL EQUATIONS AND

2.1 DEPENDENT VARIABLES AND ASSUMPTIONS. $\quad . \quad \ldots \quad$. $\quad$ • 2.1

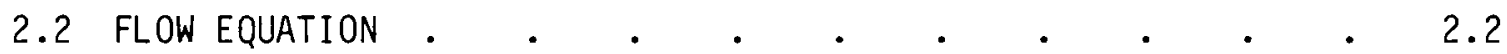

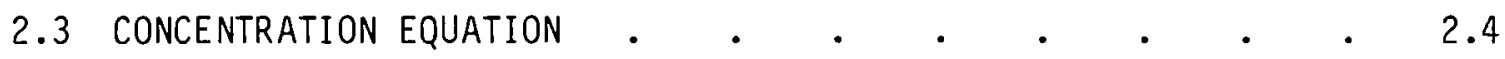

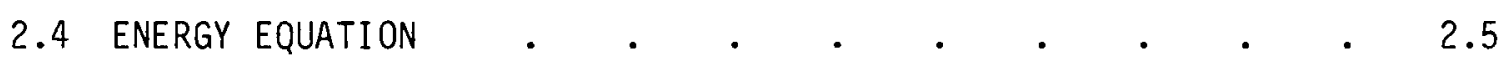

2.5 FLUID DENSITY AND POROSITY RELATIONSHIPS. $\quad$ • $\quad$ • $\quad$ • 2.8

2.6 SUBSTITUTION OF DENSITY AND POROSITY TERMS INTO
FLUID, ENERGY, AND SOLUTE TRANSPORT EQUATIONS. $\ldots . . \quad . \quad . \quad .11$

2.7 CRITERIA FOR CONVERGENCE . . . . . . . . . . . . 2.14

2.8 GALERKIN FINITE ELEMENT FORMULATION OF

2.9 GALERKIN FINITE ELEMENT FORMULATION OF TEMPERATURE EQUATION. $. \quad . \quad . \quad . \quad . \quad . \quad . \quad . \quad 2.18$

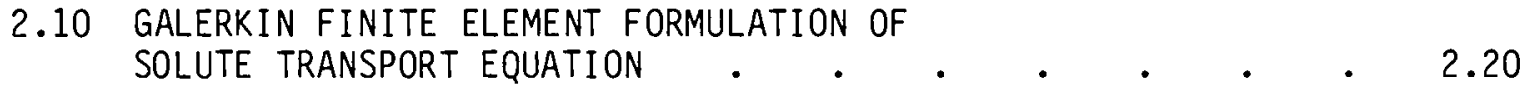

2.11 INTEGRATION OF APPROXIMATING EQUATIONS . $\quad . \quad \ldots \quad . \quad$. 2.21

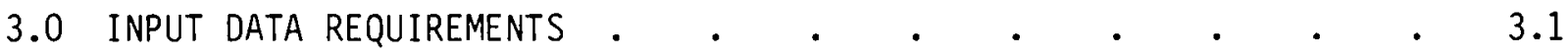

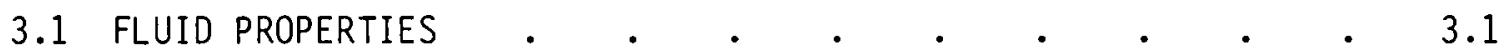




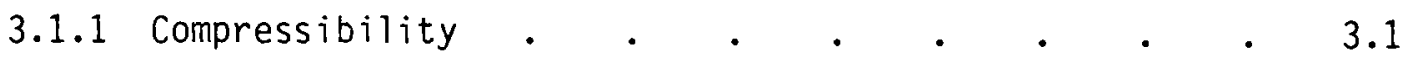

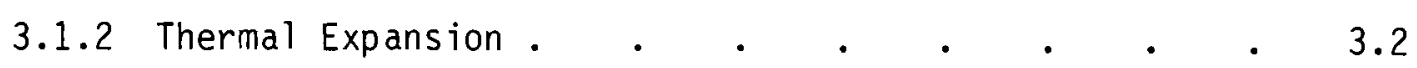

3.1.3 Composition Density Ratio . . . . . . . . 3.3

3.1 .4 Heat Capacity. . . . . . . . . . . 3.3

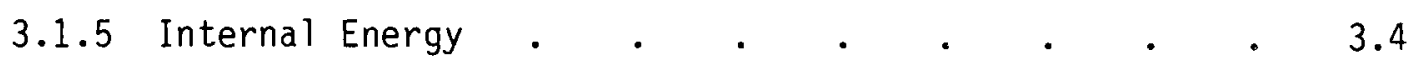

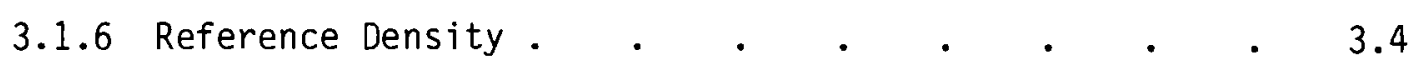

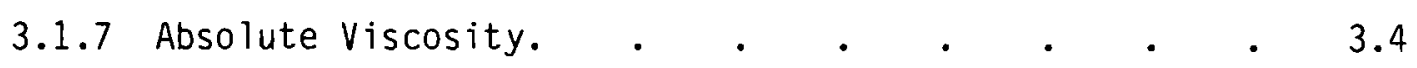

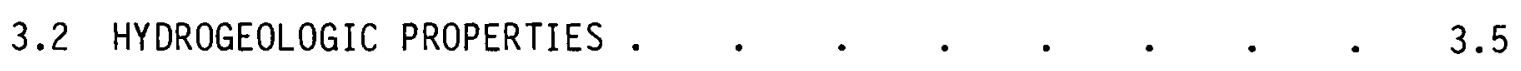

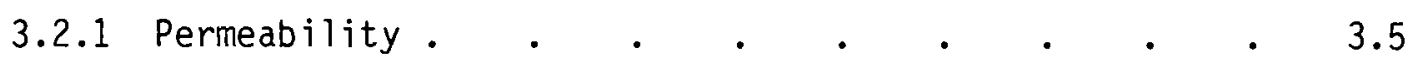

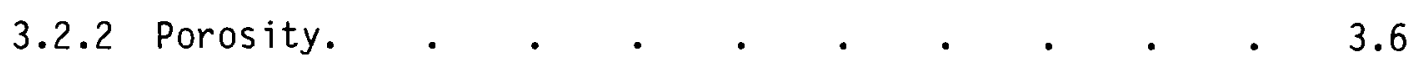

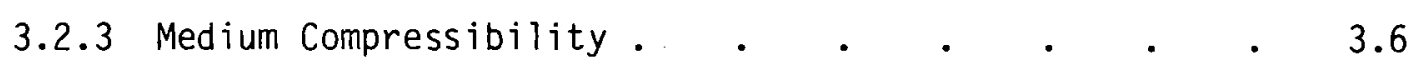

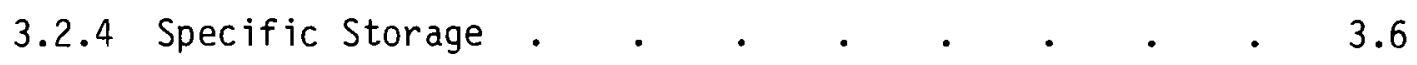

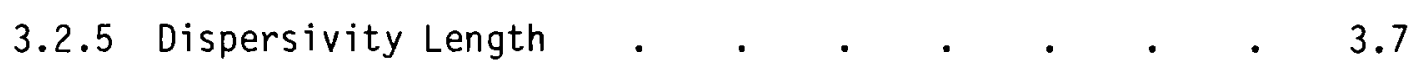

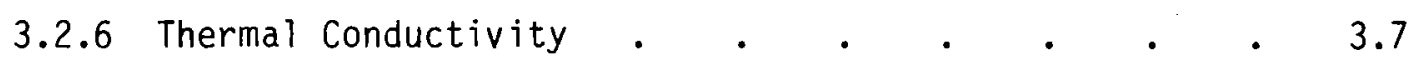

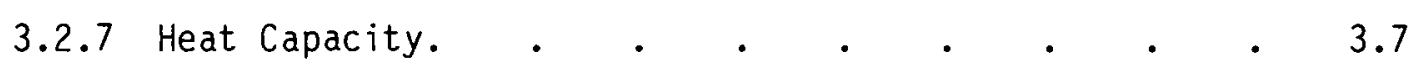

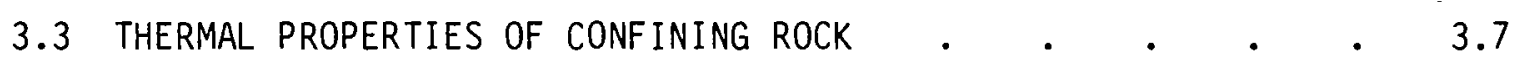

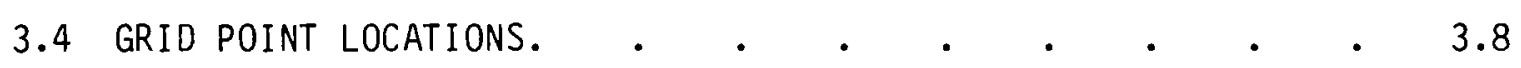

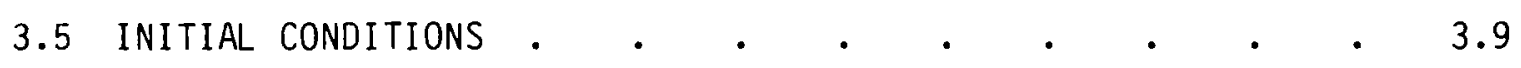

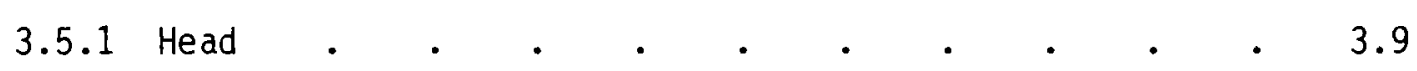

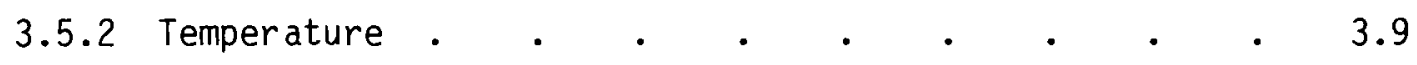

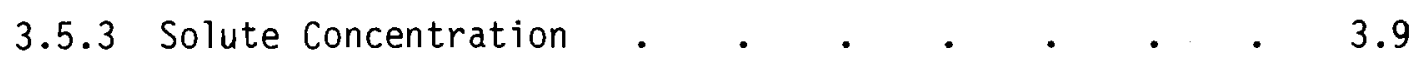

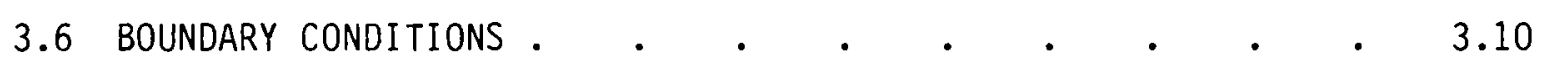

3.6.1 Dirichlet (Held) Boundary Conditions . . . . 3.10

3.6.2 Neumann (Flux) Boundary Conditions . . . . . 3.10

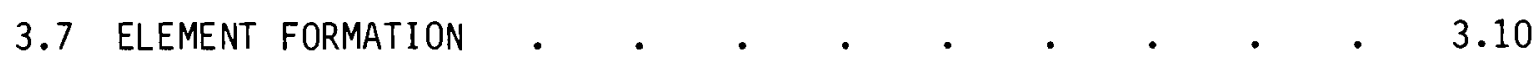

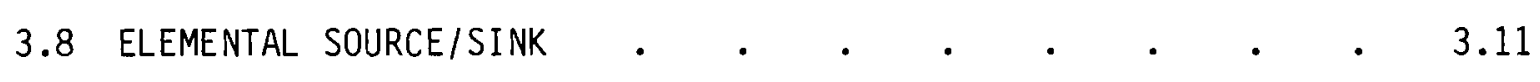


3.9 TERMINAL INTERACTIVE INPUT DATA FILE PREPARATION $\quad$ • $\quad$ • 3.12

\begin{tabular}{l}
4.0 VERIFICATION AND SENSITIVITY ANALYSES WITH ANALYTICAL \\
SOLUTIONS \\
\hline
\end{tabular}

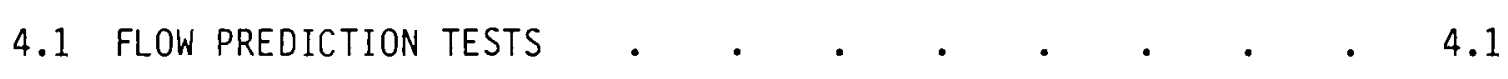

4.1.1 Steady Drawdown in a Confined Aquifer . . . . 4.1

4.1.2 Unsteady Drawdown in a Confined Aquifer . . . 4.2

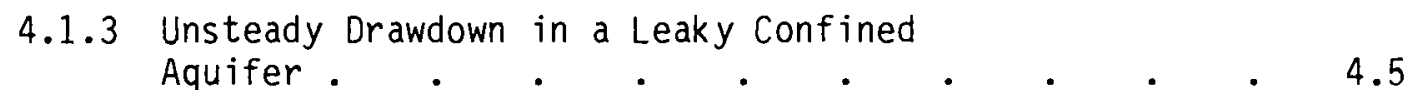

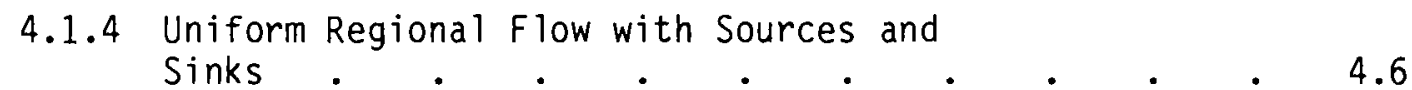

4.2 ENERGY AND SOLUTE MASS TRANSPORT VERIFICATIONS $\quad$ • $\quad$ • $\quad$ • 4.12

4.2.1 Dirichlet Upstream Boundary Condition,
Linear Geometry . . . . . . . . . . 4.12

4.2.2 Mixed Upstream Boundary Condition,
Linear Geometry . . . . . . . . . 4.13

4.2.3 Approximate Analytical Solution to an
Axisymmetric Analysis Including Radially

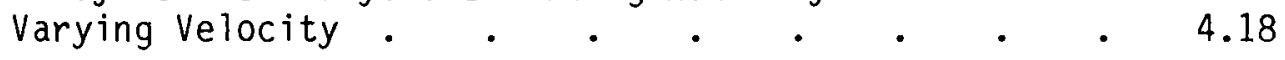

\begin{tabular}{l}
4.3 ENERGY TRANSPORT INCLUDING CAP AND BEDROCK \\
CONDUCTION \\
\hline
\end{tabular}

4.3.1 Avdonin's Radial Problem . $\quad . \quad$. $\quad . \quad$. 4.23

4.3.2 Avdonin's Linear Problem . . . . . . . 4.31

4.3.3 Gringarten-Sauty Problem . . . . . . . 4.33

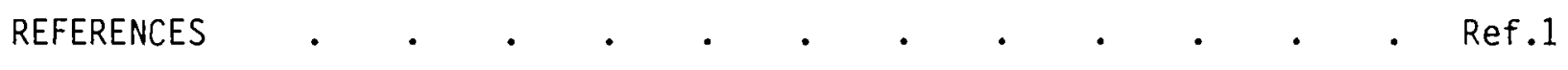




\section{FIGURES}

2.1 Definition of Angle Between Direction of Flow and

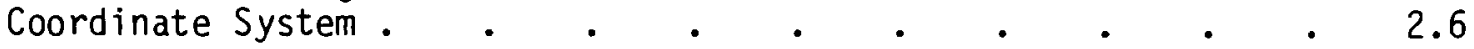

2.2 Isoparametric Elements in Global and Local Coordinates. $\quad$ - $\quad 2.22$

3.1 "Pinched" Element If Given Material Not Found . . . . . 3.11

3.2 CFEST Subprograms for Interactive Input Preparation,

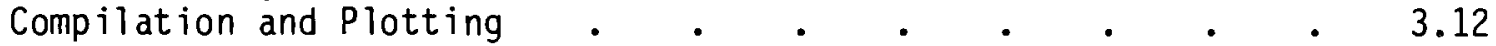

4.1 Effects of the Segment Angle on Element Shape $\quad$. . . . 4.3

4.2 Diagrammatic Representation of Exponentially Increasing Nodal Arrangement Used for Finite Element Solution with

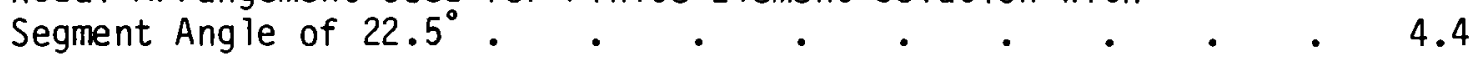

4.3 Theis and CFEST Solutions of Time Dependent Drawdown for a Well Pumped at a Constant Rate . . . . . . . 4.5

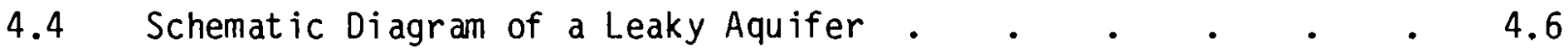

4.5 Comparison of Dimensionless Drawdown Versus Dimensionless
Time for CFEST Solution in a Leaky Aquifer . . . . . . 4.6

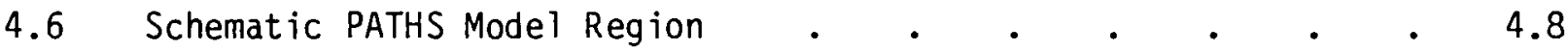

4.7 Depiction of the Regional Flow Problem Domain . $\quad$. $\quad$. $\quad 4.9$

4.8 Three-Dimensional Representation of the PATHS

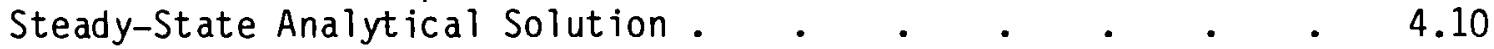

4.9 Combined Square Mesh Discretization for the Regional

Flow Analysis (a) Equal Increment Pattern and

(b) Variable Radial Pattern . . . . . . . . . 4.10

4.10 Radial Element Pattern with Variable Node Spacing. . . . 4.11

4.11 Comparison of Analytical Solution (PATHS) and

CFEST Solution for Grid Pattern Shown in

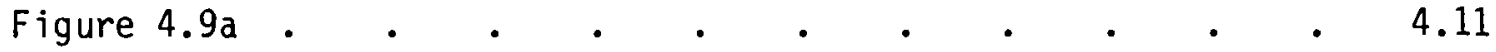

4.12 Comparison of Analytical and CFEST Solute Transport
Solution with Dirichlet Boundary Conditions

4.13 Comparison of Analytical and CFEST Solute Transport

Solution with Flux Boundary Condition at Influence and a Five Day Time Step. 
4.14 Comparison of Analytical and CFEST Solute Transport Solution with Flux Boundary Condition at Influence and a Twenty-Five Day Time Step . $\quad . \quad$. $\quad . \quad$. 4.15

4.15 Comparison of Analytical and CFEST Heat Transport Solution with an Upstream Flux Boundary Condition. . $\quad$ • 4.19

4.16 Comparison of Analytical and CFEST Heat Transport with an Upstream Flux Boundary Condition and a

Truncated Domain

4.17 Radial Analytical Versus CFEST Solution of Solute

Transport

4.18 Comparison of Avdonin Radial and CFEST Results for Equal

Equal Radial Discretization of 1 meter and Time Steps of
a) 10 days,
b) 20 days, and c) 100 days.

4.19 Comparison of Avdonin Radial and CFEST Simulations with

Sequentially Doubled Time Steps

4.20 Comparison of Radial Avdonin and CFEST Results with

Equal Grid Spacing of $10 \mathrm{~m}$ and a) 20 Days and

b) Geometric Time Steps

4.21 Comparison of Radial Avdonin and CFEST Results with

Equal Areal Spacing of $314.12 \mathrm{~m}^{2}$ and a) 20 Days,

b) 40 Days, c) 100 Days and d) Geometric Time Steps . 4.29

4.22 Comparison of Radial Avdonin and CFEST Results with Equal

Areal Increments of 3141.2 Square Meters and a Time Step

of 20 day and geometrically increasing time step

4.23 Comparison of Radial Avdonin and CFEST Results with

Sequentially Doubled Grid Spacing and Constant and

Geometric Time Steps

4.24 Comparison of Analytical and CFEST Results for the

4.25 Schematic Diagram of Doublet Problem Posed by

Gringarten and Sauty

4.26 Comparison of CFEST Results with the Semianalytical

Solution of Gringartin-Sauty for Temperature at

the Production Well as a Function of $\lambda$ and time 


\section{TABLES}

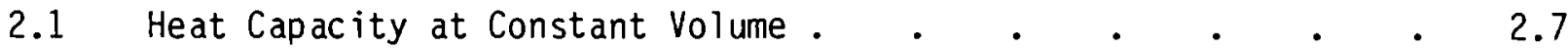

2.2 Abscissae and Weight Coefficients of the

Gaussian Quadrature Formula . . . . . . . . . 2.25

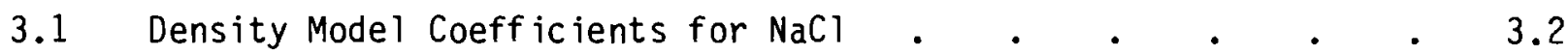

4.1 Analytical and Simulated Steady-State Drawdown

in a Conf ined Aquifer $. \quad . \quad . \quad . \quad . \quad . \quad . \quad . \quad 4.3$

4.2 Some of the Parameters Used for Leaky Aquifer Problems. • $\quad 4.7$

4.3 Parameters for the Linear Convection-Dispersion Model
with a Dirichlet Upstream Boundary Condition

4.4 Parameters for the Mixed (Concentration) Boundary
Condition, Linear Geometry Verification Test . . . . . $\quad 4.15$

4.5 Parameters for the Mixed (Temperature) Boundary
Condition, Linear Geometry Verification Test.$\quad$. . . . 4.18

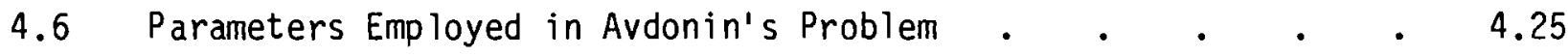

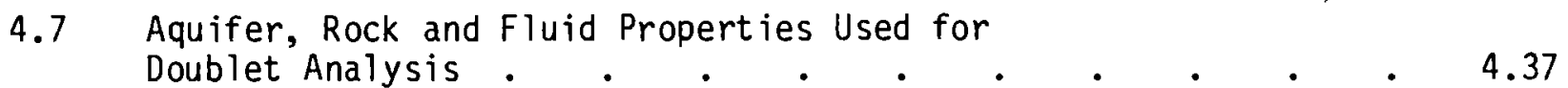




\subsection{INTRODUCTION}

\subsection{PURPOSE}

This report is the primary documentation for the Coupled Fluid, Energy and Solute Transport (CFEST) code. The CFEST code has been developed for the Underground Energy Storage (UES) Program managed for the Department of Energy (DOE) by Pacific Northwest Laboratory (PNL). The testing and application of this code was undertaken to provide the program office with a verified, responsive simulation capability for the evaluation of experimental designs and field data.

CFEST is a finite element analysis of nonisothermal events in a confined aquifer system. Only single phase, Darcian flows are considered in this multidimensional analysis package. In a Cartesian coordinate system the code can simulate flows in a horizontal plane, a vertical plane or in a fully threedimensional region. An option also exists for the axisymmetric analysis of a vertical cross-section. The code presently employs the bilinear quadrilateral element in all two-dimensional analyses and the trilinear quadrilateral solid in three-dimensional simulations. Both steady-state and dynamic simulations are possible.

Out intent is to report the physics that are encoded in CFEST and the numerical methods employed. Some concept of the code's structure is necessary within this document; however, detailed user's manuals devoted to explaining the code's structure and use will be issued for machine-specific versions of the CFEST code. CFEST is an extension of the Finite Element Three (3)Dimensional Ground Water (FE3DGW) code (Gupta et al. 1979). Both codes are highly interactive (input and output) and both employ a staged execution structure. These features and others which are not machine specific will be discussed in the context of the verification and validation applications which have been performed.

\subsection{USE OF THE CODE}

CFEST is designed to be used in a variety of ways to compliment the field studies of the UES program. It can be used to gain a more quantitative 
understanding of the complex environment of the aquifer system. This code and others like it are the tools available to the hydrologist for developing a greater understanding of the physical and chemical interactions taking place within the aquifer system. Accepted explanations of the dynamics and interrelationships of hydrologic systems can be evaluated through the application of this code. The variety of interpretations lent to limited field data can be tested by CFEST. Equally probable parameter data sets can be simulated to provide insight into the validity of interpretations. Sensitivity analyses can be performed to guide future field studies in the acquisition of the most important data.

In the conduct of coordinated computer-based studies and field programs it is essential that the modeling of events be initiated early. Throughout the program an iterative procedure should be employed to gather more appropriate data and adjust the code (model) to provide a better quantitative understanding of the aquifer system. Such a coordinated approach is being undertaken by the UES program in studying nonisothermal aquifer response. Under the UES program a quantitative understanding of nonisothermal physical and chemical interactions is being developed. To the extent that the physical and chemical mechanisms operating within the aquifer are understood, they are modeled within the CFEST code. This code is now ready to be used for analyzing and designing field experiments, and testing the interpretations of sparse field data. Since the aquifer environment is always described by a limited number of discrete data points, it is rarely if ever a known quantity which can be described within any certainty. Thus, the CFEST code and others like it should not be considered predictive tools in the strict sense until substantial calibration and validation tests have been completed for specific sites.

\subsection{ORGANIZATION AND SCOPE}

This document is designed to convey the basic physical and numerical fundamentals of the CFEST code, the input requirements of the code and the verification exercises completed to date. Three sections follow this introductory section. The second section is devoted to the partial differential equations and their numerical analogues. Coupling mechanisms between the three 
conservation equations are developed in some detail. Data requirements of the code are presented in the third section. Both fluid and media properties are discussed. The means by which one establishes the mesh discretization, and initial and boundary conditions are discussed. Verification tests and sensitivity analyses are presented in a fourth section. Comparisons are made between CFEST simulations and published analytical solutions. These simulations insure that the code has been properly encoded.

This document is not intended to be a user's manual. Detailed instructions for the operation of CFEST on specific computing systems will be prepared as part of the code conversion process for specific computing hardware. A user's manual is currently being prepared for the DEC PDP 11/70 version of CFEST.

\subsection{NOMENCLATURE}

In the work which follows we will consider bounded regions in two and three spatial dimensions. We assume that our domain has a piecewise smooth boundary. The right-hand Cartesian coordinate system is used throughout. Axisymmetric analyses also employ a right-hand system. For the Cartesian system both $X$ and $Y$ coordinates lie in the horizontal plane, and the $Z$ coordinate points vertically upward. These coordinates are also denoted as 1,2 , and 3 , respectively in the indicial notation used in this document. A general point in our bounded region or on its boundary is denoted by $x$. The Cartesian components of $x$ are denoted $x_{\alpha}, \alpha=1, \ldots$, number of dimensions.

For clarity in the mathematical expressions to follow, partial differentiation is denoted by a subscript preceded by a comma (e.g., $C_{\alpha}=\partial C / \partial x_{\alpha}$ ). With respect to indicial notation it would be appropriate to note: use of a single subscript implies an element of a vector; use of multiple subscripts implies a matrix or tensor; and repeating an index in a single term implies summation unless otherwise noted. Definitions for all abbreviated terms displayed in the second section can be found in the list of symbols. 



\subsection{GOVERNING PARTIAL DIFFERENTIAL EQUATIONS \\ AND FINITE ELEMENT FORMULATION}

The governing partial differential equations presented in this section seek to describe the isothermal and nonisothermal hydrologic responses of an aquifer. Solutions corresponding to problems of interest are obtained through the introduction of problem specific information (e.g., geometry of domain, relevant physical coefficients, initial and boundary conditions). The three governing partial differential equations solved by CFEST are based on conservation of total liquid mass, conservation of energy, and conservation of mass of a dissolved contaminant. The three equations are coupled through fluid density which is described as a function of head, temperature, and solute concentration. To reduce errors in roundoff and truncation, the change in dependent variables is simulated instead of their total value.

In this section the governing equations, dependent variables, and assumptions used in CFEST are described along with the finite element formulation. The definition of abbreviations employed in this section is given in the list of symbols.

\subsection{DEPENDENT VARIABLES AND ASSUMPTIONS}

The dependent variables; head $(h)$, temperature $(T)$, and dissolved contaminant concentration $(C)$ are functions of space and time. The aquifer fluid density $\rho$ is a function of pressure head, temperature and concentration. Fluid viscosity, $\mu$, is a function of temperature and concentration.

Basic assumptions used in the development of the mathematical model are:

1. The flow is transient and laminar (Darcian).

2. The permeability and coordinate axes are collinear. The rotation of elements to anisotropy axes is not done. Finite element formulations, in general, permit such a rotation. In aquifer problems, horizontal dimensions are far greater than vertical. 
Therefore, variation between anisotropy axes and the coordinate axes are not significant for regional models. Moreover field data is also limited on anisotropy properties.

3. Fluid density is a function of pressure, temperature and solute concentration.

4. Fluid viscosity is a function of temperature and concentration.

5. The injected fluid is miscible with the resident aquifer fluids.

6. Aquifer properties (e.g., porosity, permeability, and thickness) vary spatially. The thickness variations are nodal while material properties are element constant.

7. Hydrodynamic dispersion is as a function of fluid velocity.

8. Boundary conditions permit natural water movement in the aquifer, heat losses/gains to adjacent formations, and the location of injection, production and observation wells anywhere with in the system.

9. The porous medium and fluid are compressible.

10. The fluid and porous media are in thermal equilibrium.

11. Rock density and heat capacity remain constant.

12. Viscous dissipation is negligible with respect to the energy balance.

\subsection{FLOW EQUATION}

For general nonisothermal fluids with variable density, the ground water flow equations are most appropriately posed in terms of pressure. However, for isothermal field applications, hydraulic head is commonly used as the dependent variable. Hydraulic head, $h^{\star}$, is related to pressure by (Hubbert 1940)

$$
h *=z+\int_{p_{0}}^{p} \frac{1}{p(p) g} d p
$$


where $z$ is the elevation above the reference datum (positive upward) and $p_{0}$ is the reference pressure. For the hydraulic head to be uniquely defined, density must be a function of pressure only. In CFEST, the density is a function of pressure, temperature and solute concentration. The following flow equations are posed in terms of pressure and then another variable, $h$, is introduced to define, pressure in terms of equivalent head of aquifer resident fluid. To visualize ground water flow and to specify boundary conditions from measured field data, the equivalent head of aquifer fluid is somewhat more convenient.

Combining the continuity equation

$$
\left(\rho u_{\alpha}\right)_{\alpha}+Q=-(\theta \rho), t
$$

with Darcy's equation in three dimensions

$$
u_{\alpha}=\frac{-k_{\alpha \beta}}{\mu}\left(p, \beta,_{\beta}+\rho g z,,_{\beta}\right)
$$

results in the following equation describing single-phase flow in porous media

$$
\left[\frac{k_{\alpha \beta} \rho}{\mu}\left(p, \beta+\rho g,_{\beta}\right)\right], \alpha-Q=(\theta \rho), t
$$

The equivalent hydraulic head in terms of the aquifer's resident fiuid density is approximated by

$$
h=\frac{p}{g \rho_{0}}+z
$$

Upon substitution of Equation (2.5) into Equation (2.4) we have

$$
\left\{\rho \frac{\rho_{0} g k_{\alpha \beta}}{\mu}\left[h_{\beta}+\left(\frac{\rho-\rho_{0}}{\rho_{0}}\right) z,{ }_{\beta}\right]\right\},_{\alpha}-Q=\left(\theta_{\rho}\right),_{t}
$$


or

$$
\left\{\rho K_{\alpha \beta}\left[h_{\beta}+\left(\frac{\rho-\rho_{0}}{\rho_{0}}\right) z_{B}\right]\right\},_{\alpha}-Q=\left(\theta_{\rho}\right),_{t}
$$

where

$$
\begin{aligned}
h & =\frac{p}{\rho_{0} g}+z \\
K_{\alpha \beta} & =\frac{\rho_{0} g k_{\alpha \beta}}{\mu} \\
K_{\alpha \beta} & =K_{\alpha \beta} \delta_{\alpha \beta} \\
Q & =\sum_{i=1}^{m} Q_{W}(\bar{x}, t) \delta\left(\bar{x}-x_{\alpha i}\right) \\
Q & =\text { combined strength of sink function for } m \text { wells. } \\
\delta & =\text { the dirac delta function } \\
\delta_{\alpha \beta} & =\text { the Kronecker delta. }
\end{aligned}
$$

\subsection{CONCENTRATION EQUATION}

By mass balance, the following solute concentration equation is obtained

$$
\left(\rho D_{\alpha \beta} C,{ }_{\beta}\right),{ }_{\alpha}-\left(\rho u_{\alpha} C\right), \alpha-Q C^{\prime}=(\rho \theta C), t
$$

The dispersion tensor $D_{\alpha \beta}$ depends upon the hydrodynamic dispersivity and is defined by the following equations (Scheidegger, 1961):

$$
\begin{aligned}
& D_{L}=\varepsilon_{L}\left|\bar{u}_{\alpha}\right| \\
& D_{T}=\varepsilon_{T}\left|\bar{u}_{\alpha}\right|
\end{aligned}
$$


This dispersion tensor is based on Scheidegger's finding that for homogeneous isotropic medium there can be no more than two (longitudinal and transverse) independent dispersivity factors. When the velocity vector is divided into components along the coordinate axes, nine components of the dispersivity tensor occur.

$$
\begin{aligned}
& D_{x x}=D_{L} \cos ^{2} \omega \cos ^{2} \phi+D_{T}\left(\sin ^{2} \phi \cos ^{2} \omega+\sin ^{2} \omega\right) \\
& D_{x y}=\left(D_{L}-D_{T}\right) \sin \phi \cos \phi \cos ^{2} \omega \\
& D_{x z}=\left(D_{L}-D_{T}\right) \sin \omega \cos \omega \cos \phi \\
& D_{y x}=D_{x y} \\
& D_{y y}=D_{L} \cos ^{2} \omega \sin ^{2} \phi+D_{T}\left(\cos ^{2} \phi \cos ^{2} \omega+\sin ^{2} \omega\right) \\
& D_{y z}=\left(D_{L}-D_{T}\right) \sin \omega \cos \omega \sin \phi \\
& D_{z x}=D_{x z} \\
& D_{z z}=D_{L} \sin ^{2} \omega+D_{T} \cos ^{2} \omega
\end{aligned}
$$

where

$$
\begin{aligned}
\phi= & \text { angle between the projection of the flow vector on the } x-y \\
& \text { plane and the } x \text {-axis (see Figure 2.1) } \\
\omega= & \text { vertical angle between the direction of flow and } x-y \text { plane, } \\
& \text { measured from } x-y \text { plane. }
\end{aligned}
$$

The counter clockwise direction is taken to be positive. Molecular dispersion properties $D_{m}$ are added to the above coefficients $D_{\alpha \beta}$.

\subsection{ENERGY EQUATION}

Conservation of energy is defined as enthalpy in, minus enthalpy out, equals the change in internal energy of the system. Symbolically one has

$$
\left(E_{\alpha \beta}{ }^{\top},_{\beta}\right),_{\alpha}-\left(\rho U_{\alpha} H_{E}\right),_{\alpha}-Q\left(C_{p}^{\prime} T^{\prime}\right)=\left[\theta \rho U+(1-\theta)\left(\rho C_{p}\right)_{r}\right]^{\top},_{t}
$$




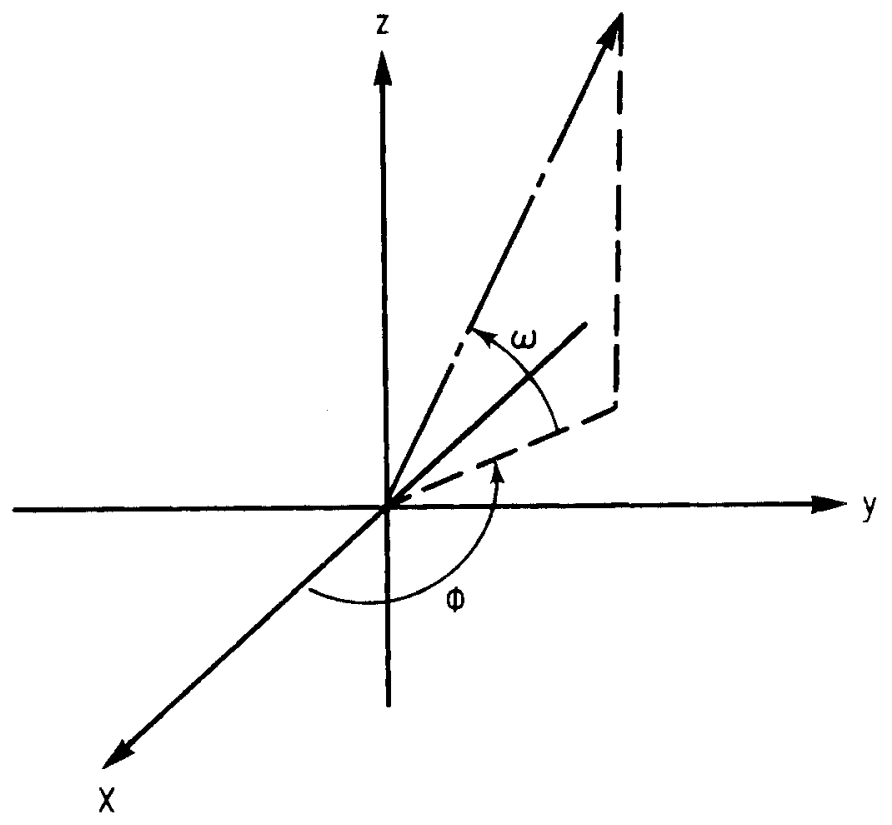

FIGURE 2.1. Definition of Angle Between Direction of Flow and Coordinate System

In Equation (2.9):

1. The apparent heat conductivity tensor, $E_{\alpha \beta}$, due to hydrodynamic dispersion (using a similar relationship as defined by Equation 2.8) in a homogeneous, isotropic porous media is taken as the product of the dispersivity, velocity, and fluid volumetric heat capacity (Intercomp 1976). The general expression for conductivity in terms of the hydrodynamic dispersivity can be expressed as

$$
\begin{aligned}
& E_{L}=\theta\left(\varepsilon_{L}|\bar{u}| / \theta\right)\left(\rho C_{p}\right)_{W} \\
& E_{T}=\theta\left(\varepsilon_{T}|\bar{u}| / \theta\right)\left(\rho C_{p}\right)_{W}
\end{aligned}
$$

The apparent heat conductivity tensor, $E_{\alpha \beta}$, is estimated using $E_{L}$ and $E_{T}$ instead of $D_{L}$ and $D_{T}$ in Equation (2.8). The molecular heat conductivity of fluid and medium, $E_{m}$, has been treated as an additive constant to $E_{\alpha B^{*}}$ 
2. The enthalpy of the fluid is expressed as a function of temperature only, i.e.,

$$
H_{E}=C_{p w}{ }^{\top}
$$

The effect of pressure, which is not as significant as temperature, can be easily included.

3. Internal energy $(U)$ of fluid in porous media is defined as

$$
U=U_{0}+C_{p w}\left(T-T_{u}\right)
$$

This model of internal energy is based upon the heat capacity of water evaluated at constant pressure. This measure of heat capacity is nearly constant over our temperature range, and it is therefore assumed constant.

A provision for an alternate definition of heat capacity has been included. To be completely rigorous one would employ heat capacities evaluated at constant volume in the analysis. This parameter is significantly more sensitive to temperature. Thus, the following tabularized input is an alternate model of heat capacity.

\begin{tabular}{|c|c|}
\hline Temperature $\left({ }^{\circ} \mathrm{C}\right)$ & Heat Capacity $\left(\begin{array}{l}\text { Joules } \\
\mathrm{kg}\end{array}\right.$ \\
\hline 20 & $0.4182 \times 10^{4}$ \\
\hline 75 & $0.3894 \times 10^{4}$ \\
\hline 125 & $0.3652 \times 10^{4}$ \\
\hline 200 & $0.3341 \times 10^{4}$ \\
\hline
\end{tabular}

TABLE 2.1. Heat Capacity at Constant Volume.

4. The energy loss or gain, $H_{L}$, from the confining media above and below the aquifer is described by

$$
H_{L}=-E_{Z} T_{B}, z=-E_{\alpha \beta}{ }^{\top}, z
$$


where

$$
\begin{aligned}
E_{Z} & =\text { vertical heat conductivity of the confining media } L^{2} E(M T t)^{-1} \\
T_{B^{\prime}} Z & =\text { vertical temperature gradient in the confining media }\left(T L^{-1}\right)
\end{aligned}
$$

The subscript $B$ is used for the over and under burden parameters. The one-dimensional energy conduction equation describes the vertical temperature distribution in the confining media.

$$
\left(E_{Z} T_{B},{ }_{Z}\right)_{Z}=\left(\rho C_{P}\right)_{B} T_{B}, t
$$

This equation is solved via an implicit finite difference technique. The most current interface temperature determined from the aquifer solution is used as a boundary condition. Temperature at the distant node (away from the aquifer) can be prescribed as a fixed temperature or as a function of an insulated boundary. The total thickness of either over or under burden material is discretized into a relatively fine grid near the interface with larger grid intervals at increasing distance from the aquifer. A three-point finite difference method is used to determine the temperature gradient at the interface. The energy loss or gain term enters the energy equation by virtue of the boundary integral in Equation 2.59 and 2.62 .

\subsection{FLUID DENSITY AND POROSITY RELATIONSHIPS}

Equations (2.6), (2.7), and (2.9) are coupled through fluid density. Fluid density is described as a function of solute concentration, temperature and pressure head and is expressed as a Taylor series:

$$
\begin{aligned}
\rho\left(C, T, h_{p}\right)=\rho_{0}\left(E_{0}\right) & +\left[\left.\frac{\partial \rho}{\partial C}\right|_{E_{0}} C+\ldots\right]+\left[\left.\frac{\partial \rho}{\partial T}\right|_{E_{0}}\left(T-T_{0}\right)+\ldots\right] \\
& +\left[\left.\frac{\partial \rho}{\partial h_{p}}\right|_{E_{0}}\left(h_{p}-h_{0}\right)+\ldots\right]
\end{aligned}
$$


where $h_{p}=h-z$ and $E_{0}=\left(0, T_{0}, h_{0}\right)$

Neglecting the second and higher order terms, the above equation is expressed as :

$$
\rho=\rho_{0}+a_{3} c+a_{2}\left(T-T_{0}\right)+a_{1}\left(h_{p}-h_{0}\right)
$$

where

$$
\begin{aligned}
& a_{3}=\left.\frac{\partial \rho}{\partial C}\right|_{E_{0}} \\
& a_{2}=\left.\frac{\partial \rho}{\partial T}\right|_{E_{0}} \\
& a_{1}=\left.\frac{\partial \rho}{\partial h_{p}}\right|_{E_{0}}
\end{aligned}
$$

and $\rho_{0}$ is the resident aquifer fluid density at a given initial zero solute concentration, temperature $\left(T_{0}\right)$, and pressure head $\left(h_{0}\right)$. The coefficient of thermal expansion is defined as

$$
C_{T} \simeq-\frac{1}{\rho}\left(\frac{\partial \rho}{\partial T}\right)
$$

This coefficient can be either a constant or variable parameter. Within the CFEST code an option is included which describes density as a function of temperature. The following relationships are employed:

$$
\begin{aligned}
& 25^{\circ} \mathrm{C} \leq \mathrm{T} \leq 100^{\circ} \mathrm{C}: \\
& \rho(T)=996.9\left\{1-3.17 \cdot 10^{-4}(T-25)-2.56 \cdot 10^{-6}(T-25)^{2}\right\} \\
& T \leq 25^{\circ} \mathrm{C}: \\
& \rho(T)=006.9\left\{1-1.87 \cdot 10^{-4}(T-25)\right\}
\end{aligned}
$$


The compressibility of fluid is given by

$$
C_{w} \simeq \frac{1}{\rho}\left(\frac{\partial \rho}{\partial h_{p}}\right)
$$

As a result, the partial derivatives of density with respect to temperature and pressure at initial aquifer conditions are:

$$
a_{2}=\left.\frac{\partial \rho}{\partial T}\right|_{E_{0}} \simeq \rho_{0} C_{T}
$$

and

$$
a_{1}=\left.\frac{\partial \rho}{\partial h_{p}}\right|_{E_{0}}=\rho_{0} C_{w}
$$

In addition to $\rho_{0}$, another known density $\rho_{1}$, at solute concentration $\left(C_{1}\right)$, temperature $\left(T_{1}\right)$, and pressure head $\left(h_{1}\right)$ is used to calculate $a_{3}$ as follows:

$$
\left.a_{3} \simeq \frac{\partial \rho}{\partial C}\right|_{E_{0}}=o_{0} C_{C}
$$

where

$$
\begin{aligned}
C_{C} & =\text { composition density ratio } \\
& =\frac{\rho_{1}\left(C_{1}, T_{1}, h_{1}\right)-\rho_{0}\left(1+C_{T}\left(T_{1}-T_{0}\right)+C_{W}\left(h_{1}-h_{0}\right)\right)}{\rho_{0}\left(C_{1}-C_{0}\right)}
\end{aligned}
$$

Porosity is defined as a function of head:

$$
\theta=\theta_{0}\left[1+C_{r}\left(h-z-h_{\theta}\right)\right]
$$


and therefore

$$
\theta_{t} \simeq \theta_{0} C_{r} h,_{t}
$$

for confined aquifers.

\subsection{SUBSTITUTION OF DENSITY AND POROSITY TERMS INTO FLUID, ENERGY,}

AND SOLUTE TRANSPORT EQUATIONS

Substituting $\rho$ and $\theta$ [Equations (2.15) and (2.24)] into Equations (2.6), (2.9) and (2.7) and expanding the right-hand side of each, we find:

Fluid Flow

$\left(\rho K_{\alpha \beta}\left(h_{\beta}+\left(\frac{\rho-\rho_{0}}{\rho_{0}}\right) z,,_{\beta}\right)\right), \alpha-Q=\theta\left(a_{1} h, t+a_{2} T, t+a_{3} C,{ }_{t}\right)+\rho \theta_{0} C_{r} h, t$

\section{Energy Transport}

$$
\begin{aligned}
& \left(E_{\alpha \beta}{ }^{T},{ }_{\beta}\right),{ }_{\alpha}-\left(\rho u_{\alpha} H_{E}\right),{ }_{\alpha}-Q\left(C_{p}^{\prime} T^{\prime}\right)=\theta U\left(a_{1} h, t+a_{2} T,{ }_{t}+a_{3} C,{ }_{t}\right) \\
& +\rho U_{\theta} C_{r} h,_{t}+\rho \theta C_{p w}{ }^{\prime},_{t}+(1-\theta)\left(\rho C_{p}\right)_{r}{ }^{T}{ }_{t}-\left(\rho C_{\rho}\right)_{r}{ }^{T} \theta_{0} C_{r} h,_{t}
\end{aligned}
$$

Solute Transport

$$
\begin{aligned}
\left(\rho D_{\alpha \beta} C,_{\beta}\right),,_{\alpha}-\left(\rho u_{\alpha} C\right),{ }_{\alpha}-Q C^{\prime}= & \theta\left(a_{1} h,_{t}+a_{2} T, t+a_{3} C,{ }_{t}\right) C \\
& +\rho \theta_{o} C_{r} h,{ }_{t} C+\theta \rho C, t
\end{aligned}
$$

Rearranging the terms of Equations (2.26), (2.27), (2.28) and expanding the sink term $(Q)$ to account for both source $\left(q_{j}\right)$ and sink $\left(q_{0}\right)$ pressure differentials which may be significant in deep aquifer systems we have

Fluid Flow

$$
\begin{gathered}
\left(\rho K_{\alpha \beta}\left(h_{\beta}+\left(\frac{\rho-\rho_{0}}{\rho_{0}}\right) z, \beta\right)\right),_{\alpha}+\left(q_{i}+\frac{d q_{i}}{d h_{p}} h_{d_{i}}\right)-\left(q_{0}+\frac{d q_{o}}{d h_{p}} h_{d_{0}}\right) \\
=\left(\theta a_{1}+\rho \theta_{0} C_{r}\right) h_{t}+\theta a_{2}{ }^{T}, t+\theta a_{3} C, t
\end{gathered}
$$


Energy Transport

$$
\begin{aligned}
& \left(E_{\alpha \beta} T,_{\beta}\right), \alpha-\left(\rho u_{\alpha} H_{E}\right), \alpha+\left(q_{i}+\frac{d q_{j}}{d h_{p}} h_{d_{i}}\right) C_{p}^{\prime} T^{\prime}-\left(q_{0}+\frac{d q_{o}}{d h_{p}} h_{d_{0}}\right) C_{p} T \\
= & {\left[\theta U a_{1}+\rho U \theta_{0} C_{r}-\left(\rho C_{p}\right)_{r} T \theta_{0} C_{r}\right] h_{t} } \\
& +\left[\theta U a_{2}+\rho \theta C_{P W}+(1-\theta)\left(\rho C_{p}\right)_{r}\right] T,_{t}+\theta U a_{3} C{ }_{t}
\end{aligned}
$$

Solute Transport

$$
\begin{aligned}
& \left(\rho D_{\alpha \beta} C,{ }_{\beta}\right),{ }_{\alpha}-\left(\rho u_{\alpha} C\right){ }_{\alpha}+\left(q_{i}+\frac{d q_{i}}{d h_{p}} h_{d_{i}}\right) C^{\prime}-\left(q_{0}+\frac{d q_{0}}{d h_{p}} h_{d_{0}}\right) c \\
& =\left({ }_{\theta C a_{1}}+{ }_{\rho \theta} C C C_{r}\right) h,_{t}+\theta C a_{2} T, t+\left(\theta C a_{3}+\theta_{\rho}\right) C,{ }_{t}
\end{aligned}
$$

where

$$
\begin{aligned}
& h_{d_{i}}=h_{p_{i}}-h_{p} \\
& h_{d_{0}}=h_{p_{\text {out }}}-h_{p}
\end{aligned}
$$

and $h_{p}$ is the pressure component of the total head, $h$.

The three equations, (2.29), (2.30), (2.31), are solved for their respective dependent variables (equivalent head, temperature, and concentration) using the Galerkin finite element method. An iterative procedure is employed for the solution. Concentration and temperature used to solve for head during the $(m+1)^{\text {th }}$ iteration are the values from the $m^{\text {th }}$ iteration. For the solution of the temperature equation, the current head after $(m+1)^{\text {th }}$ iteration is used along with concentration at $m$. The head and temperature obtained after $(m+1)$ iterations are used to update concentration. These are illustrated by using superscripts of $\mathrm{m}$ and $\mathrm{m}+1$ in the following equations.

Collecting terms to the stiffness and load sides of the equations and substituting 


$$
H_{E}=C_{p w}{ }^{\top}
$$

and

$$
U=U_{0}+C_{p w}\left(T-T_{u}\right)
$$

the equations become:

\section{Fluid Flow}

$$
\begin{aligned}
& \left(\rho^{m_{k}}{ }_{\alpha \beta}^{m} h_{\beta}^{m+1}\right), \alpha-\left(\theta^{m} a_{1}+\rho^{m} \theta_{0} C_{r}\right) h, \frac{m_{t}^{m+1}}{t}-\left(q_{0}+\frac{d q_{0}}{d h_{p}} h_{d_{0}}^{m}\right) \\
& +\left(q_{j}+\frac{d q_{i}}{d h_{p}} h_{d_{j}}^{m}\right)-\theta^{m} a_{2} T,{ }_{t}^{m}-\theta^{m} a_{3} c,{ }_{t}^{m}+\rho^{m} k_{\alpha \beta}\left(\frac{\rho^{m}-\rho_{0}}{\rho_{0}} z,{ }_{\beta}\right),{ }_{\alpha}=0
\end{aligned}
$$

\section{Energy Transport}

$$
\begin{aligned}
& \left(E_{\alpha \beta}{ }^{T},{ }_{\beta}^{m+1}\right),{ }_{\alpha}-\left(\rho^{m} U_{\alpha}^{m+1} C_{p w} T^{m+1}\right),{ }_{\alpha}-\left(q_{0}+\frac{d q_{0}}{d h_{p}} h_{d_{0}}^{m+1}\right) C_{p w} T^{m+1} \\
& +\left({ }^{\prime} C_{p}\right) r_{0}{ }_{o} C_{r} h,{ }_{t}^{m+1} T^{m+1}+\left(q_{i}+\frac{d q_{j}}{d h_{p}} h_{d_{i}}^{m+1}\right) C_{p}^{\prime} T^{\prime} \\
& -\left(\theta^{m+1} a_{1} h,{ }_{t}^{m+1}+\rho^{m} \theta_{0} C_{r} h,{ }_{t}^{m+1}+e^{m+1} a_{3} c,{ }_{t}^{m}\right)\left[U_{0}+C_{P_{W}}\left(T^{m+1}-T_{0}\right)\right] \\
& -\left[\theta^{m+1} U^{m} a_{2}+\rho^{m} \theta^{m+1} C_{p w}+\left(1-\theta^{m+1}\right)\left(\rho C_{p}\right)_{r}\right] T,{ }_{t}{ }^{m+1}=0
\end{aligned}
$$

\section{Solute Transport}

$$
\begin{aligned}
& \left(\rho^{m} D_{\alpha \beta} C,_{\beta}^{m+1}\right), \alpha-\left(\rho^{m} u_{\alpha}^{m+1} C^{m+1}\right), \alpha+\left(q_{j}+\frac{d q_{j}}{d h_{p}} h_{d_{j}}^{m+1}\right) C^{\prime} \\
& -\left(q_{0}+\frac{d q_{0}}{d h_{p}} h_{d_{0}+1}^{m+}\right) c^{m+1}-\left(e^{m+1} a_{1} h,{ }_{t}^{m+1}+\rho_{\rho}^{m} \theta_{0} c_{r} h_{t}{ }_{t}^{m+1}+\theta^{m+1} a_{2}{ }^{T},{ }_{t}^{m+1}\right) c^{m+1} \\
& -\left(e^{m+1} a_{3} c^{m}+\theta^{m+1} \rho_{\rho}^{m}\right) c^{m+1}=0
\end{aligned}
$$




\subsection{CRITERIA FOR CONVERGENCE}

The fluid, energy and solute transport equations are coupled through fluid density. Further coupling exists since the velocities calculated from the head solution define dispersivities and conductivities which directly impact the solution of concentration and temperature equations. If the fluid density at a node changes substantially due to changes in temperature or solute concentration, the fluid flow equation must be resolved for a new estimate of head. Following solution of the fluid transport equation, new estimates are made for the temperature and solute concentration distribution. Iterations are continued until the change in fluid density at each node is within a predefined tolerance. If the change in density over a time step is small, but the change in density caused by concentration is relatively significant, iteration of the solute and fluid transport equations is needed. This principle is used to test the convergence of density by separating changes caused by temperature and solute. A tolerance of 0.001 is used to test convergence of density, $\rho$ :

$$
\frac{\Delta \rho}{\rho^{\top}+\Delta \rho^{C}} \leq 0.001
$$

where

$$
\begin{aligned}
& \Delta \rho^{\top}=\begin{array}{l}
\text { the maximum change in density at any node due to change in } \\
\text { temperature over an iteration }
\end{array} \\
& \Delta \rho^{C}=\text { the maximum change in density at any node due to change in } \\
& \text { concentration over an iteration }
\end{aligned}
$$
tests are made:

$$
\begin{aligned}
& \frac{\Delta \rho^{\top}}{\rho_{0}} \leq 0.0005 \\
& \frac{\Delta \rho}{\rho_{0}} \leq 0.0005
\end{aligned}
$$


If neither of these criteria are met, all three (equivalent head, temperature and concentration) are resolved for the given time step. If only Equation (2.36) is satisfied, subsequent iterations include only the head and concentration solutions until Equation (2.37) is satisfied. After convergence is obtained, the energy equation is solved. A similar procedure is used if Equation (2.37) is satisfied but not Equation (2.36).

\subsection{GALERKIN FINITE ELEMENT FORMULATION OF FLOW EQUATION}

Equation (2.32) can be rewritten as an operator which is a function of $h$ :

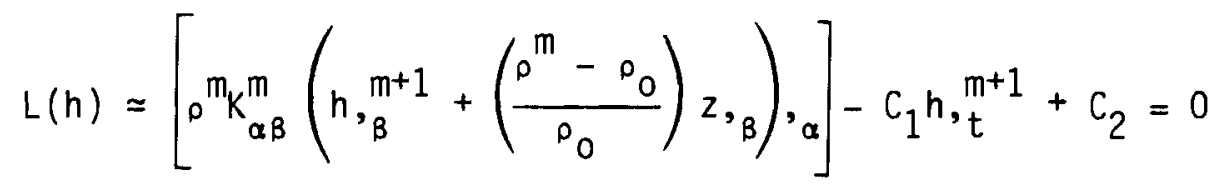

where

$$
\begin{aligned}
& c_{1}=a_{1} \theta^{m}+\theta_{0} c_{r} \rho^{m} \\
& c_{2}=q_{i}+\frac{d q_{i}}{d h_{p}} h_{d_{i}}^{m}-q_{0}-\frac{d q_{0}}{d h_{p}} h_{d_{0}}^{m}-a_{2} \theta^{m} T,{ }_{t}^{m}-a_{3} \theta^{m} c,{ }_{t}^{m}
\end{aligned}
$$

Solution of Equation (2.38) by a finite element technique requires that a trial function of the following form be substituted for the exact dependent variable.

$$
h\left(x_{\alpha}, t\right) \simeq h^{\prime}\left(x_{\alpha}, t\right)=v_{i}\left(x_{\alpha}\right) H_{j}(t) \quad i=1,2, \ldots, n
$$

where $n$ equals the number of global degrees of freedom. Further, the inner product of $L\left(h^{\prime}\right)$ and a weight function is formed. In the case of a Galerkin formulation the weight functions are identically the $v_{i}$. Setting this inner product to zero forces the error of the approximation to be orthogonal to the trial functions. One writes: 


$$
\int_{\Omega} V_{i} L\left(h^{\prime}\right) d \bar{x}=0 \quad i=1,2, \ldots, n
$$

and substituting Equation (2.38) for $L\left(h^{\prime}\right)$ one obtains:

$$
\begin{aligned}
& \int_{\Omega} v_{i}\left[\rho^{m_{k} m}{ }_{\alpha \beta}^{m}\left(h^{\prime},{ }_{\beta}^{m+1}+\left(\frac{\rho^{m}-\rho_{0}}{\rho_{0}}\right) z,{ }_{\beta}\right), \alpha\right. \\
& \left.-c_{1} h \cdot, m^{+1}+c_{2}\right] d \bar{x}=0 \quad i=1,2, \ldots, n
\end{aligned}
$$

Integration by parts applied to a typical integrand of interest yields

$$
\int_{\Omega} \psi \phi,{ }_{\alpha \beta} d \bar{x}=-\int_{\Omega} \psi,_{\beta} \phi,{ }_{\alpha} d \bar{x}+\int_{\partial \Omega} \psi \phi,,_{\alpha} \ell_{\beta} d s
$$

where $\ell_{\beta}$ are the direction cosines of the outward directed normal vector on the boundary, å. Equation (2.43) may now be rewritten as:

$$
\begin{aligned}
& \int_{\Omega}\left(\rho^{m^{m}} K_{\alpha \beta}^{m} v_{i, \alpha}\left(v_{j, \beta} H_{j}^{m+1}+\left(\frac{\rho^{m}-\rho_{0}}{\rho_{0}}\right) z_{\beta}\right)+c_{1} v_{i} v_{j} H_{j, t}{ }^{m+1}-c_{2} v_{i}\right) d \bar{x} \\
& -\int_{\partial} \rho^{m} K_{\alpha \beta}^{m} v_{i}\left(h,,_{\beta}^{m+1}+\left(\frac{\rho^{m}-\rho_{0}}{\rho_{0}}\right) z, \rho_{\beta}\right) e_{\alpha} d s=0
\end{aligned}
$$

In order to preserve the accuracy of the solution, the numerical simulation predicts the change in the total head, $\delta H^{m+1}$, i.e.,

$$
H^{m+1}=H+\delta H^{m+1}
$$

and it follows that the time derivative of $\mathrm{H}$ can be modeled by

$$
H,{ }_{t}^{m+1}=\frac{\Delta h}{\Delta t}=\frac{H^{m+1}-H}{\Delta t}=\frac{\delta H^{m+1}}{\Delta t}
$$


where $m+1$ implies the current iterate of the solution being sought at the advanced time step. The superscript m similarly implies the current iterate value while omission of $m$ superscript indicates the value of the variable at the beginning of the time interval, i.e., its value at the conclusion of the previous time step. Substituting Equation (2.47) into (2.45) and rearranging one finds:

$$
\begin{aligned}
& \int_{\Omega}\left(\rho{ }^{m} k_{\alpha \beta}^{m} v_{i}, \alpha v_{j}{ }^{\prime}+\frac{C_{1}}{\Delta t} v_{i} v_{j}\right) d \bar{x} \delta H_{j}^{m+1} \\
& +\int_{\Omega}\left(\rho^{m} K_{\alpha \beta}^{m} V_{i}, \alpha\left(V_{j, \beta} H_{j}+\left(\frac{\rho^{m}-\rho_{0}}{\rho_{o}}\right) z_{\beta}\right)-C_{2} V_{i}\right) d \bar{x} \\
& -\int_{\partial \Omega} \rho^{m} k_{\alpha \beta}^{m} v_{i}\left(h,{ }_{\beta}^{m+1}+\left(\frac{\rho^{m}-\rho_{o}}{\rho_{o}}\right) z_{\beta}\right) \ell_{\alpha} d s=0
\end{aligned}
$$

Recall that for our application due to the assumed collinearity of permeability and coordinate axes $k_{\alpha \beta}=K_{\alpha \beta} \delta_{\alpha \beta}$, therefore $h_{\beta}^{m+1} \ell_{\alpha}$ is realiy $h,{ }_{\alpha}^{m+1} \ell_{\alpha}$. It follows that the boundary integrand incorporates the Neumann boundary condition (mass flow), i.e.,

$$
-\rho^{m_{k}} k_{\alpha \beta}^{m} \alpha\left(h,{ }_{\beta}^{m+1}+\left(\frac{\rho^{m}-\rho_{0}}{\rho_{0}}\right) z,{ }_{\beta}\right)=q_{n}
$$

where $q_{n}$ is the normal flux of fluid per unit area of boundary, as. This last term is computed only when $q_{n}$ is nonzero, in which case it takes the form:

$$
\int_{\partial \Omega} v_{i} q_{n} d s
$$

Substituting the values of $C_{1}$ and $C_{2}$ into the fluid flow Equation (2.48) one finds the equation as it appears in the CFEST code: 


$$
\begin{aligned}
& \int_{\Omega}\left[\rho^{m} k_{\alpha \beta}^{m} v_{i, \alpha} v_{j ; \beta}+v_{j} v_{j}\left(\frac{a_{1} \theta^{m}+\theta_{0} C_{r} \rho^{m}}{\Delta t}\right)\right] d \bar{x} \delta H_{j}^{m+1} \\
& +\int_{\Omega}\left\{\rho_{\rho}^{m_{k} m} k_{\alpha \beta} v_{i, \alpha}\left(v_{j, \beta} H_{j}+\left(\frac{\rho^{m}-\rho_{0}}{\rho_{o}}\right) z, \beta\right)-\left[q_{j}+\frac{d q_{i}}{d h_{p}} h_{d_{j}}^{m}-q_{0}-\frac{d q_{0}}{d h_{p}} h_{d_{0}}^{m}\right.\right. \\
& \left.\left.-a_{2} \theta^{m} T,{ }_{t}^{m}-a_{3} \theta^{m} C, \frac{m}{t}\right] v_{i}\right\} d \bar{x}+\int_{\partial \Omega} v_{i} q_{n} d s=0
\end{aligned}
$$

\subsection{GALERKIN FINITE ELEMENT FORMULATION OF TEMPERATURE EQUATION}

Equation (2.33) can be rewritten as an operator $L$ on the dependent variable T.

$$
\begin{aligned}
L(T)= & \left(E_{\alpha \beta}{ }^{T}{ }_{\beta}^{m+1}\right),{ }_{\alpha}-\left(\rho_{0}^{m} u_{\alpha}^{m+1} C_{p w} T^{m+1}\right),{ }_{\alpha}+\left(C_{3}-C_{4} C_{p w}\right) T^{m+1}-C_{5}{ }^{T}{ }_{t}^{m+1} \\
& +C_{6}-C_{4}\left(U_{0}-C_{p w}{ }^{\top}\right)=0
\end{aligned}
$$

where

$$
\begin{aligned}
& c_{3}=\left({ }_{o} C_{p}\right)_{r} \theta_{0} c_{r}{ }^{h}{ }_{t}^{m+1}-\left(q_{0}+\frac{d q_{0}}{d h_{p}} h_{d_{0}}^{m+1}\right) c_{p w} T^{m+1} \\
& C_{4}=a_{1} \theta^{m+1} h,{ }_{t}^{m+1}+\theta_{0} c_{r} \rho^{m} h_{,}^{\prime m+1}+a_{3} \theta^{m+1} C,{ }_{t}^{m} \\
& C_{5}=a_{2} \theta^{m+1}\left[U_{0}+C_{p w}\left(T^{m}-T_{u}\right)\right]+C_{p w^{\rho}} \theta^{m}{ }^{m+1}+\left(1-\theta^{m+1}\right)\left(\rho C_{p}\right)_{r} \\
& c_{6}=\left(q_{i}+\frac{d q_{i}}{d h_{p}} h_{d_{i}}^{m+1}\right) C_{p}^{\prime} T^{\prime}
\end{aligned}
$$

Once again a trial function is assumed of the form 


$$
T(\bar{x}, t) \simeq T^{\prime}(\bar{x}, t)=V_{i}(\bar{x}) \hat{T}_{i}(t) .
$$

The inner product is formed and the energy equation is numerically simulated by

$$
\int_{\Omega} V_{i}\left[\left(E_{\alpha \beta}{ }^{T}, m_{\beta}^{m+1}\right),{ }_{\alpha}-\left({ }^{m} u_{\alpha}{ }^{m+1} C_{p W} T^{m+1}\right),{ }_{\alpha}+c_{7} T^{m+1}-C_{5} T,{ }_{t}^{m+1}+c_{8}\right]=0
$$

where $C_{7}=C_{3}-C_{4} c_{p w}$

$$
c_{8}=c_{6}-c_{4}\left(U_{0}-c_{p w}{ }^{\top} u\right)
$$

Integration by parts applied to the first two terms results in the following expression:

$$
\begin{aligned}
& \int_{\Omega}\left[E_{\alpha \beta} v_{i},{ }_{\alpha} v_{j}, \beta-\rho m^{m} u_{\alpha}^{m+1} C_{p w} v_{i}, v_{j} v_{j}-C_{7} v_{i} v_{j}\right] d \bar{x} \hat{T}_{j}^{m+1} \\
& -\int_{\Omega} C_{5} V_{i} V_{j} d \bar{x} T_{j}^{m+1}-\int_{\Omega} C_{8} V_{i} d \bar{x}+\int_{\partial \Omega} V_{i}\left(\rho^{m} u_{\alpha}^{m+1} C_{p w} V_{j}-E_{\alpha \beta} V_{j}, \beta\right) \ell_{\alpha} d s \hat{T}_{j}^{m+1}=0
\end{aligned}
$$

As in the case of total head the temperature is modeled by its incremental change, i.e.,

$$
\begin{aligned}
& \hat{T}_{j}^{m+1}=\hat{T}_{j}+\delta \hat{T}_{j}^{m+1} \\
& \hat{T}_{j, t}^{m+1} \simeq \frac{\delta \hat{T}_{j}^{m+1}}{\Delta t}
\end{aligned}
$$

Substituting this information into Equation (2.59) one finds 


$$
\begin{aligned}
& \int_{\Omega}\left[E_{\alpha \beta} V_{i},{ }_{\alpha} V_{j}, \beta-\rho^{m} u_{\alpha}{ }^{m+1} C_{p w} V_{i}, \alpha_{j}-C_{7} V_{i} v_{j}+\frac{C_{5}}{\Delta t} v_{i} v_{j}\right] d \bar{x} \delta \hat{T}_{j}^{m+1} \\
& +\int_{\Omega}\left[E_{\alpha \beta} V_{i}, \alpha V_{j}, \beta-\rho^{m^{m}} u_{\alpha}^{+1} C_{p w} V_{i}, \alpha V_{j}-C_{7} V_{i} V_{j}\right] d \bar{x} \hat{T}_{j} \\
& -\int_{\Omega} c_{8} v_{i} d \bar{x}+\int_{\partial} v_{i}\left(\rho^{m} u_{\alpha}^{m+1} c_{p w} v_{j}-E_{\alpha \beta} v_{j}, \beta\right)\left(\hat{T}_{j}+\delta \hat{T}_{j}^{m+1}\right) \ell_{\alpha} d s=0
\end{aligned}
$$

\subsection{GALERK IN FINITE ELEMENT FORMULATION OF SOLUTE TRANSPORT EQUATION}

Equation (2.34) is rewritten as an operation $L$ upon a function $C$ :

$L(C)=\left(\rho^{m} D_{\alpha \beta} C{ }_{\beta}^{m+1}\right),{ }_{\alpha}-\left(\rho^{m} u_{\alpha}^{m+1} C^{m+1}\right),{ }_{\alpha}-C_{10} C^{m+1}-C_{11} C{ }^{m+1} t+C_{12}=0$

where

$$
\begin{aligned}
& c_{10}=\left(a_{0}+\frac{d q_{0}}{d h_{p}} h_{d_{0}}^{m+1}\right)+\left(a_{1} \theta^{m+1}+\theta_{0} c_{r} \rho^{m}\right) h,{ }_{t}^{m+1}+a_{2} e^{m+1} T, r_{t}^{m+1} \\
& C_{11}=\theta^{m+1} \quad a_{3} c^{m}+\theta^{m+1} \rho_{\rho}^{m} \\
& c_{12}=\left(a_{1}+\frac{d q_{i}}{d h_{p}} h_{d_{i}}^{m+1}\right) c^{\prime}
\end{aligned}
$$

A trial function of the form

$$
C\left(x_{\alpha}, t\right) \simeq C^{\prime}\left(x_{\alpha}, t\right)=v_{j}\left(x_{\alpha}\right) \hat{C}_{j}(t)
$$

is employed in the Galerkin form of the equation. Integration by parts applied to the customary inner product, yields the following representation

$$
\begin{gathered}
\int_{\Omega}\left[\rho^{m} D_{\alpha \beta} v_{i},{ }_{\alpha} v_{j, \beta}-\rho^{m} u_{\alpha}^{m+1} v_{i}, \alpha v_{j}-C_{10} v_{i} v_{j}\right] d \bar{x} \hat{C}_{j}^{m+1} \\
+\int_{\Omega} C_{11} v_{i} v_{j} d \bar{x} \hat{C},{ }_{t}^{m+1}-\int_{\Omega} v_{i} C_{12} d \bar{x}+\int_{\partial \Omega} v_{i} \rho^{m}\left(u_{\alpha}^{m+1} v_{j}-D_{\alpha \beta} v_{j, \beta}\right) d s \ell_{\alpha} \hat{c}_{j}^{m+1}=0
\end{gathered}
$$


Incremental concentration is predicted in a way completely analogous to Equation (2.46) for head, i.e.,

$$
\hat{C}_{j}^{m+1}=\hat{C}_{j}+\delta \hat{C}_{j}^{m+1}
$$

The time partial of solute concentration is modeled explicitly by

$$
c_{t}^{m+1} \simeq\left(\frac{\hat{C}_{j}^{m+1}-\hat{C}_{j}}{\Delta t}\right)=\frac{\delta \hat{C}_{j}^{m+1}}{\Delta t}
$$

Substitution of these expressions into Equation (2.65) yields

$$
\begin{aligned}
& \int_{\Omega}\left(\rho^{m} D_{\alpha \beta} v_{i}, \alpha v_{j}, \beta-\int_{\Omega} \rho^{m} u_{\alpha}^{m+1} v_{i}, \alpha v_{j}-C_{10} v_{i} v_{j}\right) d \bar{x}\left(\delta C^{m+1}+c^{m}\right) \\
& +\int_{\Omega} C_{11} v_{i} v_{j} d \bar{x} \frac{\delta C^{m+1}}{\Delta t}-\int_{\Omega} V_{i} C_{12} d \bar{x} \\
& +\int_{\partial \Omega} \rho v_{i} v_{\alpha}\left(v_{j} u_{\alpha}^{m+1}-D_{\alpha \beta} v_{j}, \beta\right) \ell_{\alpha}^{d s}\left(\delta C_{j}^{m+1}+C_{j}^{m}\right)=0
\end{aligned}
$$

\subsection{INTEGRATION OF APPROXIMATING EQUATIONS}

Gaussian quadrature is used for numerical integration within CFEST. In the computer program, shape functions and derivatives of shape functions are evaluated by Gaussian quadrature of the order specified by the user.

Numerical integration is described in many textbooks (Zienkiewicz 1971; Pinder and Gray 1978). For completeness, a brief description of numerical integration as it applies to the finite element equations is included.

Numerical integration is performed on a generic square or cube domain. The shape functions, $v_{i}$, are functions of local coordinates and $v_{i, \alpha}$ are their derivatives with respect to local coordinates. An isoparametric transformation from global to local is effected by first relating global to local coordinates (Figure 2.2) via the shape functions. 

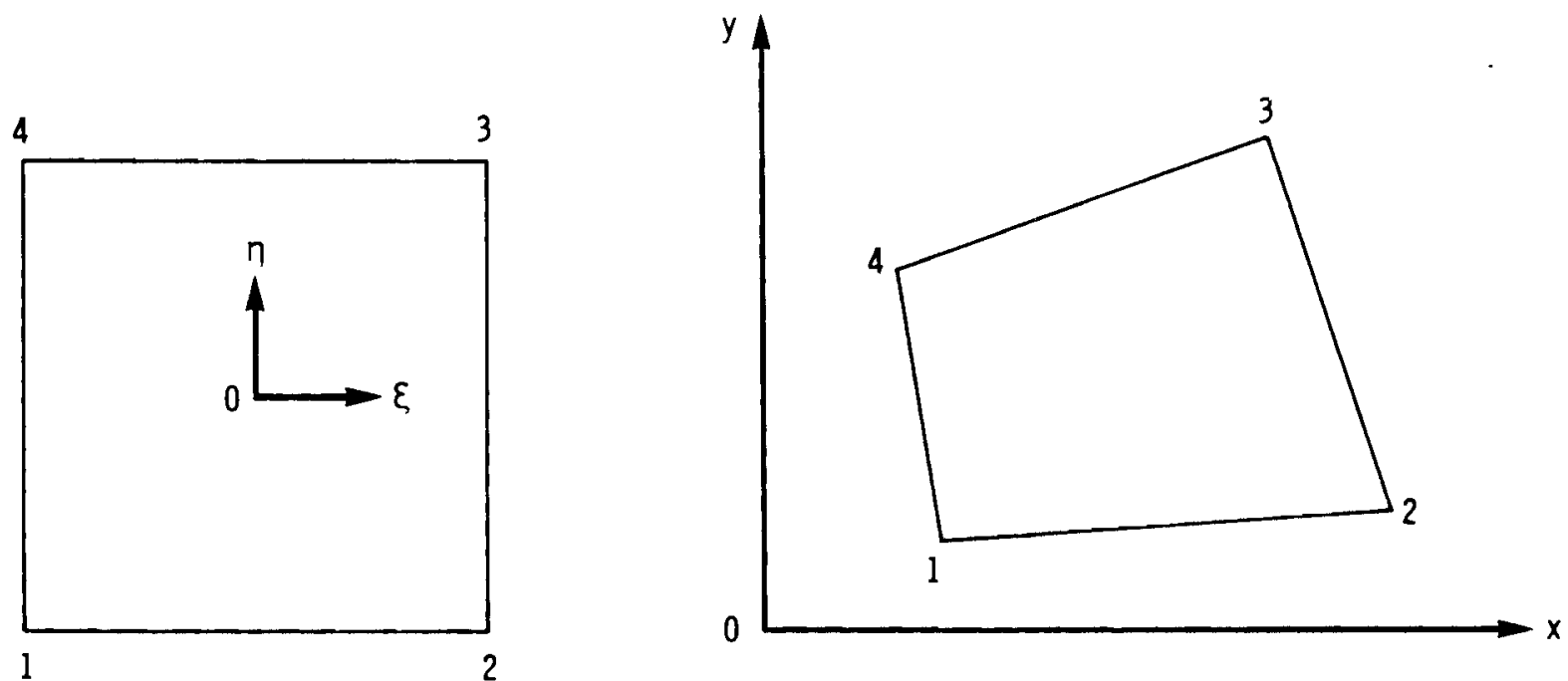

a) TWO-DIMENS IONAL BILINEAR ELEMENTS (LOCAL AND GLOBAL)
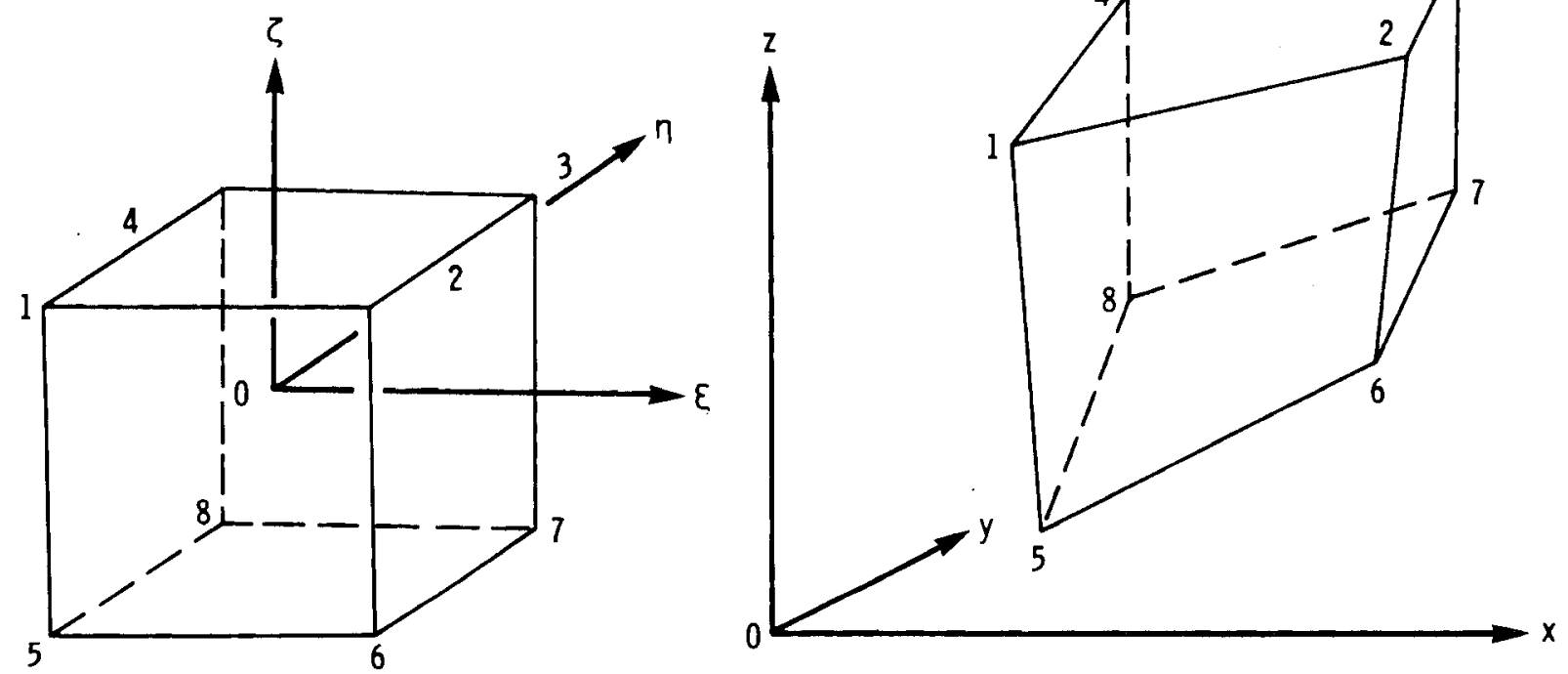

b) THREE-DIMENSI ONAL TRILINEAR ELEMENTS LOCAL AND GLOBAL)

FIGURE 2.2. Isoparametric Elements in Global and Local Coordinates. (a) twodimensional element (b) three-dimensional element.

$$
\begin{aligned}
& x=\sum_{i=1}^{n} v_{i}(\xi, n, \tau) x_{i} \\
& y=\sum_{i=1}^{n} v_{i}(\xi, n, \tau) y_{i}
\end{aligned}
$$




$$
z=\sum_{i=1}^{n} v_{i}(\xi, n, \tau) z_{i}
$$

The partial differential of the shape function with respect to the local coordinate can be obtained through an application of the chain rule, i.e.,

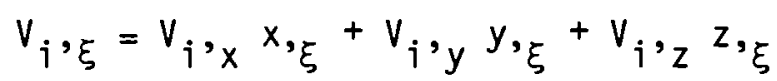

Forming analogous differentials for the remaining two local coordinates and expressing them in matrix form, we have:

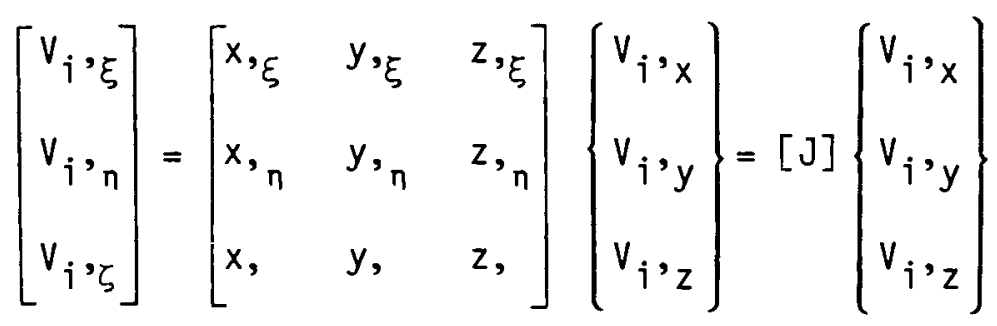

The left-hand side of Equation (2.73) can be evaluated since the $v_{j}$ are functions of local coordinates. Furthermore, $x, y$, and $z$ are explicitly given by the relation defining the curvilinear coordinates [Equations (2.68) to $(2.71)]$. Thus, there are three unknowns, $\left(V_{i}, x, v_{i}, y\right.$, and $\left.v_{i}, z\right)$ and three equations in Equation (2.73). To find the global derivatives, we invert [J] and write

$$
\left\{\begin{array}{l}
v_{i, x} \\
v_{i, y} \\
v_{i, z}
\end{array}\right\}=[J]^{-1}\left\{\begin{array}{l}
v_{i} \\
v_{i, n} \\
v_{i, \zeta}
\end{array}\right\}
$$

Assuming that the inverse of [J] can be formed, the first term of Equation (2.48) can be written for the three dimensional problem as: 


$$
\begin{aligned}
\int \rho^{m} k_{\alpha \beta}^{m} V_{i}, v_{j, \beta} d \vec{x} & =\int_{-1}^{1} \int_{-1}^{1} \int_{-1}^{1} \rho^{m}\left(k_{x x} V_{i}, x^{V_{j}, x}+k_{y y}^{m} V_{i}, v_{j}, y\right. \\
& \left.+k_{z z}^{m} V_{i}, v_{j}, z\right) \operatorname{det}[j] d \xi d \eta d \zeta \\
& =\int_{-1}^{1} \int_{-1}^{1} \int_{-1}^{1} f(\xi, n, \zeta) \operatorname{det}[J] d \xi d n d \zeta
\end{aligned}
$$

Note that the relationship between control volumes (areas) of the two coordinates systems is given by:

$$
d \bar{x}=\operatorname{det}[J] d \xi d \eta d \zeta
$$

Gaussian quadrature can now be used to perform the integration indicated. The integral is evaluated by summing the $N$ products of the polynomial's value and its associated weight at $N$ distinct quadrature points. This integration process can be carried out easily for polynomials of any order, in multiple dimensions. By this technique, a one-dimensional polynomial $f(x)$ of degree $2 \mathrm{~N}-1$ is integrated exactly. The integral of Equation (2.75) is simply replaced by a summation, i.e.,

$$
\begin{aligned}
& \int_{-1}^{1} \int_{-1}^{1} \int^{1} f(\xi, n, \zeta) \operatorname{det}[j] d \xi d n d \zeta \\
& \approx \sum_{j=1}^{N} \sum_{j=1}^{N} \sum_{k=1}^{N} w_{i} w_{j} w_{k} f\left(\xi_{i}, n_{j}, \zeta_{k}\right) \operatorname{det}[J]
\end{aligned}
$$

where $w_{j}, w_{j}, w_{k}$ are the weights associated with the quadrature point $\left(\xi_{j}, n_{j}, \zeta_{k}\right)$. Gaussian quadrature abscissae (coordinates) and weights are given for up to a 10 point rule on the domain $(-1,1)$ in Table 2.2. 
TABLE 2.2. Abscissae and Weight Coefficients of the Gaussian Quadrature Formula

$$
\int_{-1}^{1} f(x) d x=\sum_{j=1}^{N} w_{j} f\left(a_{j}\right),
$$

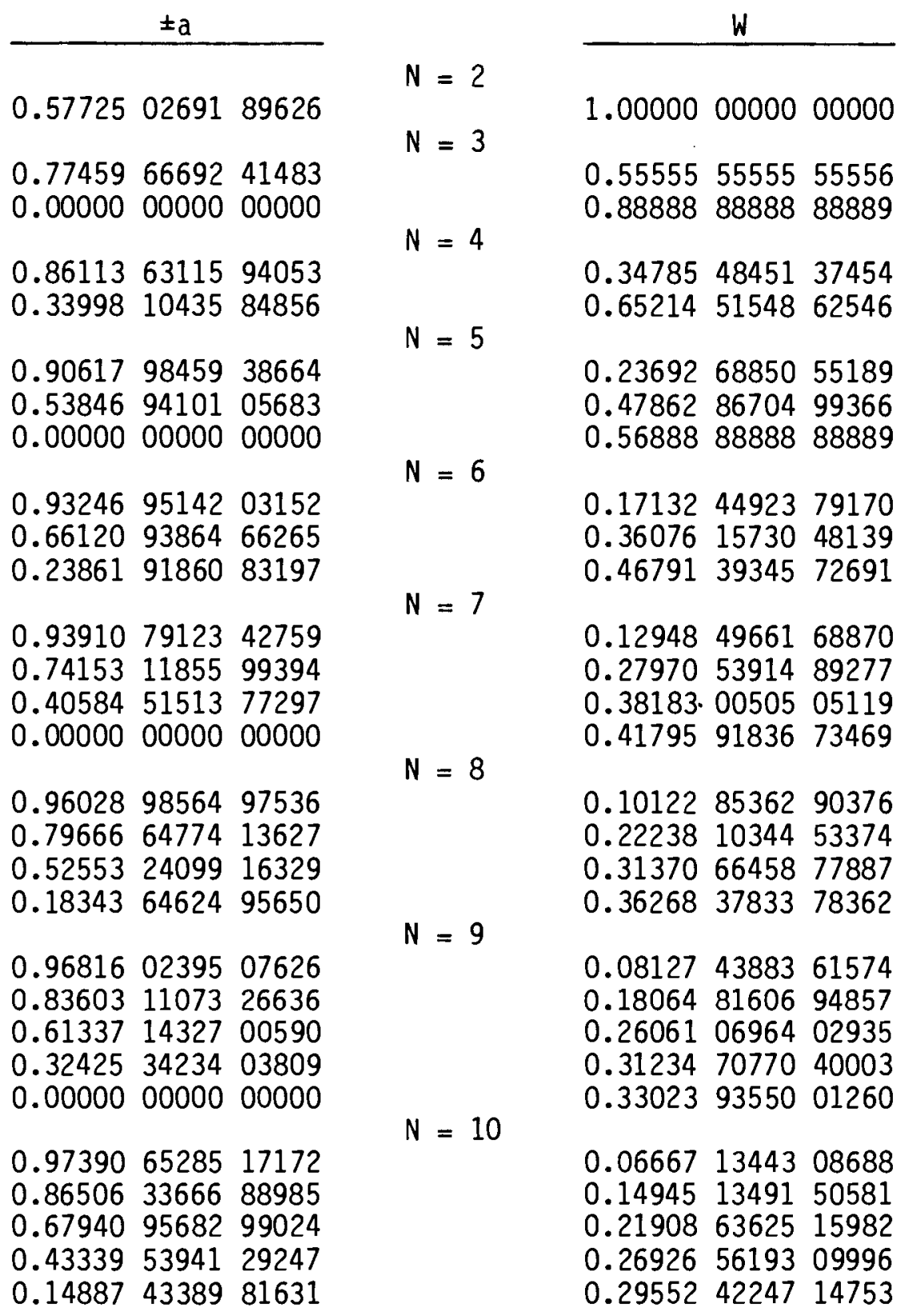




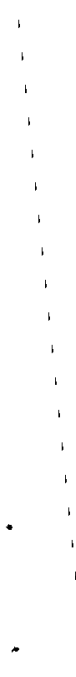




\subsection{INPUT DATA REQUIREMENTS}

Compilation of an accurate and consistent data set is fundamental to numerical simulation. The importance of various parameters and guidelines for their units are presented in this section. Many of the physical and transport properties required as input to the CFEST code are functions of head, temperature, solute concentration and density. The code contains options for constant properties also. Any consistent system of units can be employed. Within this document the symbols $L, T, C, M, t$, and $E$ are used to indicate length, temperature, solute concentration, mass, time, and energy units respectively.

\subsection{FLUID PROPERTIES}

The CFEST code includes density as a function of pressure, temperature and composition [Equation (2.15)]. Fluid density, $\rho$, has been expanded in a threedimensional, first order Taylor series about the resident aquifer fluid density at reference head $\left(h_{0}\right)$, temperature $\left(T_{0}\right)$, and concentration $\left(C_{0}\right)$. The input data on compressibility, thermal expansion, and concentration-density ratio are required along with the reference density, $\rho\left(h_{0}, T_{0}, C_{0}\right)$. Data on absolute viscosity, as a function of temperature and concentration, are required if hydraulic conductivity is to be estimated as a function of energy and solute levels.

\subsubsection{Compressibility}

Density is expressed as a function (see Section 2.5) of pressure by:

$$
\left.\frac{\partial \rho}{\partial h_{p}}\right|_{E_{0}}=C_{W} \rho_{0}
$$

Fluid compressibility $\left(C_{W}\right)$ must be entered for a transient flow simulation. Compressibility is entered at the reference condition of $E_{0}\left(=h_{0}, T_{0}\right.$, and $\left.C_{0}\right)$. Since CFEST uses equivalent head with reference to a given resident aquifer fluid density, the compressibility, commonly given as per unit pressure, must 
be converted to a per unit head measure. Head affects fluid density significantly less than temperature and composition.

Units: $L^{-1}$

\subsubsection{Thermal Expansion}

The thermal coefficient of expansion $\left(C_{T}\right)$ exhibits a significant variation with changes in composition or temperature. As illustrated in Table 3.1, an average value of the coefficient for temperatures between $60^{\circ} \mathrm{F}$ and $200^{\circ} \mathrm{F}$, and composition varying from 4 to $20 \%$ of $\mathrm{NaCl}$ (brine), introduces as much as a $30 \%$ error in $C_{T}$. However, within the normal range of expected temperature and concentration values, the errors in density calculations introduced by average values of $C_{T}$ will not be outside the range of uncertainty in injections and other field parameters.

TABLE 3.1. Density Model Coefficients for NaCl (Brine) (Intercomp 1976)

\section{Coefficient $^{(a)}$}

$\mathrm{a}_{2} \times 10^{2} \mathrm{lb} / \mathrm{ft}^{3 \circ} \mathrm{F}$

a3 $1 b / f t^{3} \%$

$\mathrm{a}_{2} \times 10^{2} \mathrm{bb} / \mathrm{ft}^{3} \mathrm{~F}$

a3 $\quad 1 b / f^{3} \%$

$\mathrm{a}_{2} \times 10^{2} \mathrm{lb} / \mathrm{ft}^{3} \mathrm{~F}$

a3 $\quad 1 b / \mathrm{ft}^{3} \%$

$\mathrm{a}_{2} \times 10^{2} \mathrm{lb} / \mathrm{ft}^{3 \circ} \mathrm{F}$

a3 $\quad 1 b / f t^{3} \%$ wt \%

4

12

$-1.66$

0.46

$-2.11$

0.49

$-1.70$

0.47
Temperature

$60^{\circ} \mathrm{F} \quad 130^{\circ} \mathrm{F} \quad 200^{\circ} \mathrm{F}$

$-1.81$

0.43

$-2.51$

0.42

$-1.82$

0.45

0.46

$-2.22$

$-1.65$

0.48

0.47

$-1.95$

$-2.0$

over

Comp.

(a) Note: $a_{2}=\rho_{0} C_{T}, a_{3}=\rho_{0} C_{C}$ 
Values of the thermal coefficient of expansion are entered at the aquifer resident fluid temperature $\left(T_{0}\right)$, head $\left(h_{0}\right)$, and zero solute concentration. This coefficient must be entered for energy transport simulation.

Units: $T^{-1}$

\subsubsection{Composition Density Ratio}

Solute concentration (C) within an aquifer fluid is commonly defined as the amount of substance by weight, moles, or equivalents contained in one unit volume of fluid. Concentration is generally defined either as the number of parts by weight of solute per million parts of volume (ppm) which is equivalent to milligrams per liter $(\mathrm{mg} / 1)$ or as the percentage (\%) of the solution weight attributable to the solute.

The partial derivative describing change in density per unit change in solute concentration is defined as (see also Section 2.5):

$$
\left.\frac{\partial \rho}{\partial C}\right|_{E_{0}}=C_{C} \rho_{0}
$$

Composition density ratio $\left(C_{c}\right)$ must be entered if solute concentration is being simulated. The ratio is dimensionless, however it is entered as a percentage rather than a simple fraction.

\section{1 .4 Heat Capacity}

Heat capacity $\left(C_{p w}\right)$ is the quantity of energy required to increase the temperature of one unit mass of the fluid by one degree temperature from a heat capacity reference temperature, $T_{u}$. It is a function of both temperature and pressure. It is measured in the laboratory under conditions of either constant pressure or constant volume. In general, one would like to use the heat capacity at constant pressure since it is essentially constant over the temperature range under consideration; however, for nonisothermal analyses the appropriate heat capacity to employ is constant volume. This parameter does exhibit a 
temperature dependence as shown in Table 2.1. A provision is included within CFEST for the user to select either the constant pressure or constant volume value of heat capacity.

Units: $E M^{-1} T^{-1}$

\subsubsection{Internal Energy}

Internal energy is understood to be the energy associated with the random translational and internal motions of the molecules plus the energy associated with the interaction between molecules. It is readily seen that internal energy is dependent upon the temperature and density of the resident fluid. The internal energy $(U)$ of the fluid is described as:

$$
U=U_{0}+C_{p w}\left(T-T_{u}\right)
$$

where $U_{0}$ is the internal energy at the heat capacity reference temperature $T_{u}$. Units: $\mathrm{E} \mathrm{M}^{-1}$

\subsubsection{Reference Density}

A reference density $\left(\rho_{0}\right)$ is used repeatedly in the definition of density as a function of pressure, temperature and concentration. The most convenient and logical choice is the density of the resident aquifer liquid (i.e., water). This reference density serves as a datum for evaluating changes in density. The ambient liquids density will naturally be a function of the confining pressure of the aquifer $\left(h_{0}\right)$, the liquid's ambient temperature $\left(T_{0}\right)$, and an assumed zero solute concentration. The reference density representing these values of pressure, temperature and concentration must be entered.

Units: $M^{-3}$

\subsubsection{Absolute Viscosity}

Absolute fluid viscosity $(\mu)$ is used in the calculation of hydraulic conductivity. Viscosity is affected by temperature and composition of the fluid. The model of viscosity used in the code depends on which of these two variables are simulated. The relationship of viscosity to concentration is entered at 
the viscosity reference temperature, $T_{r}$. Effects of temperature on viscosity are described by a regression coefficient $\left(B_{r}\right)$, or by entering tabulated data. The viscosity at a given temperature and solute concentration is calculated by:

$$
\mu(C, T)=\mu\left(T_{r}, C\right) \exp \left[B_{r}\left(1 / T-1 / T_{r}\right)\right]
$$

Units: $\quad \mathrm{M} \mathrm{T}^{-1} \mathrm{~L}^{-1}$

\subsection{HYDROGEOLOGIC PROPERTIES}

Vertical stratigraphy at each of the surface nodes is defined by assigning a number to each geologic unit in the modeled region. Each geologic unit revealed by the well $10 \mathrm{~g}$ data is modeled as one or more finite elements. It is essential that the properties of each geologic unit be entered. Both isotropic and anisotropic properties can be employed within the CFEST code. However, anisotropy can be modeled only when the coordinate axes and the major and minor property axes are collinear.

\subsubsection{Permeability}

Using Darcy's equation, the flow velocity in a porous medium with a varying fluid density is described by:

$$
\begin{gathered}
u_{\alpha}=\frac{\rho_{0} g k_{\alpha \beta}}{\mu}\left(h_{, \beta}+\frac{\left(\rho-\rho_{0}\right)}{\rho_{0}} z_{\beta}\right) \\
\text { where } k_{\alpha \beta}=\text { intrinsic permeability, } L^{2} \\
\text { and } k_{\alpha \beta}=\frac{\rho_{0} g k_{\alpha \beta}}{\mu}=\text { hydraulic conductivity tensor, } \mathrm{Lt}^{-1},
\end{gathered}
$$

One has the option to employ either intrinsic permeability or hydraulic conductivity. Their units are specified above. 


\subsubsection{Porosity}

Porosity $(\theta)$ is an important parameter for transport problems. It represents the volume of pore space in a unit volume of aquifer. The reference value of porosity, $\theta_{0}$, is specified at a porosity reference head $\left(h_{\theta}\right)$.

Units: Dimensionless

\subsubsection{Medium Compressibility}

Pressure affects upon pore volume are described by

$$
\theta=\theta_{0}\left[1+C_{r}\left(h-z-h_{\theta}\right)\right]
$$

where $\theta_{0}=$ reference porosity, dimensionless fraction;

$C_{r}=$ compressibility of the medium, $L^{-1}$;

$h_{\theta}=$ head at which $\theta_{0}$ is measured, $L$.

The coefficient for the rate of change in pore volume per unit change of pore water pressure head defines the compressibility of the medium. If only specific storage data is available, $C_{r}$ is approximated by Equation (3.9). Units: $\mathrm{L}^{-1}$

\subsubsection{Specific Storage}

The specific storage $\left(S_{S}\right)$ is defined as the volume of water released by a unit volume of aquifer per unit decline in hydraulic head. It is usually obtained from pumping test data. Specific storage includes the affects of compressibility of fluid and medium.

$$
S_{s}=C_{r} \theta_{0}+\theta C_{w}
$$

If $C_{r}$ is not entered, it is approximated by

$$
C_{r}=\left(s_{s}-\theta_{0} C_{w}\right) / \theta_{0}
$$

Units: $L^{-1}$ 


\subsubsection{Dispersivity Length}

Both mass and thermal dispersivities are calculated as the sums of the hydrodynamic dispersion and molecular diffusion (see Section 2.3). Longitudinal $\left(\varepsilon_{L}\right)$ and transverse $\left(\varepsilon_{T}\right)$ dispersivity length must be defined for energy and solute transport problems.

Units: L

\subsubsection{Thermal Conductivity}

The thermal conductivity $\left(E_{m}\right)$ is defined as the molecular energy conductivity of combined fluid and medium. Thermal conductivity is considered as an additive term to hydrodynamic dispersion.

Units: $E t^{-1} T^{-1} L^{-1}$

\subsubsection{Heat Capacity}

The heat capacity per unit volume of the composite aquifer $\left(U_{T}\right)$ is the energy required to raise the temperature of one unit volume of aquifer (fluid and rock matrix) one degree. The accepted model for a composite heat capacity for the aquifer is given by (Reffstrup 1979),

$$
U_{T}=\theta\left(\rho C_{p}\right)_{W}+(1-\theta)\left(\rho C_{p}\right)_{r}
$$

where subscripts $w$ and $r$ refer to the water and rock matrix heat capacity, respectively. Density of the rock matrix is considered constant and therefore $\left({ }_{\rho} C_{p}\right)_{r}$ is entered for a unit volume. For energy transport simulation, heat capacity must be entered.

Units: $E T^{-1} L^{-3}$

\subsection{THERMAL PROPERTIES OF CONFINING ROCK}

CFEST simulates heat loss by vertical conduction to the confining rock strata. The following properties and initial condition of confining strata are employed. 
1. Thickness of over and underlying rock strata $\left(B_{0 B}, B_{U N}\right)$ can be read in as a constant or variable, $L$.

2. Vertical heat conductance $\left(U_{K O B}, U_{K U N}\right) ; E^{-1} t^{-1} L^{-1}$.

3. Heat capacity $\left({ }^{\circ} C_{r}\right)_{O B},\left({ }_{O} C_{r}\right)_{U N} ; E T^{-1} L^{-3}$.

4. Held temperature at outer edge $\left(T_{O B}, T_{U N}\right) ; T$.

5. Initial vertical temperature distribution; $T$.

\subsection{GRID POINT LOCATIONS}

Numerical simulation, specifically the transport problem with dominant convective flow, is sensitive to the selection of grid nodes. No discrete set of guidelines for an ideal or "best" suited grid are available for a given problem. Normally, by a few trials, a suitable grid pattern and spacing for a particular problem can be developed. The following discussion lists general guidelines for grid preparation:

1. Geology, geography and surface-water hydrology control groundwater flow. Geologic factors include stratigraphy, thickness of each layer, discontinuities, and other structural controls such as fault zones or folds. Breaks in slope are geographic features. Bodies of surface water such as lakes, rivers or oceans serve as sources for recharge or sinks for withdrawal from ground-water flow systems. Grids developed for simulation should represent these features effectively.

2. Finite element methodology allows the use of variable grids. However, acute distortion of elements from rectangular shape and sudden changes in grid size increase computation errors in a simulation due to roundoff or truncation.

3. Closer grid spacing should be used in areas where high gradients of head, temperature and/or concentration are anticipated.

4. The cost of simulation increases with an increase in the number of grid points. 
5. The maximum number of grid points cannot exceed the capacity of the code. The present version of CFEST allows a maximum of 1280 grid points. Future versions of the code could be expanded to include a greater number of grid points.

\subsection{INITIAL CONDITIONS}

Initial conditions are required for transient simulation of the dependent variables of interest ( $h, T$, and/or $c)$.

\section{5 .1 Head}

Field data giving the vertical distribution of head are limited. Therefore, as a general rule, all the grid points vertically below a point are assigned the head entered for the top of the aquifer. An option for defining vertical head variation is included.

Units: L

\subsubsection{Temperature}

One expects to find increasing temperature with increasing depth below the surface. Elevation and temperature are read in at a specified number of points. The vertical profile should extend from the top of the upper confining rock to the base of the lower confining rock. An option for entering an initial vertical temperature profile at each node is also included. Units: $T$

\subsubsection{Solute Concentration}

Two options to read in initial solute concentration distribution are included. Concentration at all vertical nodes below a given surface node can be made equal to the concentration associated with the surface node. Alternatively, along with stratigraphic data, the initial vertical concentration distribution may be entered.

Units of concentration should be consistent with those described in Section 3.1.3. 


\subsection{BOUNDARY CONDITIONS}

Boundary conditions at the periphery of the ground-water system, intersection of the system with surface water bodies, and injection/production wells are of prime importance. Either Dirichlet, or Neumann conditions must be applied at all periphery nodes.

\subsubsection{Dirichlet (Held) Boundary Conditions}

Head, temperature and solute concentration must be specified for at least one node and preferably more. The following are general guidelines for specifying Dirichlet conditions:

1. Surface water bodies which are intercepted by aquifers can be considered as Dirichlet boundary conditions, provided their parameters (head, temperature, and/or concentration) are not functions of the ground-water flow.

2. The periphery of the ground-water system which is remote from near field zone of influence can be taken as a Dirichlet boundary.

Injection or production wells which penetrate an aquifer of interest may introduce Dirichlet boundary conditons. Fluids to be introduced to the aquifer system at specific temperature and/or concentration are examples.

\subsubsection{Neumann (Flux) Boundary Conditions}

Neumann boundary conditions can be homogeneous as in the case of "natural boundary conditions" which arise at impermeable boundaries, or nonhomogeneous as in the case of boundaries across which fluid passes at a specific rate. Thus, candidates for Neumann boundary conditions are impervious boundaries, points of injection and withdrawal, and infiltration or evaporation from the surface in the case of a vertical (two or three-dimensional) analysis.

\subsection{ELEMENT FORMATION}

For two-dimensional simulation, CFEST uses bilinear quadralateral elements. The four nodes of each element must be entered in a counterclockwise rotation. Wherever possible, all angles of the element should approximate a right angle $\left(90^{\circ}\right)$. In any case, angles approaching $180^{\circ}$ must be avoided. 
Vertical or axisymmetric analyses in the $x-z$ or $r-z$ coordinate systems respectively, require specification of the $x$ or $r$ coordinate for the two top nodes. Nodal stratigraphy data are used to automatically generate vertical layers below the surface nodes. An element is created for each material. If a given material is not found on both the nodes, a "pinched" element is generated (Figure 3.1).

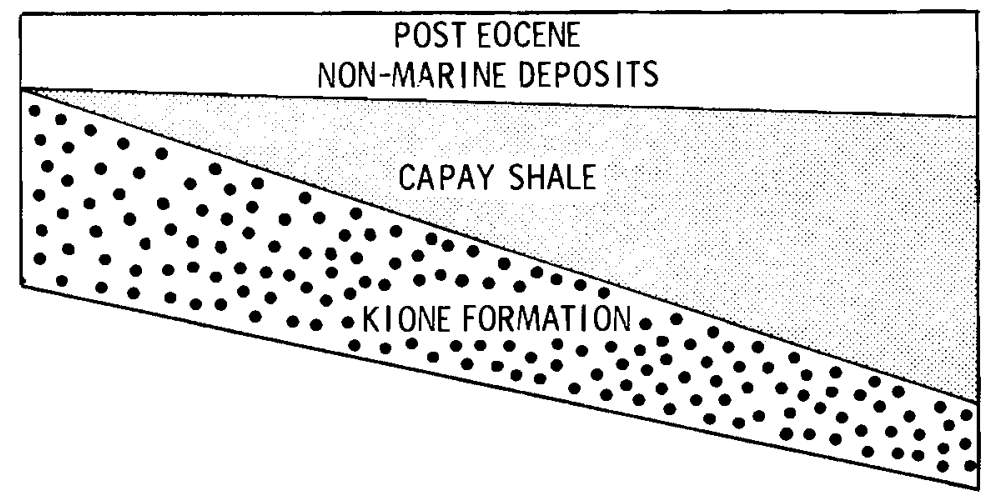

FIGURE 3.1. "Pinched" Element if Given Material not Found

Three-dimensional simulation uses the eight node brick or trilinear element (Figure 2.2). The eight node brick elements are automatically generated by combining the four node, bilinear surface elements and stratigraphy data entered for each node. If a given material is not found in all the nodes, a "pinched" element is once again created.

\subsection{ELEMENTAL SOURCE/SINK}

Distributed source or sink terms associated with any element are also considered in CFEST. For source terms (e.g., infiltration, composite injection), flow rates, temperature, and concentration are prescribed along with injection head. For sink terms (e.g., evaporation, composite withdrawal), only flow rates are entered. Temperature and solute concentration of withdrawal are a function of simulated results approaching and hence passing through the exit boundary. 


\subsection{TERMINAL INTERACTIVE INPUT DATA FILE PREPARATION}

To assist in the preparation of input data for CFEST, a number of programs have been developed (Figure 3.2). The required data can be either entered directly or line printer listings of data requirements can be generated. These programs are an integral part of the CFEST code package and are discussed further in the user's manual.

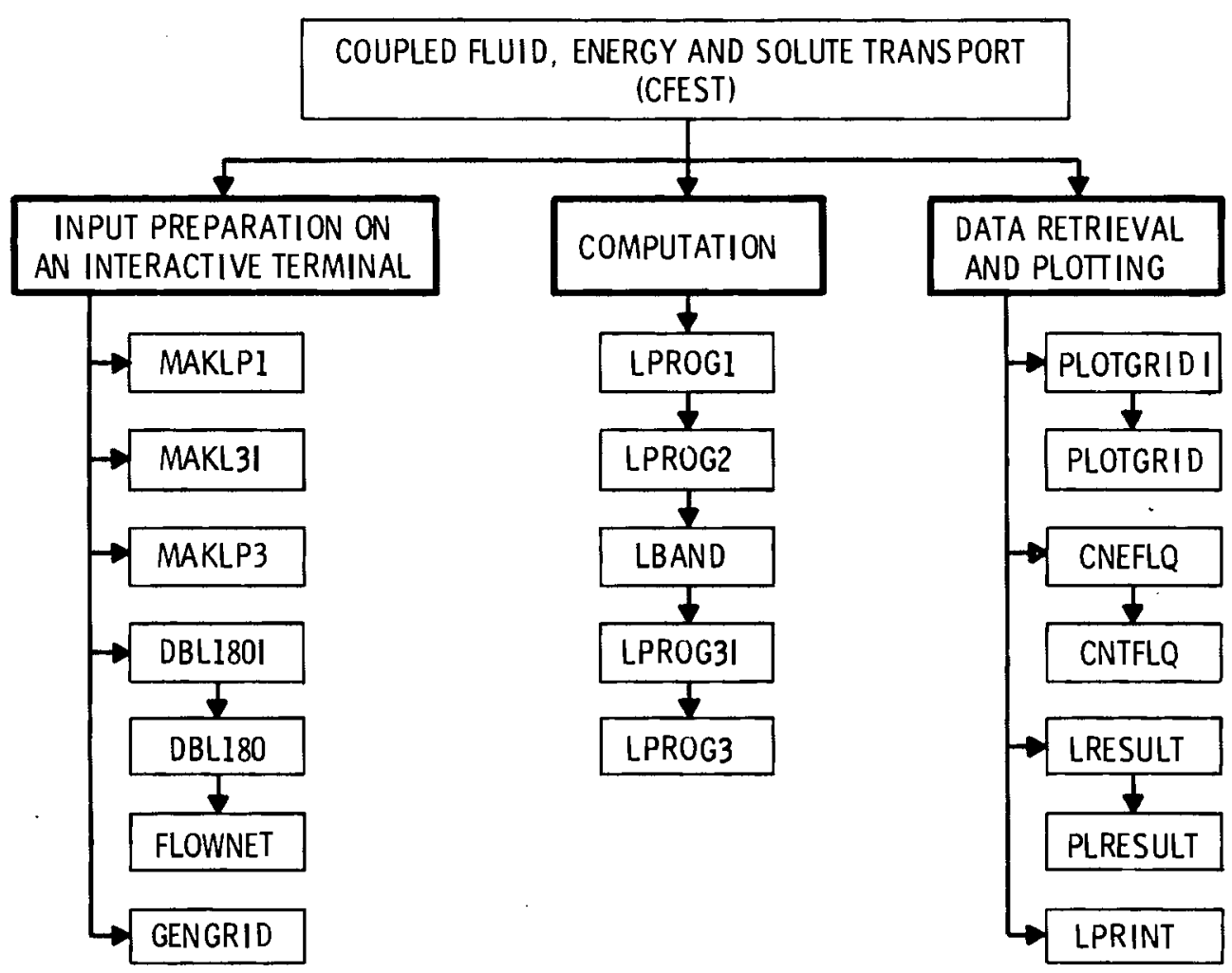

FIGURE 3.2. CFEST Subprograms for Interactive Input Preparation, Compilation and Plotting 


\subsection{VERIFICATION AND SENSITIVITY ANALYSES WITH ANALYTICAL SOLUTIONS}

Anaytical solutions of idealized fluid, energy and solute transport problems provide the means to check that the formulation is coded properly. These solutions also serve as a check upon the simulative ability of the code. In this section the analytical solutions used in verifying CFEST are presented and the sensitivity analyses on the affects of grid size and time steps are discussed.

For numerical solutions, the grid size and time steps used have important impacts upon accuracy. For idealized problems, modelers usually adjust the grid size and time steps to match the analytical solution. However, for practical problems modelers normally do sensitivity analyses with the grid size and time step until the results are independent of both. In this document, along with "best" results, some of the poor results of the grid size and time step sensitivity analyses are included. Review of the verification tests will illustrate that numerical solutions for a given problem are not unique, and that the "best" solution may require a few trials.

\subsection{FLOW PREDICTION TESTS}

The CFEST code is based upon a previously published and extensively applied ground water code (Gupta et al. 1979). Included herein are three commonly cited one-dimensional and/or axisymmetric verification cases and a fourth case which demonstrates some two-dimensional aspects of this multidimensional code. Both steady (Bear 1979) and unsteady (Theis 1935) flow within a strictly confined aquifer are modeled. The boundary value problem of leaky over and underburden confining media (Hantush 1959) is also examined. Finally, a twodimensional analytical solution to sources and sinks in a uniform flow field (Nelson and Schur 1978) is employed to further demonstrate the CFEST code's areal ground water simulative ability.

\subsubsection{Steady Drawdown in a Confined Aquifer}

Drawdown resulting from steady flow to a well in a confined aquifer is reported by Bear (1979) to be defined as, 


$$
S=\frac{Q}{2 \pi K m} \ln \left(R_{0} / R\right)
$$

where

$$
\begin{aligned}
S & =\text { drawdown }, L \\
Q & =\text { flow rate, } L^{3} t^{-1} \\
K & =\text { hydraulic conductivity, } L^{-1} \\
R & =\text { radius of observation, } L \\
R_{0} & =\text { radius of influence, } L \\
m & =\text { thickness of aquifer, } L .
\end{aligned}
$$

The following parameters were used:

$$
\begin{aligned}
K_{x} & =K_{y}=1 \mathrm{~m} / \text { day } \\
R_{0} & =20 \mathrm{~m} \\
m & =1 \mathrm{~m} \\
Q & =10 \mathrm{~m}^{3} / \text { day } / \mathrm{m}
\end{aligned}
$$

Five simulations are reported, two used an axisymetric $(r-z)$ grid, and three employed a Cartesian $(x-y)$ grid. Two uniform grid spacings were used, $\Delta r=0.5 \mathrm{~m}$ and $\Delta r=2.0 \mathrm{~m}$. Quadrant angles of $11.25^{\circ}$ and $45.0^{\circ}$ were employed in the Cartesian grid.

The analytic and simulated results are given in Table 4.1. It is apparent from the tabularized results that the simulative ability of the code improves with a reduction of grid size and quadrant angle. With a larger segment angle, the element sizes increase rapidly and there is a greater element distortion with increased distance from the well (Figure 4.1). The virtue of the axisymmetric analysis is also readily seen in these results. This is expected since the analytical solution employs an axisymmetric analysis.

\subsubsection{Unsteady Drawdown in a Confined Aquifer}

Theis (1935) defines the time dependent drawdown for a well pumped at a constant rate in an infinite, homogeneous and isotropic aquifer by the following nonequilibrium equation: 
TABLE 4.1. Analytical and Simulated Steady-State Drawdown in a Confined Aquifer

\begin{tabular}{|c|c|c|c|c|c|c|}
\hline \multirow[b]{2}{*}{$\begin{array}{l}\text { Radial Dist. } \\
\text { from Well (m) }\end{array}$} & & \multicolumn{3}{|c|}{$\begin{array}{c}\text { CFEST With Quadrant } \\
\text { Grid }\end{array}$} & \multirow{2}{*}{\multicolumn{2}{|c|}{$\begin{array}{c}\text { CFEST with } \\
\text { Axisymmetric Grid }\end{array}$}} \\
\hline & $\begin{array}{l}\text { Analytic } \\
\text { Solution }\end{array}$ & $\begin{array}{l}\Delta \mathrm{R}=2 \mathrm{~m} \\
\leq=45^{\circ}\end{array}$ & $\begin{array}{c}\Delta \mathrm{R}=2 \mathrm{~m} \\
\leq=11.25^{\circ}\end{array}$ & $\begin{array}{r}\Delta R=.5 \mathrm{~m} \\
\angle=11.25^{\circ}\end{array}$ & & \\
\hline 2 & 3.665 & 3.420 & 3.596 & 3.649 & 3.607 & 3.661 \\
\hline 4 & 2.561 & 2.414 & 2.538 & 2.552 & 2.546 & 2.561 \\
\hline 6 & 1.916 & 1.810 & 1.903 & 1.910 & 1.910 & 1.916 \\
\hline 8 & 1.458 & 1.379 & 1.450 & 1.453 & 1.455 & 1.458 \\
\hline 10 & 1.103 & 1.044 & 1.098 & 1.099 & 1.101 & 1.103 \\
\hline 12 & 0.813 & 0.770 & 0.809 & 0.810 & 0.812 & 0.813 \\
\hline 14 & 0.568 & 0.537 & 0.565 & 0.566 & 0.567 & 0.568 \\
\hline 16 & 0.355 & 0.336 & 0.354 & 0.354 & 0.355 & 0.355 \\
\hline 18 & 0.168 & 0.158 & 0.167 & 0.167 & 0.168 & 0.168 \\
\hline 20 & 0.000 & 0.000 & 0.000 & 0.000 & 0.000 & 0.000 \\
\hline
\end{tabular}
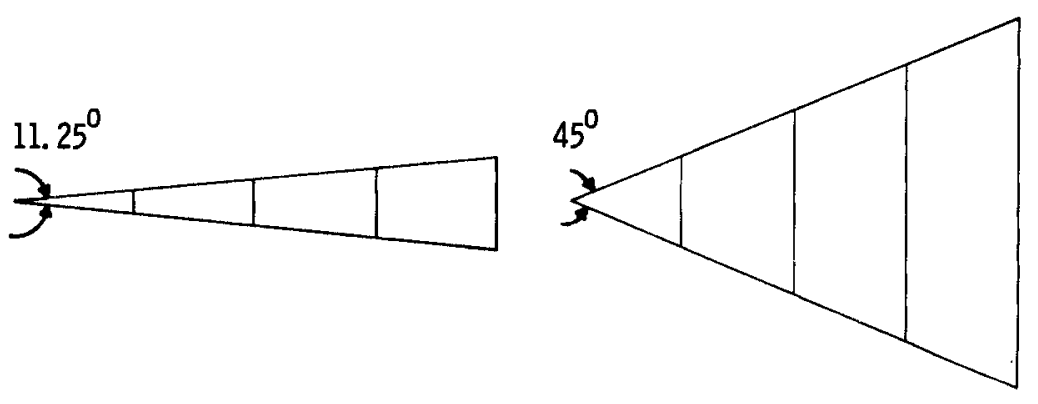

FIGURE 4.1. Effects of the Segment Angle on Element Shape

$$
\begin{aligned}
h_{0}-h & =Q / 4 \pi T \int_{u}^{\infty} \frac{e^{-u} d u}{u} \\
u & =r^{2} \text { s/4Tt }
\end{aligned}
$$


where

$$
\begin{aligned}
h_{0}-\mathrm{h} & =\text { drawdown, } L \\
\mathrm{Q} & =\text { well discharge, } L^{3} t^{-1} \\
\mathrm{~T} & =\text { transmissivity, } L^{2} t^{-1} \\
r & =\text { distance from pumping well to observation point, } L \\
\mathrm{~S} & =\text { storage coefficient, dimensionless } \\
\mathrm{t} & =\text { pumping time, } t
\end{aligned}
$$

Because of the symmetry of radial flow to a single pumping well, a pieshaped wedge was modeled with finite elements. A $22.5^{\circ}$ angle, representing $1 / 16$ of the influenced area, was selected. By necessity, the aquifer is required to be bounded at a large distance from the we11. This was achieved by prescribing progressively larger radial increments at increasing distances from the well (Figure 4.2).

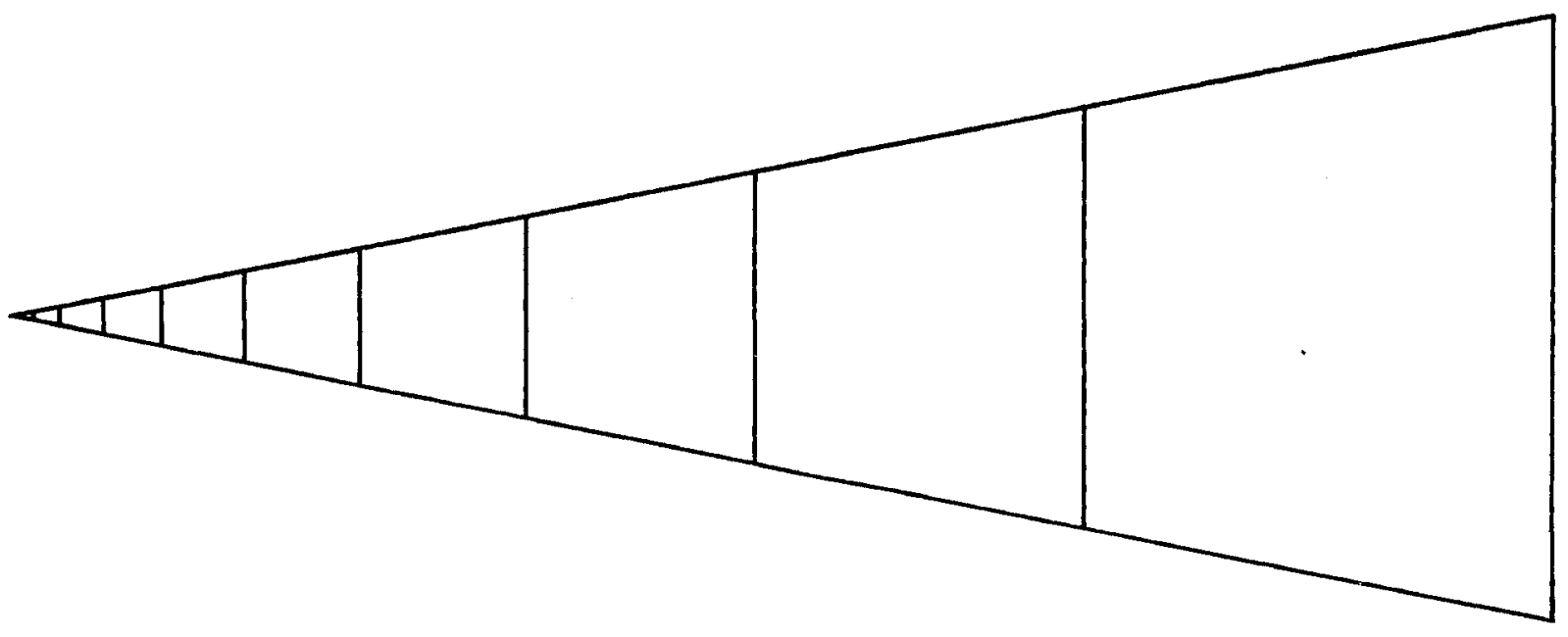

FIGURE 4.2. Diagrammatic Representation of Exponentially Increasing $\left(\Delta r_{i}=1.414 \Delta r_{i-1}\right)$ Nodal Arrangement Used for Finite Element Solution With Segment Angle of $22.5^{\circ}$

Numerical test cases were run using increasing time increments (i.e., $\Delta t_{i}=4 \Delta t_{i-1} ; \Delta t_{1}=10^{-5}$ days). Figure 4.3 compares the finite element solution with the analytical Theis equation. 


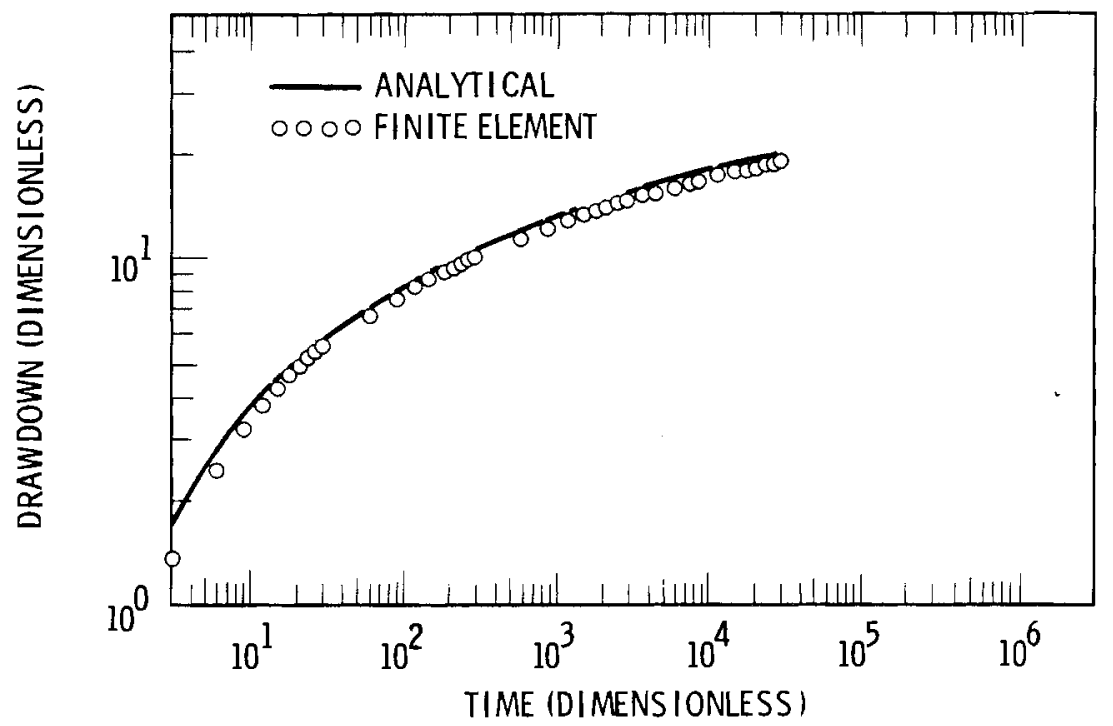

FIGURE 4.3. Theis and CFEST Solutions of Time Dependent Drawdown for a Well Pumped at a Constant Rate

\subsubsection{Unsteady Drawdown in a Leaky Confined Aquifer}

Hantush (1959) developed an analytical solution to determine the drawdown distribution in the vicinity of a steadily pumped well draining an elastic artesian aquifer confined by semipervious, elastic strata. Well discharge is supplied by reduction of storage in the aquifer and by leakage from the semipervious layers. The leakage is obtained from reduction of storage in the semipervious elastic beds or from other bodies of water over and/or underlying the semipervious beds or from both sources. The hydraulic conductivities in the semiconfining layers are assumed small compared with those in pumped aquifers, so that flow is vertical through the confining beds and horizontal in the main aquifer. For the purposes of the multi-layer, horizontal analysis employed herein, the completely refracted leakages are considered to be uniformly distributed throughout the horizontal flow in the main aquifer (Figure 4.4). Using the same spatial and time discretizations employed in the Theis solution, a finite element simulation of the Hantush problem was performed. Figure 4.5 shows comparisons of dimensionless drawdown and dimensionless time at radii of $1.0 \mathrm{~m}, 2.178 \mathrm{~m}$, and $7.389 \mathrm{~m}$. The aquifer and fluid properties used for this test are summarized in Table 4.2. 


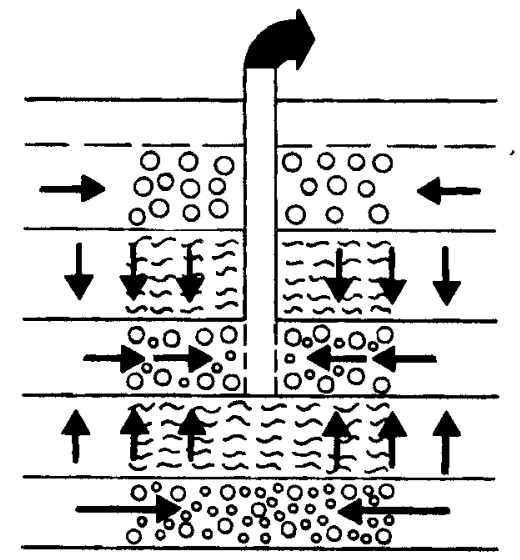

WATER TABLE AQUIFER

WITH CONSTANT POTENTIAL

AQUITARD

AQUIFER (PUMPED)

AQUITARD

AQUIFER WITH

CONSTANT POTENTIAL

FIGURE 4.4. Schematic Diagram of a Leaky Aquifer

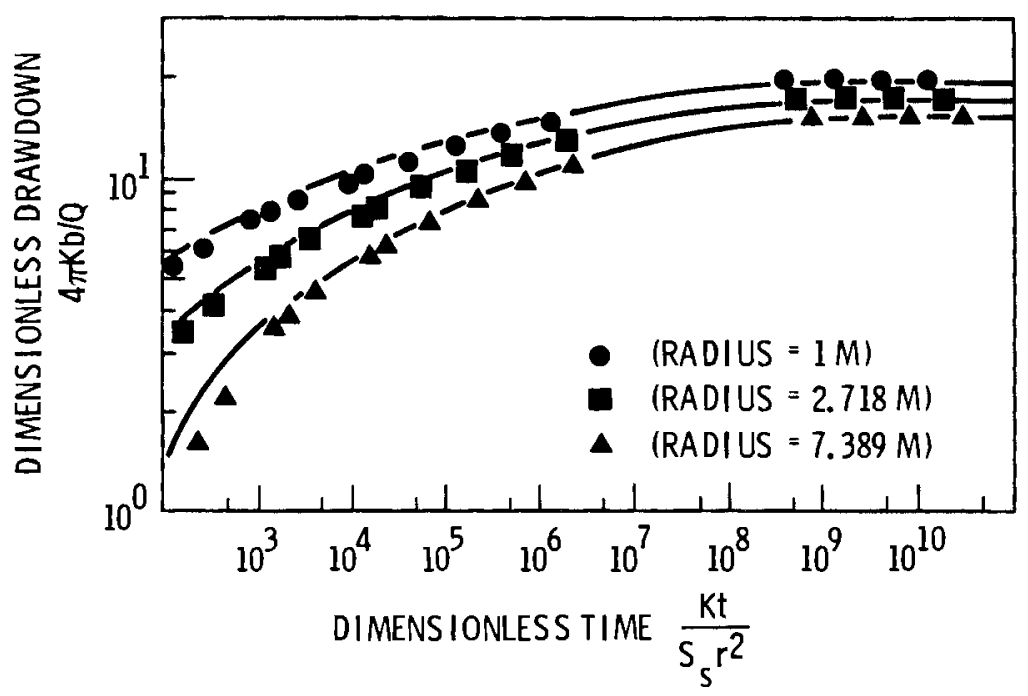

FIGURE 4.5. Comparison of Dimensionless Drawdown Versus Dimensionless Time for CFEST Solution in a Leaky Aquifer

\subsubsection{Uniform Regional Flow with Sources and Sinks}

Nelson and Schur (1978) published an analytical solution for regional flow in a confined, horizontal stratum of uniform vertical thickness which is interrupted by multiple sources and sinks. The stratum is assumed homogeneous, having isotropic hydraulic conductivity and constant effective porosity. A 
TABLE 4.2. Some of the Parameters Used for Leaky
Aquifer Problem

$\begin{array}{ll}\frac{\text { Aquifer }}{\text { Hydraulic Conductivity }} & 100 \mathrm{ft} / \text { day } \\ \text { Specific Storage } & 0.001 / \mathrm{ft} \\ \text { Thickness } & 10 \mathrm{ft} \\ \text { Pumping Rate } & 103 \mathrm{ft} / \text { day }\end{array}$

$\begin{array}{ll}\frac{\text { Aquitard }}{\text { Vertical Conductivity }} & 0.0001 \mathrm{ft} / \mathrm{day} \\ \text { Specific Storage } & 5 \times 10-1 / \mathrm{ft}\end{array}$

uniform lateral flow gradient is assumed within the stratum and the superimposed sources and/or sinks are from vertical, cylindrical ponds or caverns respectively that completely penetrate the entire stratum. Figure 4.6 displays the general problem which the Nelson and Schur (1978) code (PATHS) is capable of analyzing.

For the purposes of CFEST verification, a single subset of the PATHS problem set has been simulated. The problem chosen includes a single source of specified hydraulic head within an otherwise uniform flow. The equation defining the ground water potential distribution in the aquifer is given by Nelson and Schur (1978) as:

$$
\phi=H_{0}-U_{0} x+\frac{U_{0}\left(r_{0}\right)^{2} x}{\left(x^{2}+y^{2}\right)}-\frac{H_{0}}{\ln \left(\frac{R}{r_{0}}\right)} \ln \sqrt{\frac{x^{2}+y^{2}}{r_{0}}}
$$

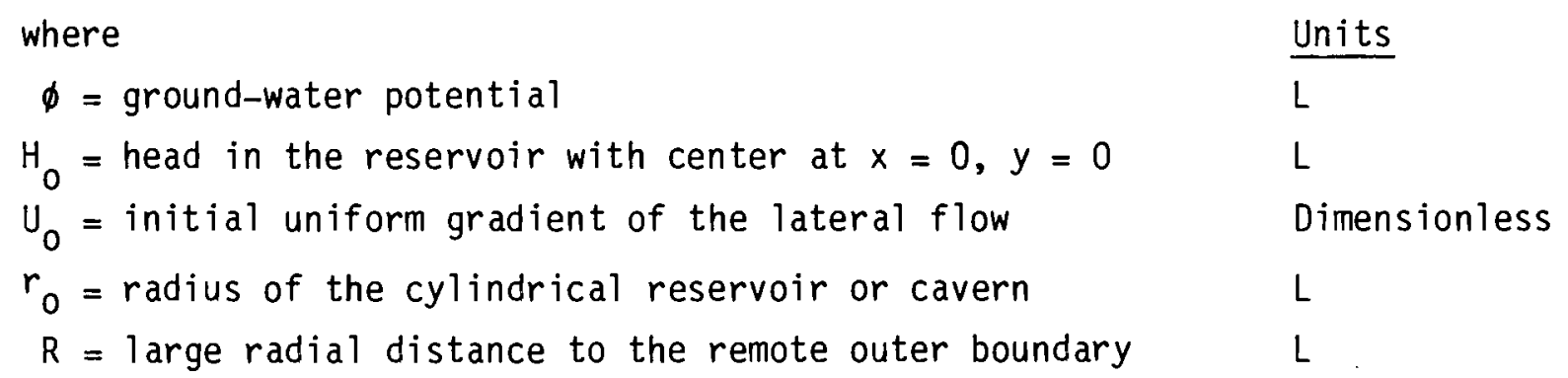




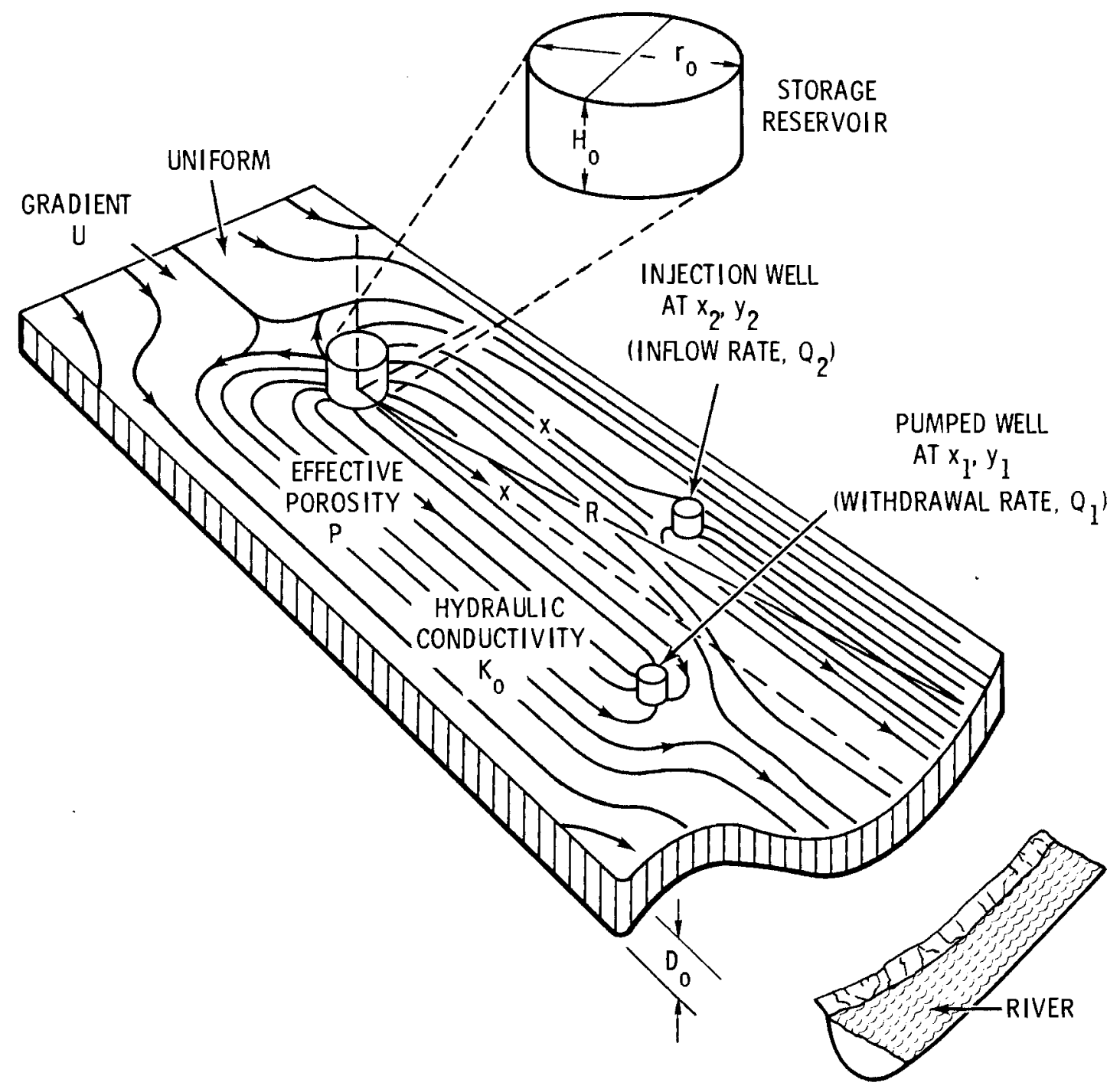

FIGURE 4.6. Schematic PATHS Model Region (Nelson and Schur, 1979)

A local rectangular subregion of an infinite aquifer is shown in Figure 4.7. The important dimensions are shown in the figure and due to the obvious symmetry of the domain, only half of the area was simulated. It was assumed that the regional water table had a uniform gradient of one foot per thousand $(0.001 \mathrm{ft} / \mathrm{ft})$, and the head in the 2000 foot radius reservoir (source) was twenty-five (25) feet above the ambient water table at its center. The reservoir is assumed to supply a continuous source of water at the specified head. 


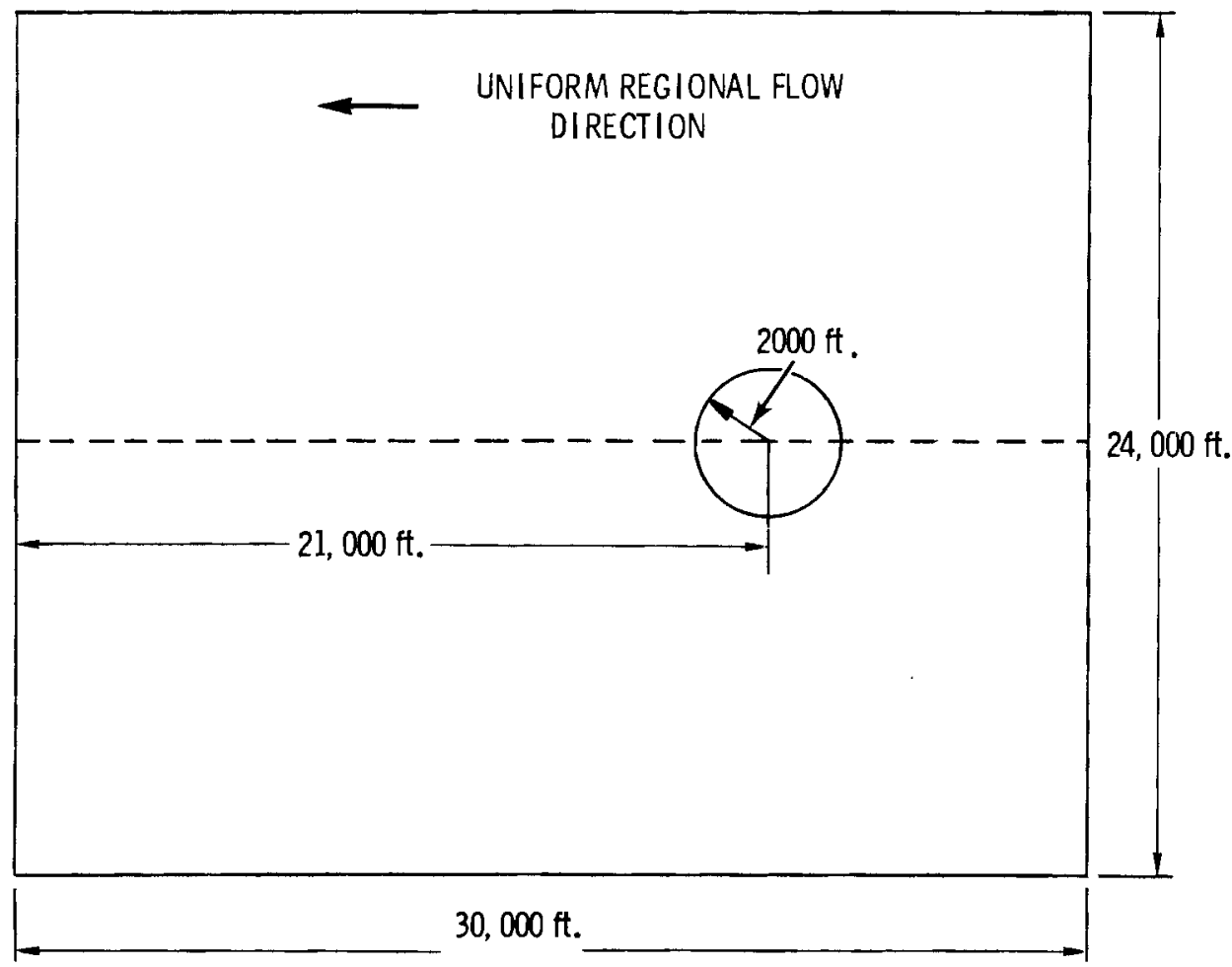

FIGURE 4.7. Depiction of the Regional Flow Problem Domain

A three-dimensional display of the steady-state analytical (PATHS) solution over the complete region for the single aquifer system is shown in Figure 4.8. Because of the limited size of the test case region, the driving head in the reservoir affects the flow pattern and head values along the boundaries. Therefore, all three external boundaries were considered as held potential boundaries in the finite element solution. The symmetry boundary condition on the fourth boundary allows the numerical simulation to select head values which best approximate a no flux situation.

A variety of mesh discretization patterns were used to simulate this two-dimensional domain. The coarsest mesh is shown in Figure 4.9(a). It employed a set of square $(6000 \mathrm{ft})$ elements surrounding a single square subregion radially discretized to depict the circular source as a half of a hexagon. Another of the discretizations [Figure 4.9(b)] employed roughly twice as many square element $(3000 \mathrm{ft})$ and most importantly radial increments designed to provide greater resolution near the reservoir. Note that the 


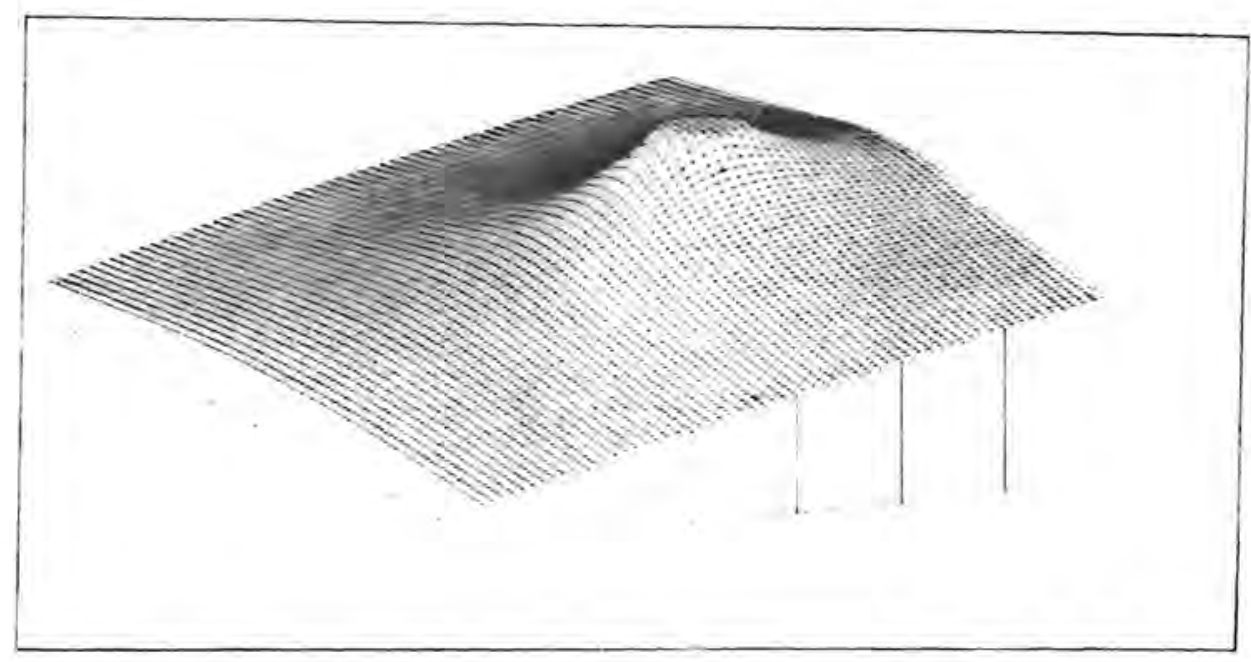

FIGURE 4.8. Three-Dimensional Representation of the PATHS Steady-State Analytical Solution

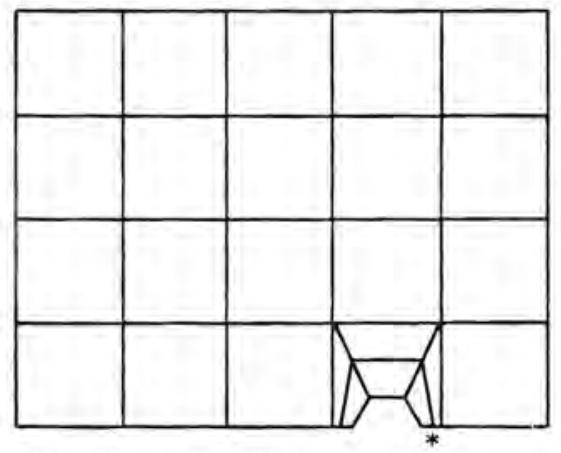

"MAXIMUM DIFFERENCE $=0.025$

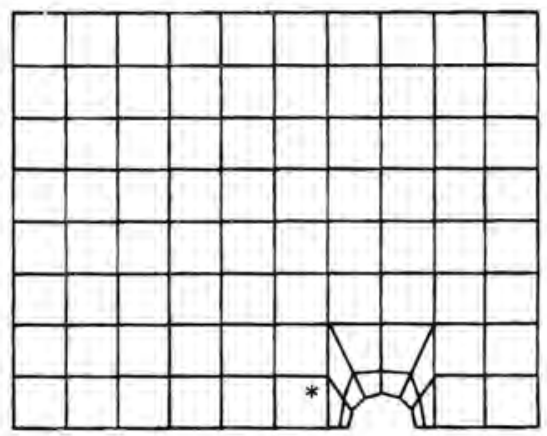

${ }^{*}$ MAXIMUM DIFFERENCE $=0.019$

FIGURE 4.9. Combined Square Mesh Discretization for the Regional Flow Analysis (a) Equal Increment Pattern and (b) Variable Radial Pattern

geometry of the source is much improved in the second discretization due to the smaller elements. Both of the mesh designs cited above were run for square discretizations of 6000,3000 , and $1500 \mathrm{ft}$. The third mesh pattern employed is shown in Figure 4.10 to use a much expanded radial element pattern.

The CFEST results for all mesh designs compared closely with the analytical solution provided by PATHS (Figure 4.11). For all test cases, progressive spacing of radial nodes near the cavern performed better than the equidistant 


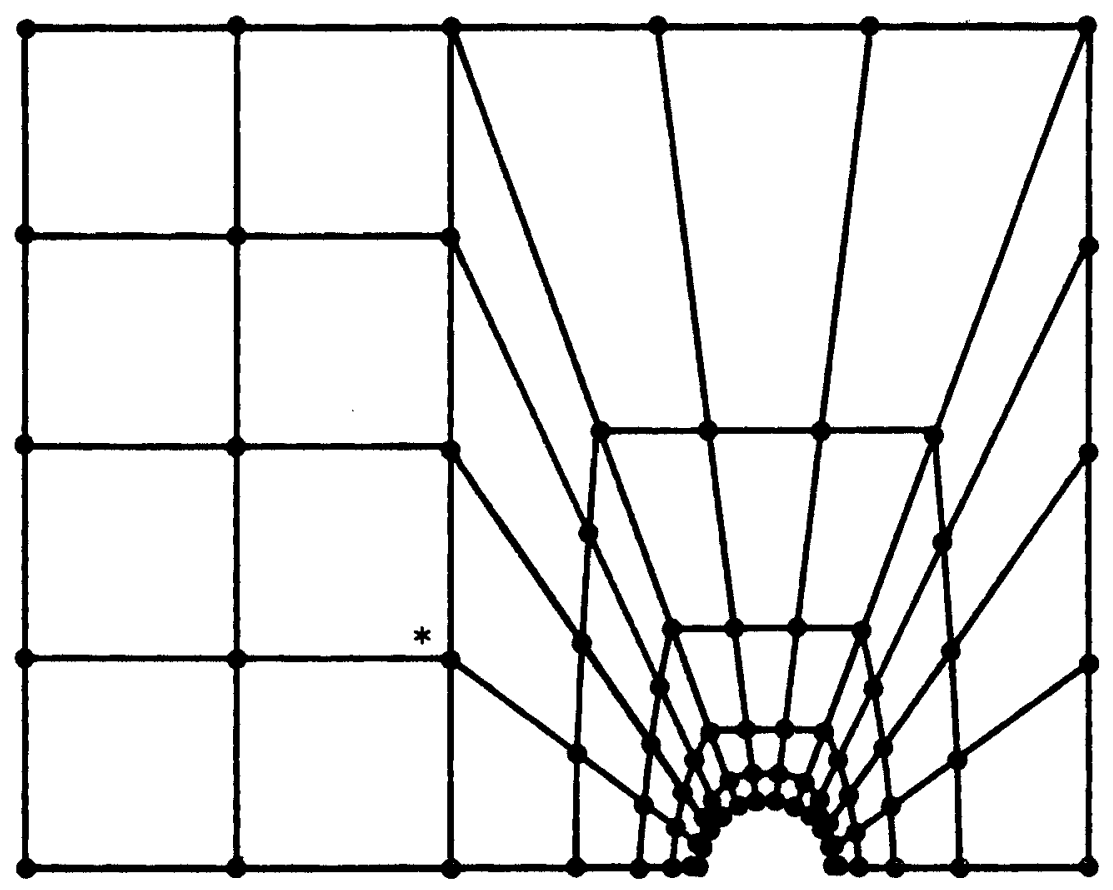

*MAXIMUM DIFFERENCE $=0.013$

FIGURE 4.10. Radial Element Pattern with Variable Node Spacing

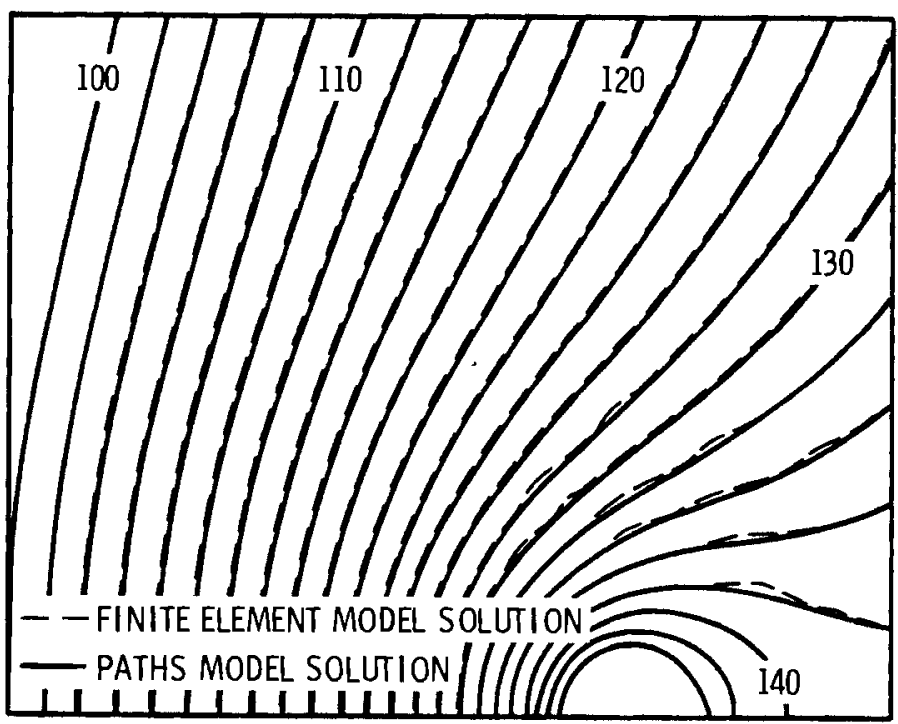

FIGURE 4.11. Comparison of Analytical Solution (PATHS) and CFEST Solution for Grid Pattern Shown in

Figure $4.9 a$ 
spacing. For an equal number of nodes, the radial pattern (Figure 4.10) had a lower maximum difference than either of the combined square and radial grid patterns. The location and magnitude of maximum differences between analytical and finite element solutions are indicated on the figures of the test cases.

\subsection{ENERGY AND SOLUTE MASS TRANSPORT VERIFICATIONS}

Both of the energy and solute mass conservation equations that are modeled by CFEST $\mathrm{c}$ an be classed as a single convection-dispersion equation. Several of the analytical solutions which are available for verification can be couched in terms of either energy or solute mass. Thus, the given solutions can be used to verify both formulations. These analytical solutions are available for linear one-dimensional and radial axisymmetric boundary value problems which neglect the caprock and bedrock interactions. Being one-dimensional, these problems are distinguished by their upstream and downstream boundary conditions and their constant or variable coefficients. The verification solutions included in this subsection include two discussed by coats and Smith (1964) which explore the virtue of a mixed Dirichlet and Neumann boundary condition as opposed to a strictly Dirichlet boundary condition at the upstream boundary, and one by Hoopes and Harleman (1967) which includes an approximation to radially varying velocity.

\subsubsection{Dirichlet Upstream Boundary Condition, Linear Geometry}

The classical transient convection-dispersion problem with a Dirichlet (held) upstream boundary condition is expressed by the following governing equation, initial and boundary conditions on a one-dimensional domain.

$$
\begin{aligned}
& \text { PDE: } C, t+u_{x} c, x=\left(D_{x} C,,_{x}\right),{ }_{x} \\
& \text { IC: } C(x, 0)=0 ; 0<x<1 \\
& B C: C(0, t)=C_{0} ; t>0 \\
& C(, t)=0 ; t \geq 0
\end{aligned}
$$


where $u_{x}$ is a constant, positive value velocity, $D_{x}$ is the diffusion/dispersion coefficient, and $C_{0}$ is a suddenly applied and uniformly maintained solute concentration source at the upstream boundary. The solution for this boundary value problem is given by Coats and Smith (1964) as,

$$
\frac{c(x, t)}{C_{0}}=\frac{1}{2} \quad \operatorname{erfc} \frac{x-u_{x} t}{2 \overline{D_{x} t}}+\exp \frac{x u_{x}}{D_{x}} \operatorname{erfc} \frac{x+u_{x} t}{2 \overline{D_{x} t}}
$$

The solute concentration predicted by CFEST for the parameters given in Table 4.3 is compared to the analytical solution in Figure 4.12 . The results are in good agreement throughout the simulation period. The one thousand day profile corresponds to a nondimensional pore volume $\left(u_{x} t / \theta L\right)$ of 0.25 , well away from the downstream boundary.

TABLE 4.3. Parameters for the Linear Convection-Dispersion Model with a Dirichlet Upstream Boundary Condition

$$
\begin{array}{ll}
u_{x}=\text { Darcian velocity } & 0.01 \mathrm{~m}^{3} / \mathrm{m}^{2} / \text { day } \\
\varepsilon=\text { longitudinal dispersivity factor } & 16 \mathrm{~m} \\
D_{x}=\varepsilon u_{x} & 0.16 \mathrm{~m}^{2} / \text { day } \\
\theta=\text { porosity } & 0.1 \text { (fraction) } \\
L=\text { finite length of CFEST domain } & 400 \mathrm{~m}
\end{array}
$$

\subsubsection{Mixed Upstream Boundary Condition, Linear Geometry}

In the previous solution the solute concentration, or analogously the temperature, was held at the upstream or influent boundary. This is done to placate our knowledge that the soil interfacing with the source is at the source concentration. However, in doing so one ignores the fact that the continuum is discretized by whatever numerical technique employed, and one also ignores the role of that diffusion/dispersion plays in the introduction of solute to the column. If we chose to examine another influent plane some small distance removed from the point of contact of soil and source, then one can balance the solute concentration (or temperature) with its gradient and achieve a far more conservative (i.e., mass or energy) solution. 


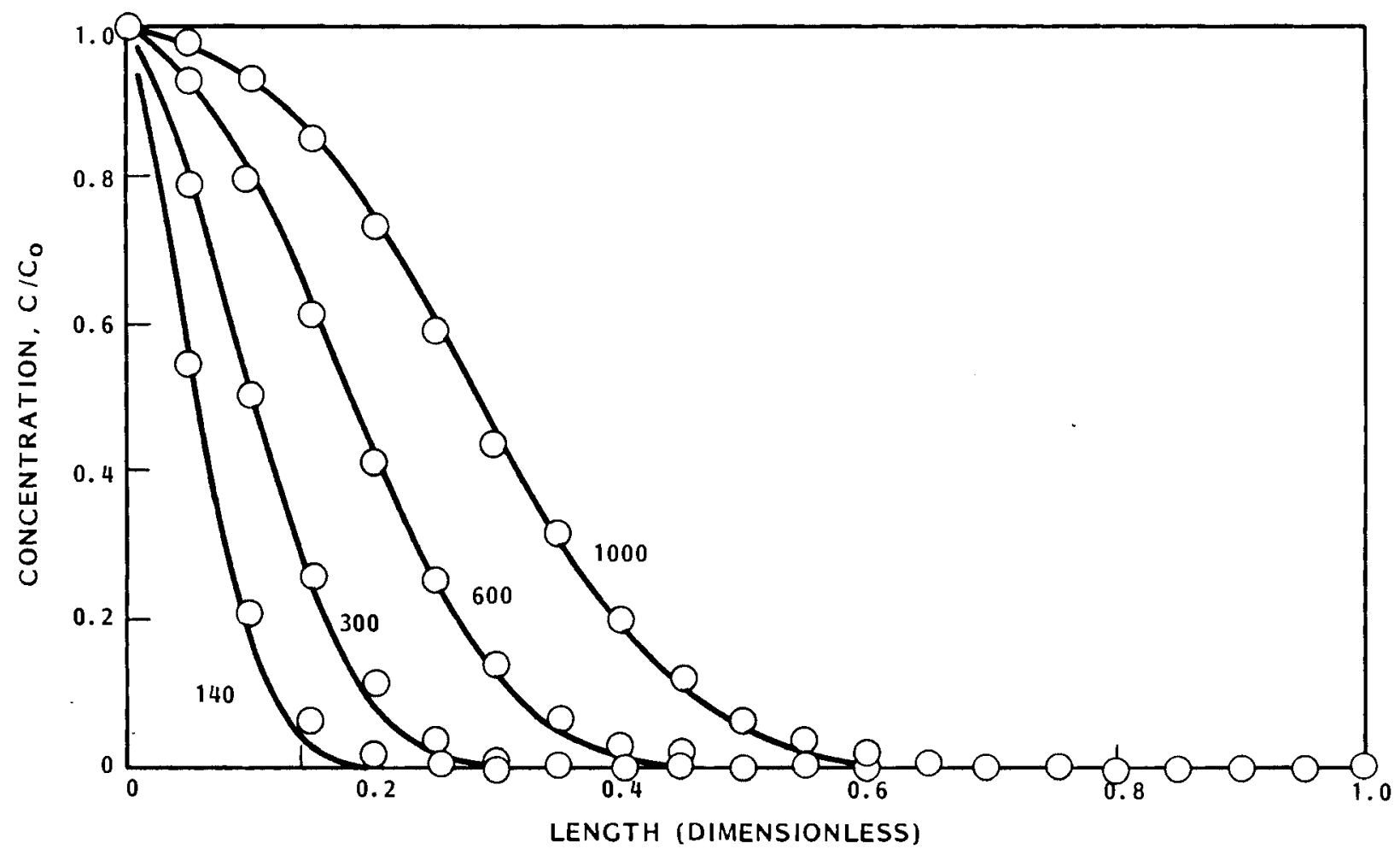

FIGURE 4.12. Comparison of Analytical and CFEST Solute Transport Solution with Dirichlet Boundary Conditions

The boundary value problem which imposes a mixed Dirichlet and Neumann boundary condition at its upstream boundary is expressed as:

$$
\begin{aligned}
& \text { PDE: } C,_{t}+u_{x} C,_{x}=\left(D_{x} C,,_{x}\right),_{x} \\
& \text { IC: } C(x, 0)=0 ; 0<x<1 \\
& \text { BC: } u_{x} C_{0}=u_{x} C(0, t)-D_{x} C(0, t),_{x} ; t>0 \\
& C(\infty, t)=0 ; t \geq 0
\end{aligned}
$$

The essential concept expressed by the mixed boundary condition is that one knows neither the concentration value nor its gradient a priori. However, one does know the total convective and dispersive flux contributions must equal the convective mass (or energy) flux across the source interface. 
The solution to this boundary value problem is reported by coats and Smith (1964) as:

$$
\begin{aligned}
\frac{c}{C_{0}}= & \frac{1}{2}\left[\operatorname{erfc}\left(\frac{x-u_{x} t}{2 \sqrt{D_{x} t}}\right)-\exp \left(\frac{x u_{x}}{D_{x}}\right) \operatorname{erfc}\left(\frac{x+u_{x} t}{2 \sqrt{D_{x} t}}\right)\right] \\
& -\frac{u_{x}}{2 D_{x}}\left(x+u_{x} t\right) \exp \left(\frac{x u_{x}}{D_{x}}\right) \operatorname{erfc}\left(\frac{x+u_{x} t}{2 \sqrt{t D_{x}}}\right) \\
& +u_{x} \sqrt{\frac{t}{D_{x}}} \exp \left(\frac{\left(x-u_{x} t\right)^{2}}{4 t D_{x}}\right)
\end{aligned}
$$

This boundary value problem was simulated by CFEST using the parameters given in Table 4.4. Note that porosity must be reported since the solute mass is carried by the fluid and is transported only within the pore space volume. A Dirichlet boundary condition was employed at the downstream or exit boundary. The results presented consider maximum pore volume displacements of 0.4 and therefore the exit boundary is not expected to affect the simulations. Of the two simulations displayed, the first, Figure 4.13, employed a five day time step and showed a sharper front than the analytical solution. In the second case, Figure 4.14, a twenty-five day time step yields a more dispersed front than the analytical solution.

TABLE 4.4. Parameters for the Mixed (Concentration) Boundary Condition, Linear Geometry Verification Test

$$
\begin{aligned}
u_{x} & =\text { Darcian velocity } & & 0.1 \mathrm{~m}^{3} / \mathrm{m}^{2} / \text { day } \\
\varepsilon & =\text { longitudinal dispersivity factor } & & 52 \mathrm{~m} \\
D_{x} & =\varepsilon u_{x} & & 5.2 \mathrm{~m}^{2} / \text { day } \\
\theta & =\text { porosity } & & 0.1 \text { (fraction) } \\
L & =\text { Finite length of CFEST domain } & & 2000 \mathrm{~m} \\
\Delta x & =\text { grid spacing } & & 100 \mathrm{~m}
\end{aligned}
$$




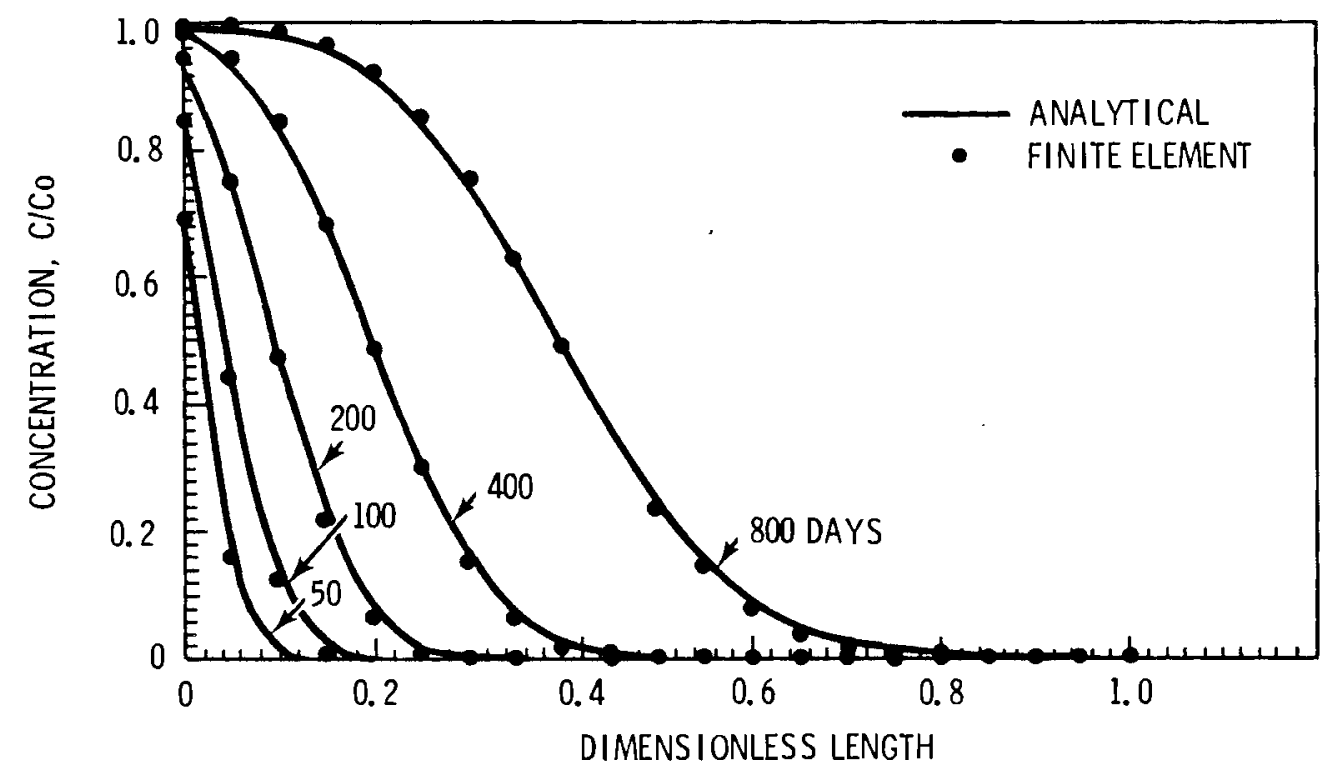

FIGURE 4.13. Comparison of Analytical and CFEST Solute Transport Solution with Flux Boundary Condition at Influence and a Five Day Time Step

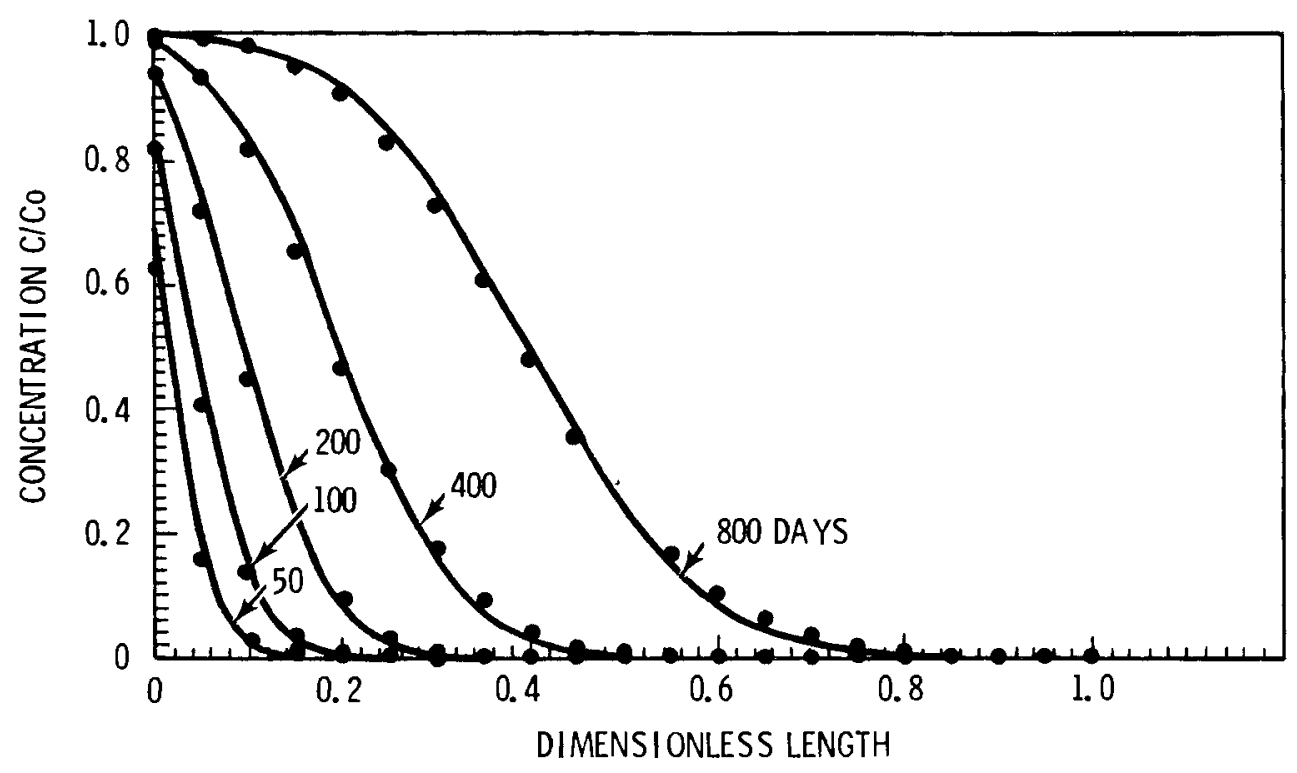

FIGURE 4.14. Comparison of Analytical and CFEST Solute Transport Solution with Flux Boundary Condition at Influence and a Twenty-Five Day Time Step 
The same mixed boundary condition solution that has been reported for solute mass transport can be used to verify the energy conservation formulation. Writing the convection-dispersion equation for energy (as opposed to solute mass) one finds that the leading coefficients have been altered. The boundary value problem is stated as follows:

$$
\begin{aligned}
& \text { PDE: } \quad\left(\rho_{p}\right)_{a} T,_{t}+u_{x} \rho_{w} C_{p w} T,_{x}=\left(E_{x} T,_{z}\right),_{z} \\
& \text { IC: } T(x, 0)=0 ; 0 \leq x \leq 1 \\
& B C: \quad u_{x} \rho_{w} C_{p w} T_{0}=u_{x} \rho_{w} C_{p w} T(0, t)-E_{x} T(0, t),{ }_{x} ; t>0 \\
& T(\infty, t)=0 ; \quad t \geq 0
\end{aligned}
$$

where

$$
\left(\rho C_{p}\right)_{a}=\theta \rho_{w} C_{p w}+(1-\theta)\left(\rho C_{p}\right)_{r}
$$

The solution, which is identical to Equation (4.11), is best written in terms of the following nondimensional parameters.

$$
\begin{aligned}
& \gamma=\text { dimensionless diffusivity, } \frac{u_{x} L}{E_{x} /\left(\rho C_{p}\right)_{w}} \\
& y=\text { dimensionless distance, } x / L \\
& I=\text { injected column length, } \frac{u_{x}\left(\rho C_{p}\right)_{w} t}{\left(\rho C_{p}\right)_{a} L}
\end{aligned}
$$

The nondimensionalized solution is given as (Coats and Smith 1964),

$$
\begin{aligned}
\frac{T_{0}}{T_{0}}= & \frac{1}{2}\left[\operatorname{erfc}\left(\frac{\sqrt{\gamma}}{2} \frac{y-I}{\sqrt{I}}\right)-e^{\gamma y} \operatorname{erfc}\left(\frac{\sqrt{\gamma}}{2} \frac{y+I}{\sqrt{I}}\right)\{1+\gamma(y+I)\}\right] \\
& +\frac{\overline{\gamma I}}{\pi} \exp \left\{-\frac{\gamma}{4 I}(y-I)^{2}\right\}
\end{aligned}
$$


The aquifer and fluid properties used for this test are summarized in Table 4.5. Figure 4.15 illustrates the comparison of analytical and CFEST results. The grid used was $50 \mathrm{ft}$ and the time step was 100 days. The results shown employed an extreme boundary far beyond the zone of influence. Thus, temperatures along the outflow periphery do not affect the solution. To test the option for outflow boundary conditions, the linear problem was simulated with a $250 \mathrm{ft}$ region. Thus the system was truncated at the end of the fifth element. The temperature at the outflow boundary was free to assume a value consistent with the natural boundary condition and the mesh discretization employed. Results of the CFEST analysis are shown in Figure 4.16 to compare favorably with the analytical solution. One must be cognizant of the implicit dependence of this result upon the mesh.

TABLE 4.5. Parameters for the Mixed (Temperature) Boundary Condition, Linear Geometry Verification Test

$\begin{array}{ll}\text { Fluid density, } \rho_{w} & 62.4 \mathrm{lb} / \mathrm{ft}^{3} \\ \text { Porosity, } \theta & 0.1 \mathrm{fraction} \\ \text { Longitudinal dispersivity factor, } \alpha & 52 \mathrm{ft} \\ \text { Fluid heat capacity, } C_{p w} & 1 \mathrm{Btu} /\left(1 \mathrm{~b}{ }^{\circ} \mathrm{F}\right) \\ \text { Volumetric rock heat capacity }\left({ }^{\circ} \mathrm{C}_{\mathrm{p}}\right)_{\mathrm{r}} & 30 \mathrm{Btu} /\left(\mathrm{ft}^{3}{ }^{\circ} \mathrm{F}\right) \\ \text { Thermal heat conductivity of medium } & 30 \mathrm{Btu} /\left(\mathrm{ft}-\text { day- }{ }^{\circ} \mathrm{F}\right) \\ \quad \text { and fluid, } E_{m} & 0.1 \mathrm{ft} / \mathrm{day} \\ \text { Constant flow (Darcian) velocity, } u_{x} & 100 \mathrm{ft} \\ \text { Grid Spacing, } \Delta x & \end{array}$

\subsubsection{Approximate Analytical Solution to an Axisymmetric Analysis Including Radially Varying Velocity}

A single well represents a point source in a horizontal plane and a vertical line source in an axisymmetric analysis. As a result, the flow velocity leaving the well varies with radial distance from the well. Dispersion is commonly modeled as a function of velocity. In all of the previous verification analyses the velocity and dispersion have been constant due to the use of the Cartesian coordinate system and a lateral line source. Hoopes and Harleman (1967) published an approximate solution for the case of a radially varying 


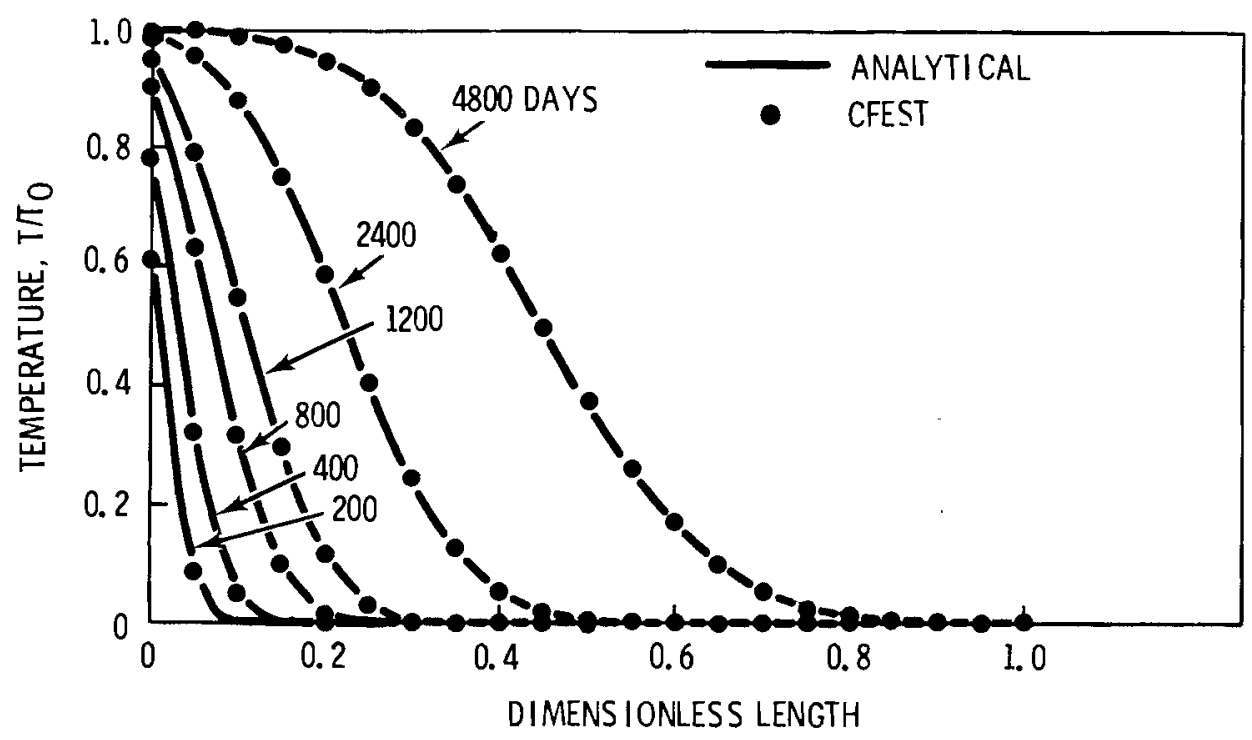

FIGURE 4.15. Comparison of Analytical and CFEST Heat Transport Solution with an Upstream Flux Boundary Condition ( Time Step $=100$ Days)

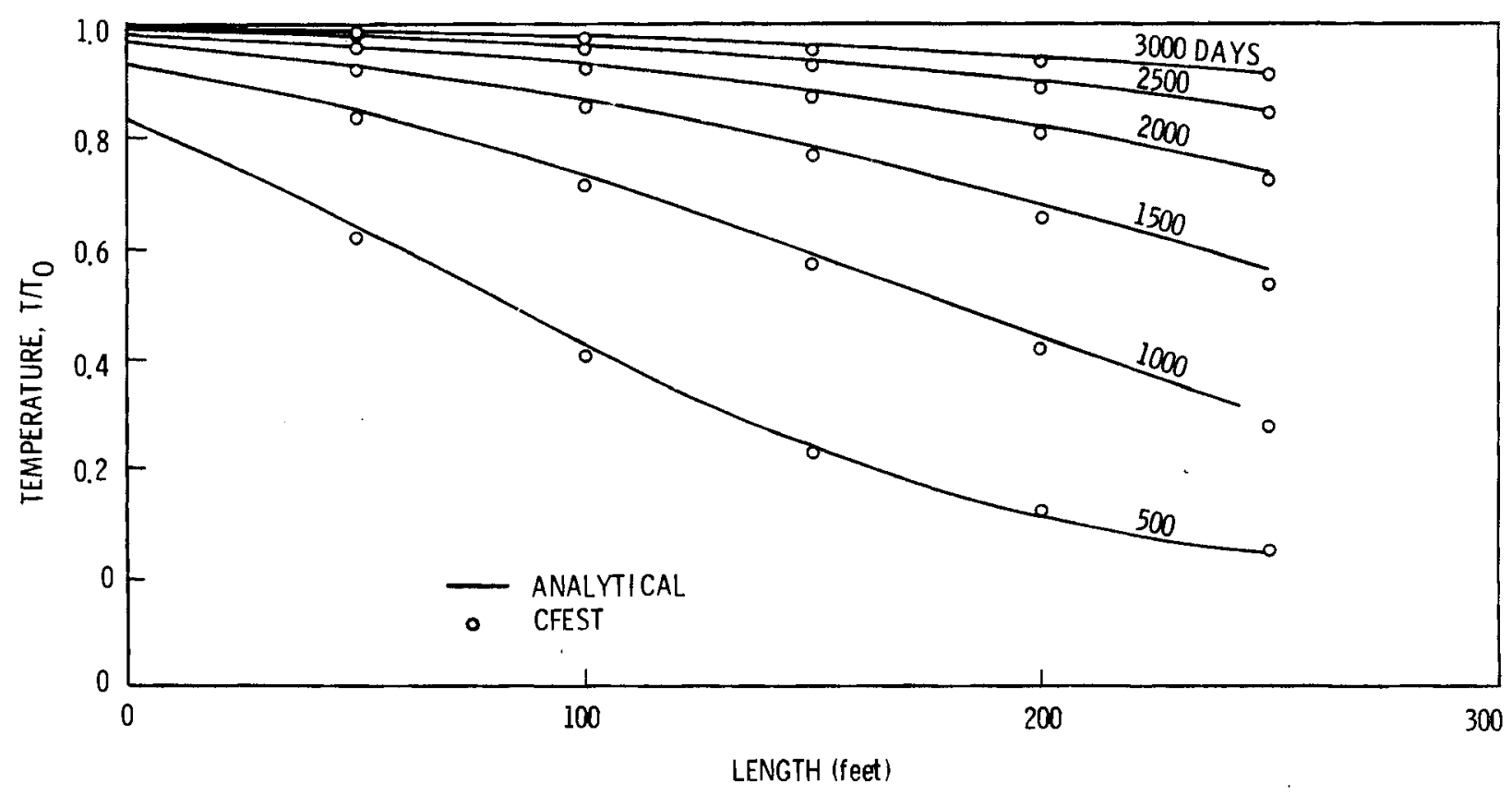

FIGURE 4.16. Comparison of Analytical and CFEST Heat Transport with an Upstream Flux Boundary Condition and a Truncated Domain (Time Step - 10 days) 
velocity and dispersion. Essential elements of the boundary value problem are as follows. A solution is sought to the following partial differential equation,

$$
C,_{t}+\frac{A}{r} C_{,_{r}}=\alpha^{\prime} \frac{A}{r}\left(C,,_{r}\right),_{r}+\frac{D_{m}}{r}\left(r C,_{r}\right),_{r}
$$

where

$$
\begin{aligned}
A & =Q / 2 \pi \mathrm{b} \theta \\
\alpha^{\prime} & =\text { longitudinal dispersion } \\
Q & =\text { injection rate } \\
\mathrm{b} & =\text { aquifer thickness } \\
\theta & =\text { porosity }
\end{aligned}
$$

Hoopes and Harleman (1967) assume "that at some distance from the source, the influences of dispersion and diffusion on the concentration distribution, as the substance moves by a point, are small in comparison to the total dispersion and diffusion that has taken place up to that point. Thus..." the PDE given by Equation 4.17 can be posed as the following boundary value problem.

$$
\begin{aligned}
& \text { PDE: } C,_{t}+\frac{A}{r} C,_{r}=\left[\alpha \frac{r}{A}+\right. \\
& \text { IC: } C(r, 0)=0 ; 0<r<\infty \\
& B C: C(0, t)=C_{0} ; \quad t>0 \\
& C(\infty, t)=0 ; \quad t \geq 0
\end{aligned}
$$

The solution to this (approximate) boundary value problem is given as

$$
\frac{C}{C_{0}}=\frac{1}{2} \operatorname{erfc}\left[\left(\frac{r^{2}}{2}-A t\right) /\left(\frac{4}{3} \alpha^{1} r^{3}+\frac{D}{A} r^{4}\right)^{1 / 2}\right]
$$


Hoopes and Harleman (1967) note that the above is an approximate solution to the PDE and its associated initial and boundary conditions because "it does not satisfy the initial condition." As a result, the above solution predicts a finite initial mass within the media.

The analogous energy boundary value problem simply replaces the following parameters with their energy formultion counterpart. The counterparts are,

\begin{tabular}{|c|c|}
\hline Solute Mass & Energy \\
\hline$A$ & $A^{\prime}=A / \Lambda$ \\
\hline$\alpha^{\prime}$ & $\alpha^{\prime \prime}=\alpha^{\prime} / \rho C_{p w}$ \\
\hline $\mathrm{D}_{\mathrm{m}}$ & $D_{m}^{\prime}=D_{m} / \rho \theta C_{p w} \Lambda$ \\
\hline
\end{tabular}

where

$$
\Lambda=\text { dimensionless heat capacity }=1+\frac{(1-\theta)\left(\rho C_{p}\right)_{r}}{\theta_{\rho} C_{p w}}
$$

Substituting these counterparts into Equation (4.21) one finds,

$$
\frac{T}{T_{0}}=\frac{1}{2} \operatorname{erfc}\left[\left(\frac{r^{2}}{2}-A^{\prime} t\right) /\left(\frac{4}{3} \alpha^{\prime \prime} r^{3}+\frac{D_{m}^{\prime}}{A^{\prime}} r^{4}\right) 1 / 2\right]
$$

Both horizontal and axisymetric analysis were performed with the CFEST code for solute mass and energy transport. In all cases the approximate analytical solution predicts a greater level of energy within the aquifer than the CFEST code. This can be attributed to the nonzero initial condition of the analytical solution. Figure 4.17 shows a typical comparison between the analytical and CFEST simulations for a radial analysis of solute mass transport.

Radially varying dispersion analytical solution (Hoopes and Harleman 1967) compared to CFEST solution for a solute transport case. 


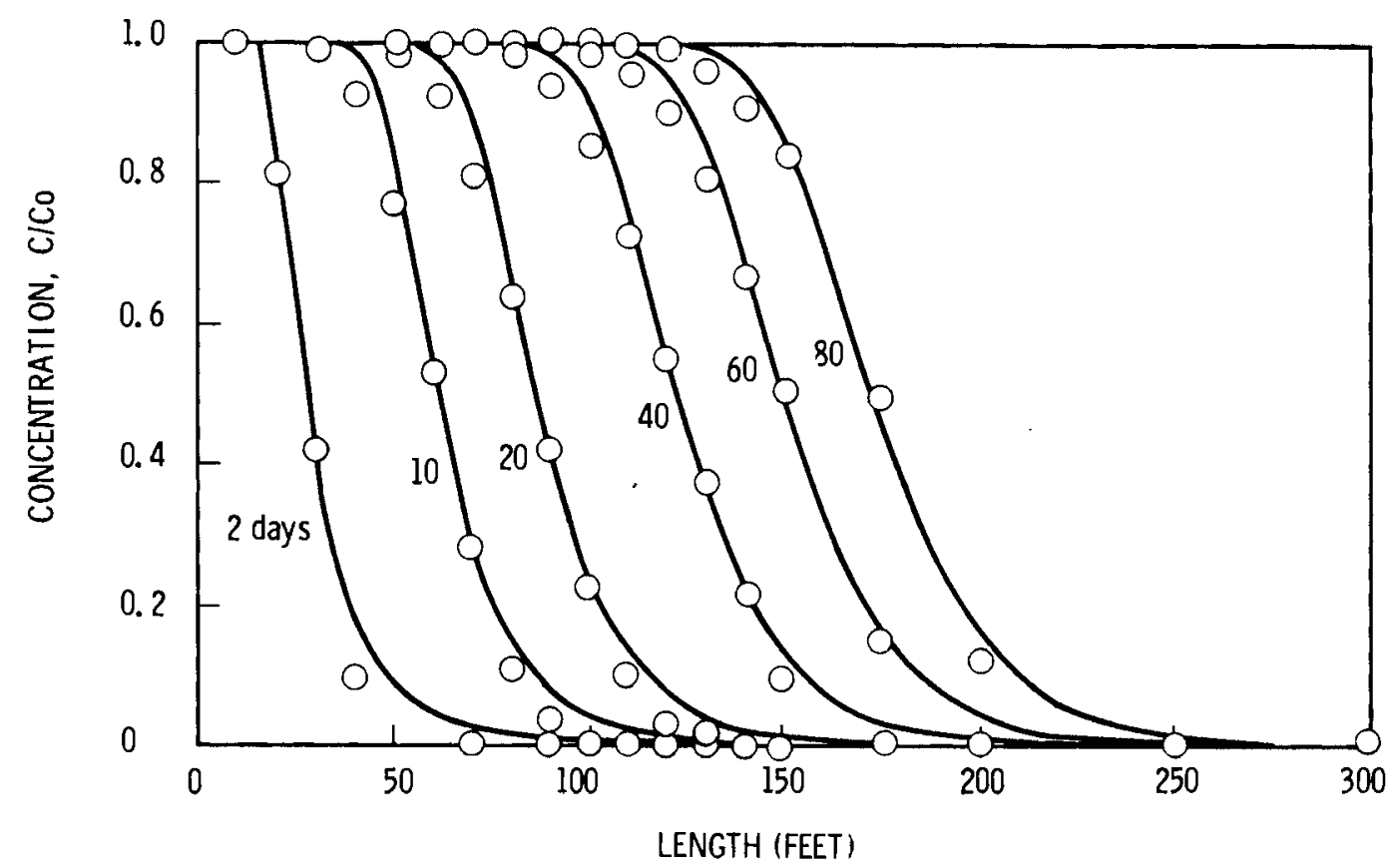

FIGURE 4.17. Radial Analytical Versus CFEST Solution of Solute Transport

\subsection{ENERGY TRANSPORT INCLUDING CAP AND BEDROCK CONDUCTION}

The phenomena of energy losses to the confining media and its influence upon our solution have not been included in the preceding verification analyses. Two solutions have been identified in the literature and will be presented here. In the first, Avdonin (1964) developed solutions to the problem of energy injection to a vertically uniform aquifer with conductive losses to the confining media. Solutions for both the linear $(x, z)$ and radial $(r, z)$ coordinate systems are given in his paper. A later work by Gringarten and Sauty (1975) provides a combined analytical and numerical solution to the problem of the temperature of water recovered from a continuously pumped well of an injection/recovery loop employing a heat pump. Energy losses to the overburden and underburden materials are included in their analysis also. Through comparison of CFEST simulations against these published analyses we will have verified the simulative ability of CFEST's conductive cap rock and bedrock model. 


\subsubsection{Avdonin's Radial Problem}

The temperature field of a formation experiencing a thermal injection is presented. Thermal conductivity of the impermeable overlying and underlying media is included in this analysis. The boundary value problem for the radial case is formulated as follows (Avdonin 1964):

\section{Confining Media}

$$
\begin{aligned}
& \text { PDE: }(u, z), z=\frac{1}{a^{2}} u, t ; z>0, t>0 \\
& \text { IC: } u(z, 0)=0 ; \quad z \geq 0 \\
& \text { BC: } u(0, t)=1 ; \quad t>0, r=0 \\
& \text { limit } u(z, t)=0 ; \quad t \geq 0 \\
& z \rightarrow \infty
\end{aligned}
$$

Confined Formation

$$
\begin{aligned}
& \text { PDE: }(u, r),_{r}+\frac{1-2 v}{r} u,_{r}+\alpha u,_{z}=u,_{t} ; \\
& z=0, r>0, t>0 \\
& \text { IC: } u(r, z, 0)=0 ; \quad r>0, z=0 \\
& \text { BC: } u(0,0, t)=1 ; \quad t>0 \\
& \operatorname{limit} u(r, z, t)=0 \\
& z^{2}+r^{2} \rightarrow \infty
\end{aligned}
$$

where

$$
\begin{aligned}
u & \left.=\left(T-T_{0}\right) / T_{1}-T_{0}\right)=\text { normalized temperature } \\
T_{1} & =\text { injection temperature } \\
a^{2} & =a_{1}^{2} / a_{0}^{2}
\end{aligned}
$$




$$
\begin{aligned}
a_{i}^{2} & =k_{i} / c_{i} p_{i} \\
k_{i} & =\text { thermal conductivity } \\
c_{i} & =\text { heat capacity } \\
\rho_{i} & =\text { density } \\
\nu & =Q c_{2} \rho_{2} / 4 \pi h k_{0}=\text { convective parameter } \\
\alpha & =k_{1} / k_{0} \\
r & =2 r_{p} / h \\
z & =2 z_{p} / h \\
t & =4 a_{0}^{2} t_{p} / h^{2}
\end{aligned}
$$

and scripts

$$
\begin{aligned}
& i=0=\text { formation } \\
& i=1=\text { confining media } \\
& i=2=\text { injected fluid } \\
& p=\text { point of interest in the time and space domain. }
\end{aligned}
$$

A formula for calculating the temperature in the formation $(z=0)$ is given by Avdonin (1964) as,

$u(r, t)=\frac{1}{\Gamma(v)}\left(\frac{r^{2}}{4 t}\right)^{\nu} \int_{0}^{1} \exp \left(\frac{-r^{2}}{4 t x}\right) \operatorname{erfc}\left(\frac{b \sqrt{t} x}{2 \sqrt{1-x}}\right) \frac{d x}{x^{\nu+I}} \cdot$

CFEST simulations of this boundary value problem were completed using parameters defined by Faust and Mercer (1976) and summarized in Table 4.6. Sensitivity analyses were performed by varying both the domain discretization and the time steps employed by CFEST. Three schemes of discretization were tried; they consisted of equal radial increments, equal area or volume elements, and progressively doubling previous radial increments. Time steps for most simulations were held constant. However, for each discretization style, a time step increasing with time $\left(\Delta t_{i}=2 \delta t_{i-1}\right)$ was simulated to determine the impact of this common and cost saving means of simulating long term events. 
TABLE 4.6. Parameters Emp loyed in Avdonin's Problem

$\begin{array}{ll}\text { Injection Rate (radial problem) } & 2.00 \times 10^{4} \mathrm{~cm}^{3} / \mathrm{sec} \\ \text { Darcian velocity (linear problem) } & 1.28 \times 10^{-4} \mathrm{~cm} / \mathrm{sec} \\ \text { Porosity } & 0.20 \\ \text { Reservoir thermal conductivity }\left(\mathrm{E}_{\mathrm{r}+\mathrm{w}}\right) & 3.20 \times 10^{6} \mathrm{ergs} / \mathrm{sec}-\mathrm{cm}{ }^{\circ} \mathrm{C} \\ \text { Confining bed thermal conductivity }\left(\mathrm{K}_{\mathrm{oa}}, \mathrm{K}_{\mathrm{an}}\right) & 3.20 \times 10^{5} \mathrm{ergs} / \mathrm{sec}-\mathrm{cm}{ }^{\circ} \mathrm{C} \\ \text { Rock heat capacity }\left({ }^{\circ} \mathrm{C}_{\mathrm{p}}\right) \mathrm{r} & 2.525 \times 10^{7} \mathrm{ergs} / \mathrm{cm}^{3}{ }^{\circ} \mathrm{C} \\ \text { Initial temperature }\left(\mathrm{T}_{0}\right) & 80.19^{\circ} \mathrm{C} \\ \text { Injection temperature }\left(\mathrm{T}_{\mathrm{i}}\right) & 40.01^{\circ} \mathrm{C} \\ \text { Fluid density } & 0.99 \mathrm{~g} / \mathrm{cm}^{3} \\ \text { Fluid specific heat }\left(\mathrm{C}_{\mathrm{pw}}\right) & 4.18 \times 10^{7} \mathrm{ergs} / \mathrm{g}^{\circ} \mathrm{C} \\ \text { Aquifer thickness }(\mathrm{b}) & 2.00 \times 10^{4} \mathrm{~cm}\end{array}$

\section{Equal Radial Increments}

Figure 4.18 a contrasts the analytical and CFEST results where the spatial grid employed one meter equal radial increments and the time step was a constant of 10 days. As time increases, the simulation converges to the analytical solution. Initially, however, nodes nearer to the well were overestimated and nodes away from the well were underestimated. Doubling the time step while retaining one meter equal radial increments results in a relatively greater initial error (Figure 4.18b). Results obtained using this time step also converge to the analytical solution for all practical purposes. The time step was increased to 100 days (Figure $4.18 \mathrm{c}$ ). No oscillations appeared in the CFEST solution but the results deviated significantly from the analytical solution.

Geometric time increments were used with the one meter radial increment. Each time step was double the previous one. Figure 4.19 illustrates that with each time step increase, the deviations from analytical solution increase.

To study the effects of a coarser grid, simulations were undertaken with radial increment of $10 \mathrm{~m}$ instead of $1 \mathrm{~m}$. Figure 4.20 illustrates some of the results. The predicted results were lower than the analytical solution. With increasing simulation period, the results tend to converge to the analytical solution (Figure 4.20a). For the case of geometrically increasing time steps, 

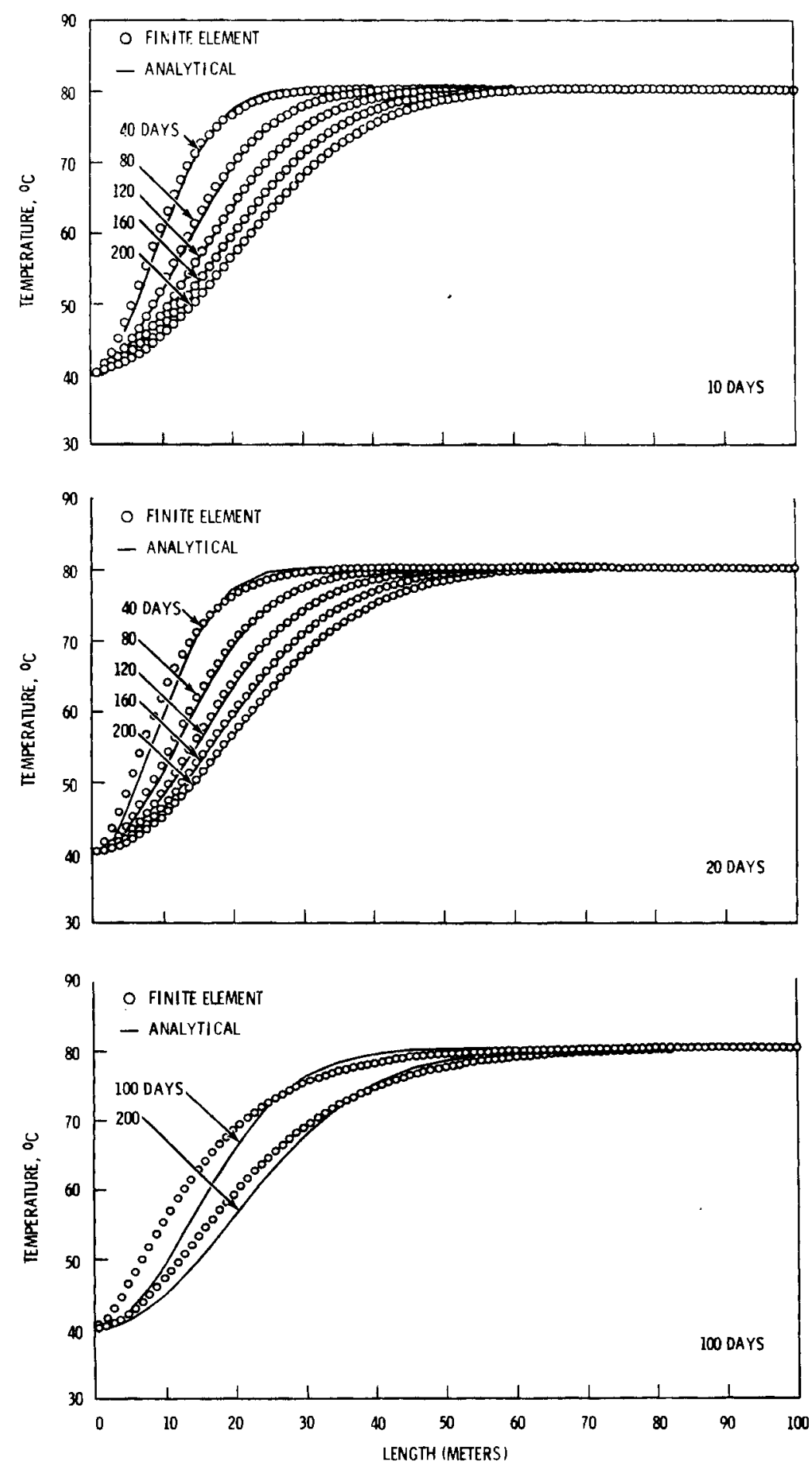

FIGURE 4.18. Comparison of Avdon in Radial and CFEST Results for Equal Radial Discretization of 1 meter and Time Steps of a) 10 days, b) 20 days, and

c) 100 days 


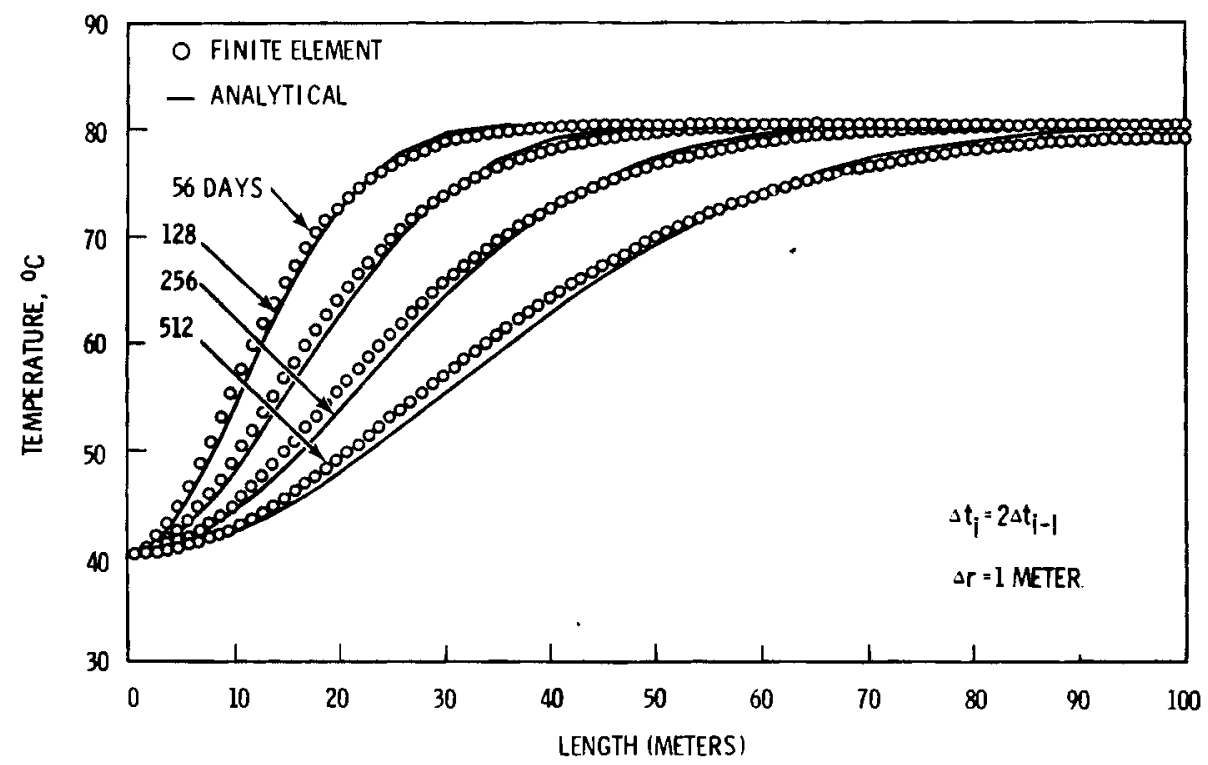

FIGURE 4.19. Comparison of Avdonin Radial and CFEST Simulations with Sequentially Doubled Time Steps ( $i . e ., \Delta t_{j}=$ $\left.2 \Delta t_{j-1}\right)$

the initial results were underestimated throughout. However, at 256 days the numerical simulation oscillates spatially about the analytical solution (Figure $4.20 b$ ).

\section{Equal Area (Volume) Increments}

Radial grid spacing based on equal areas results in a decreasing radial increment with increasing distance from the well. The virtue of such a discretization lies in the observation that an injected plume of water would displace equal volumes during equal time increments. Thus, coupled with equal time increments, the concept of equal area increments is potentially useful discretization method.

The previously defined boundary value problem was simulated with 100 nodes over the 100 meter radial extent of the analysis. The area of the equal increments was 314.12 square meters. Figure 4.21 illustrates the sensitivity of simulation with different time steps. The analytical and CFEST results converge with increasing elapsed time for the 20 and 40 day time steps but not for 


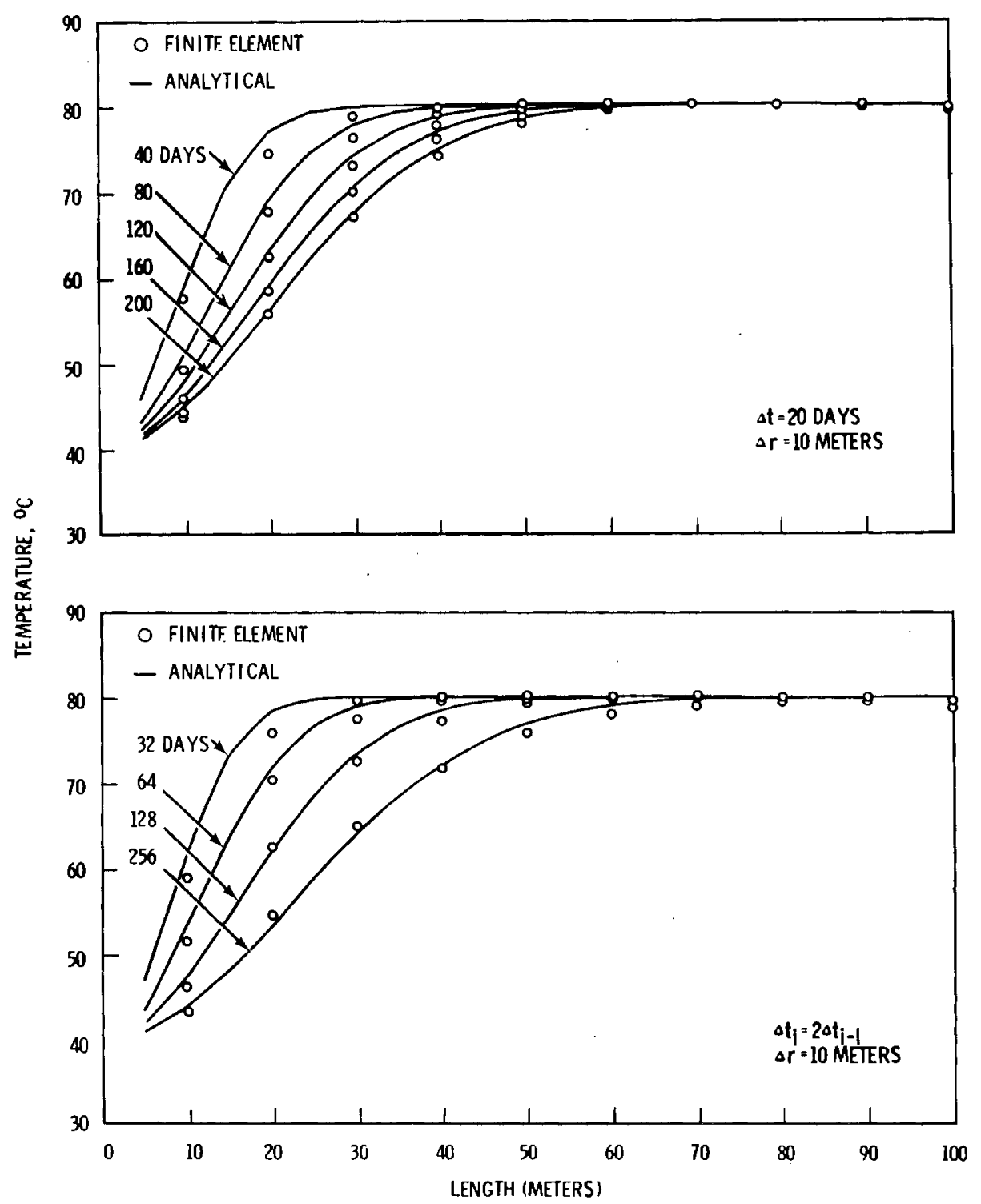

FIGURE 4.20. Comparison of Radial Avdonin and CFEST Results with Equal Grid Spacing of $10 \mathrm{~m}$ and a) 20 Days and b) Geometric Time Steps

the 100 day time step. Initially the CFEST solutions over estimate for the trailing half of the front region and underestimate for the leading half. By increasing the time step from 20 to 40 days, the deviations during the initial time increased. For sequentially doubled time steps the deviation was less than for the 40 day constant time step case. The good agreement of the 20 day 

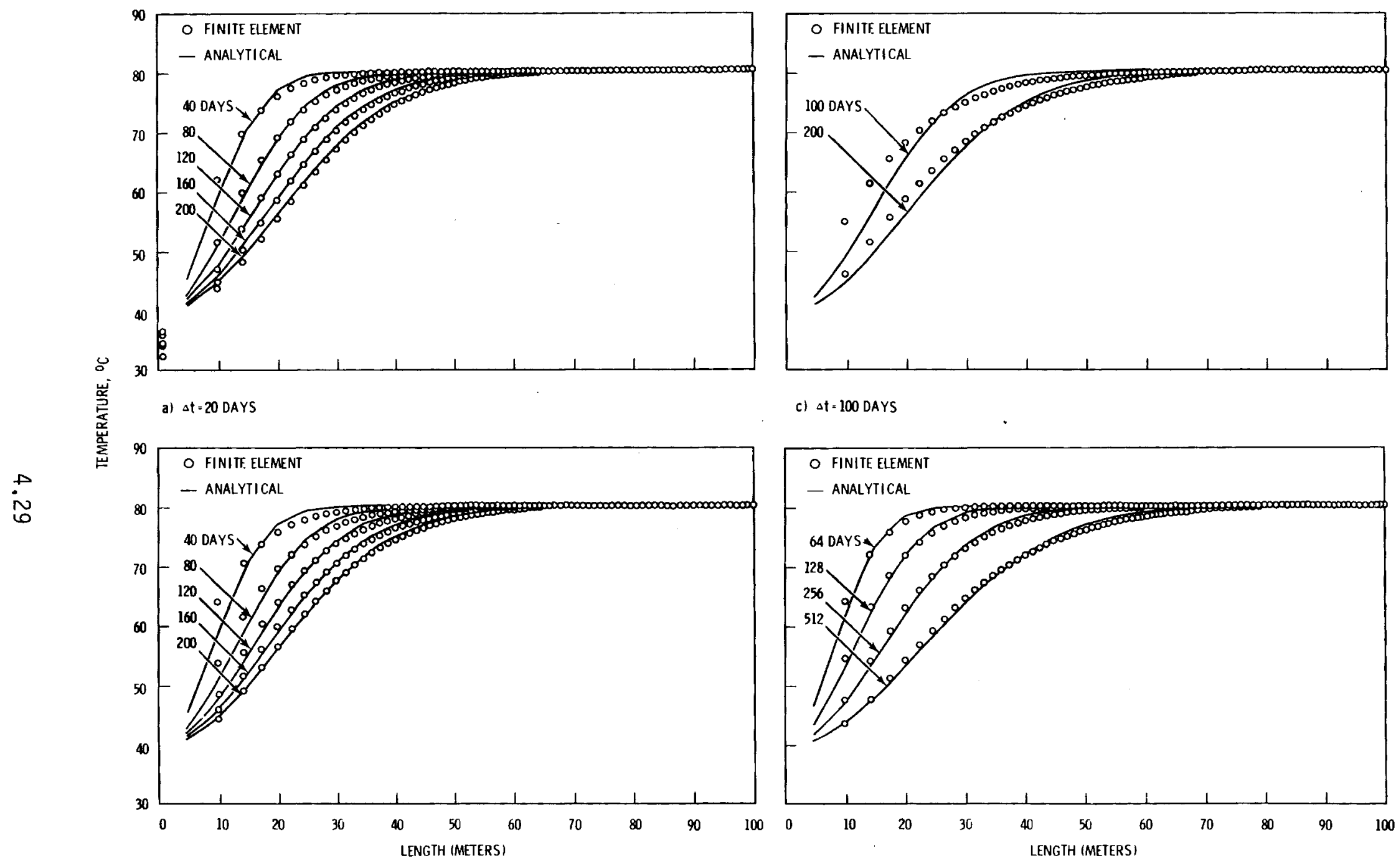

c) $\triangle t=100$ DAYS

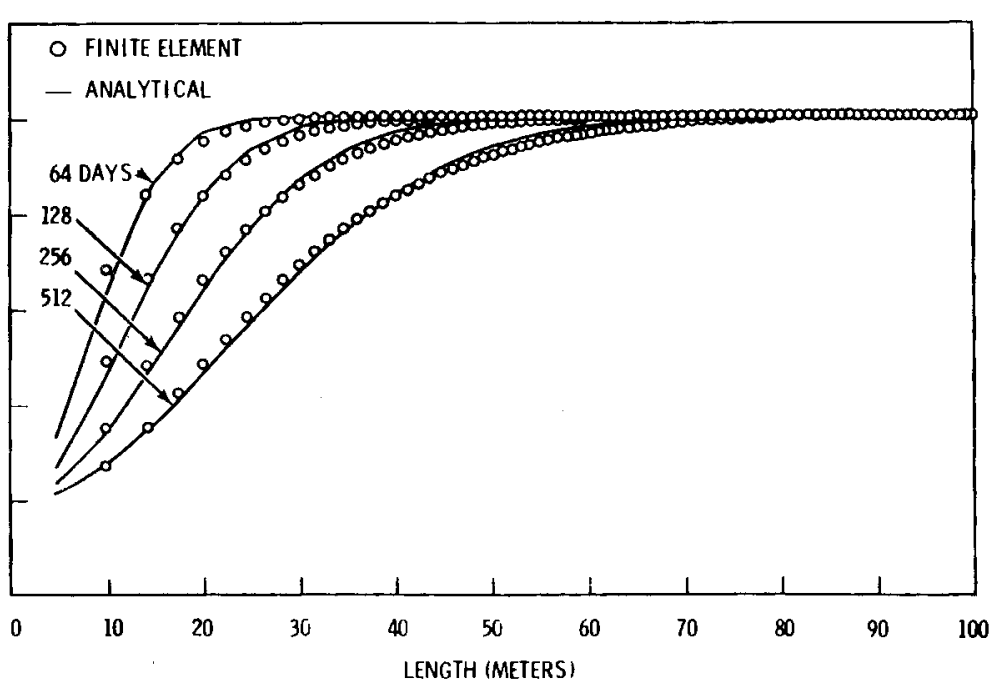

b) $\Delta t=40$ DAYS

d) $s t_{i}=2 \Delta t_{i-1}$

FIGURE 4.21. Comparison of Radial Avdonin and CFEST Results with Equal Areal Spacing of $314.12 \mathrm{~m}^{2}$ and a) 20 Days, b) 40 Days, c) 100 Days and d) Geometric Time Steps 
time step case is not unexpected, since assuming a square front results in a 25 day displacement time for 314.12 square meters.

Figure 4.22 displays the results based on an equal area grid having increments of 3141.2 square meters (i.e., 10 nodes in $100 \mathrm{~m}$ ). For both a 20 day time step and also for geometrically increasing time steps, the coarser grid

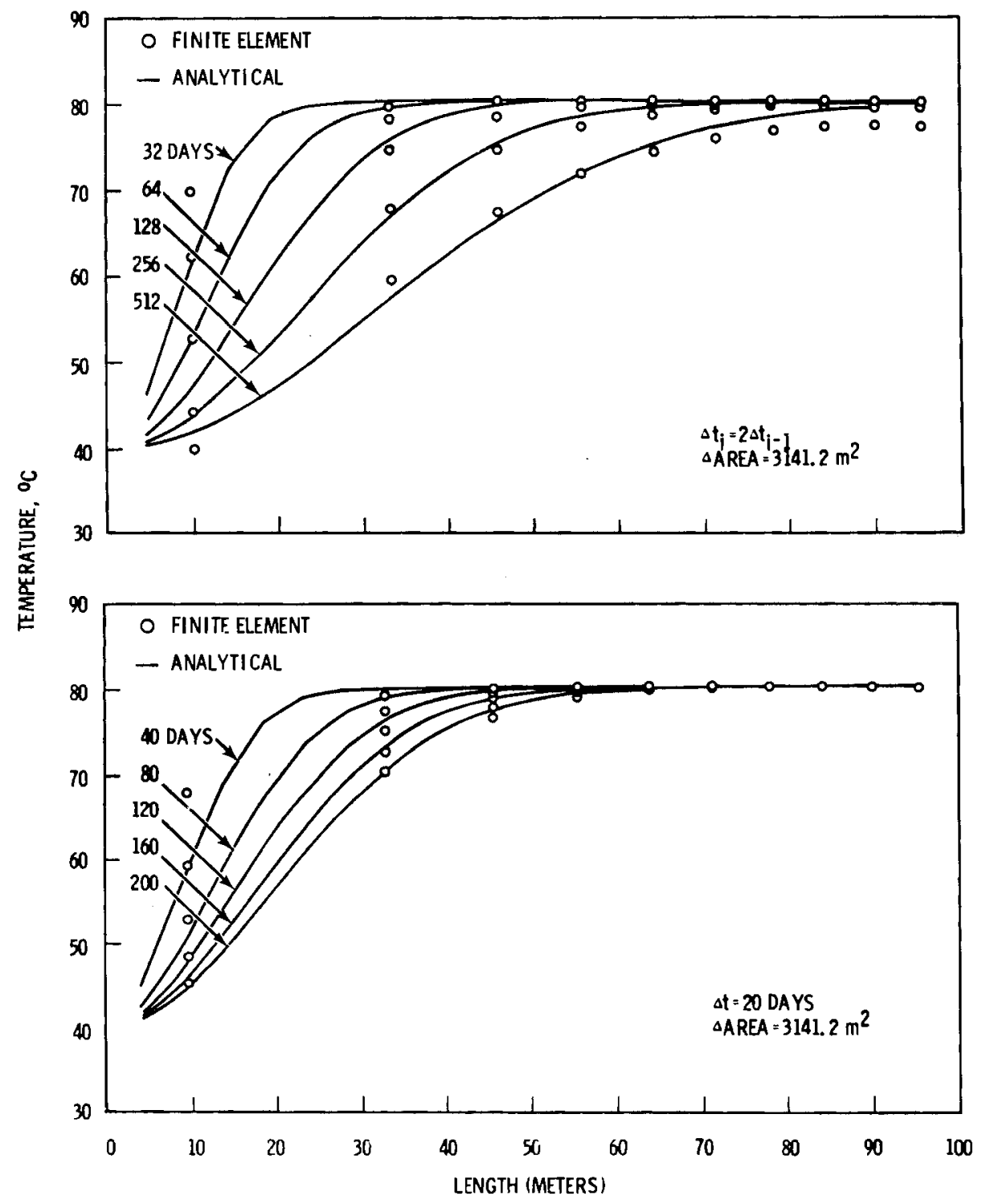

FIGURE 4.22. Comparison of Radial Avdonin and CFEST Results with Equal Areal Increments of 3141.2 Square Meters and a Time Step of 20 day and geometrically increasing time step 
near the well did not have the desired resolution to predict the temperature. After 200 days the differences between analytical and simulated results decreased considerably.

Sequentially Doubled Spatial Increments

In the classical analysis of pressure or water level surrounding a well, the greatest resolution is required nearest the well bore. Hence, analyses commonly employ discretizations which in some way increase the nodal spacing as one moves away from the well. We will examine the results of using such a discretization to model the thermal response of an aquifer. The discretization chosen here sequentially doubles the spatial increments with increasing radial distance. Over the 100 meter radial extent of the domain both 100 and 10 node discretizations have been employed.

Comparison between Avdonin's solution and CFEST simulations are shown in Figure 4.23. As in the previously described results, the smaller constant time step solutions appear to converge to the analytical solution at advanced cumulative time. Increases in time step produce solutions which degenerate in quality. The use of the doubled time increment step procedure provided solutions which exhibited a severe underestimation in the far field for the longterm predictions.

\subsubsection{Avdonin Linear Problem}

The temperature field in a plane-parallel or linear domain is also described by Avdonin (1964). This boundary value problem uses the same confining media model as described in the previous section. The statement of the problem for the linear domain's confined formation is:

$$
\begin{aligned}
& \text { PDE: } \begin{aligned}
\left(u,,_{x}\right),,_{x}-2 \gamma u_{x} & +\alpha u,_{z}=u, t \\
& ; z=0, x>0, t>0
\end{aligned} \\
& \text { IC: } u(x, z, 0)=0 ; z=0, x>0
\end{aligned}
$$




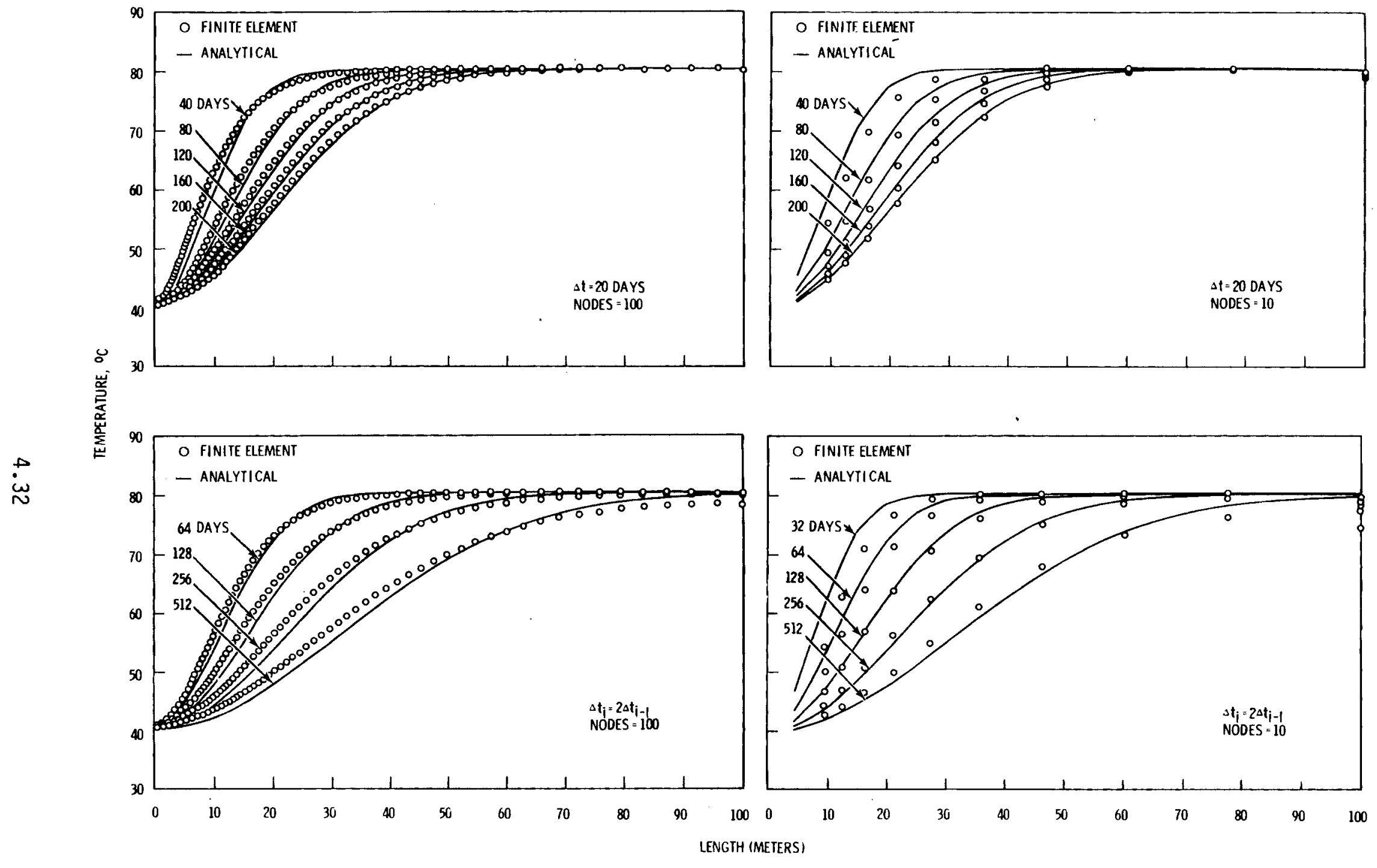

FIGURE 4.23. Comparison of Radial Avdonin and CFEST Results with Sequentially Doubled Grid Spacing and Constant and Geometric Time Steps 


$$
\text { BC: } \begin{aligned}
& u(0,0, t)=1 ; t>0 \\
& \text { limit } u(x, z, t)=0 \\
& z^{2}+x^{2} \rightarrow \infty
\end{aligned}
$$

where $a, a, z, t$ are as defined in Section 4.3 .1 , and

$$
\begin{aligned}
& X=2 x_{p} / h \\
& Y=Q C_{2} \rho_{2} / 4 k_{0} \\
& Q=\text { flow rate per meter of injection path. }
\end{aligned}
$$

Temperature in the formation is defined by:

$$
u(x, t)=\frac{x}{\sqrt{\pi t}} \int_{0}^{1} \exp \left\{-\left(\gamma s \sqrt{t}-\frac{x}{2 s \sqrt{t}}\right)^{2}\right\} \operatorname{erfc}\left(\frac{b \sqrt{t}}{2} \frac{s^{2}}{{\sqrt{1-s^{2}}}^{2}}\right) \frac{d s}{s^{2}}
$$

A limited number of simulations were performed for the linear boundary value problem. The parameters employed are identical to those of the radial problem (Table 4.6) with the exception that a velocity of $1.2810^{-4} \mathrm{~cm} / \mathrm{sec}$ replaces the discharge value of $2.010^{4} \mathrm{~cm}^{3} / \mathrm{sec}$. Three cases are shown in Figure 4.24 displaying the deterioration of the CFEST simulation when both the spatial and time discretizations are doubled in successive simulations. It is the experience of the authors that both time step and spatial discretizations should be gradually reduced until the simulation obtained by CFEST (or any other computer based package) is independent of the discretizations chosen.

\subsubsection{Gringarten-Sauty Problem}

Gringarten and Sauty (1975) present a mathematical model and analys is of the unsteady thermal response of a pumped aquifer which is simultaneously being injected with water at a temperature different than that of the native fluid. This problem is of interest since an areal analysis is necessary to simulate both injection and recovery wells. Assumptions central to the published analysis include: 1) an aquifer which is horizontal and of uniform thickness, 2) a fluid flow which is steady and essentially isothermal, (3) within the aquifer and its confining units the horizontal thermal conductivity can be neglected, and (4) confining media and aquifer are at the same temperature at their interface. A schematic diagram of the problem is shown in Figure 4.25 . 

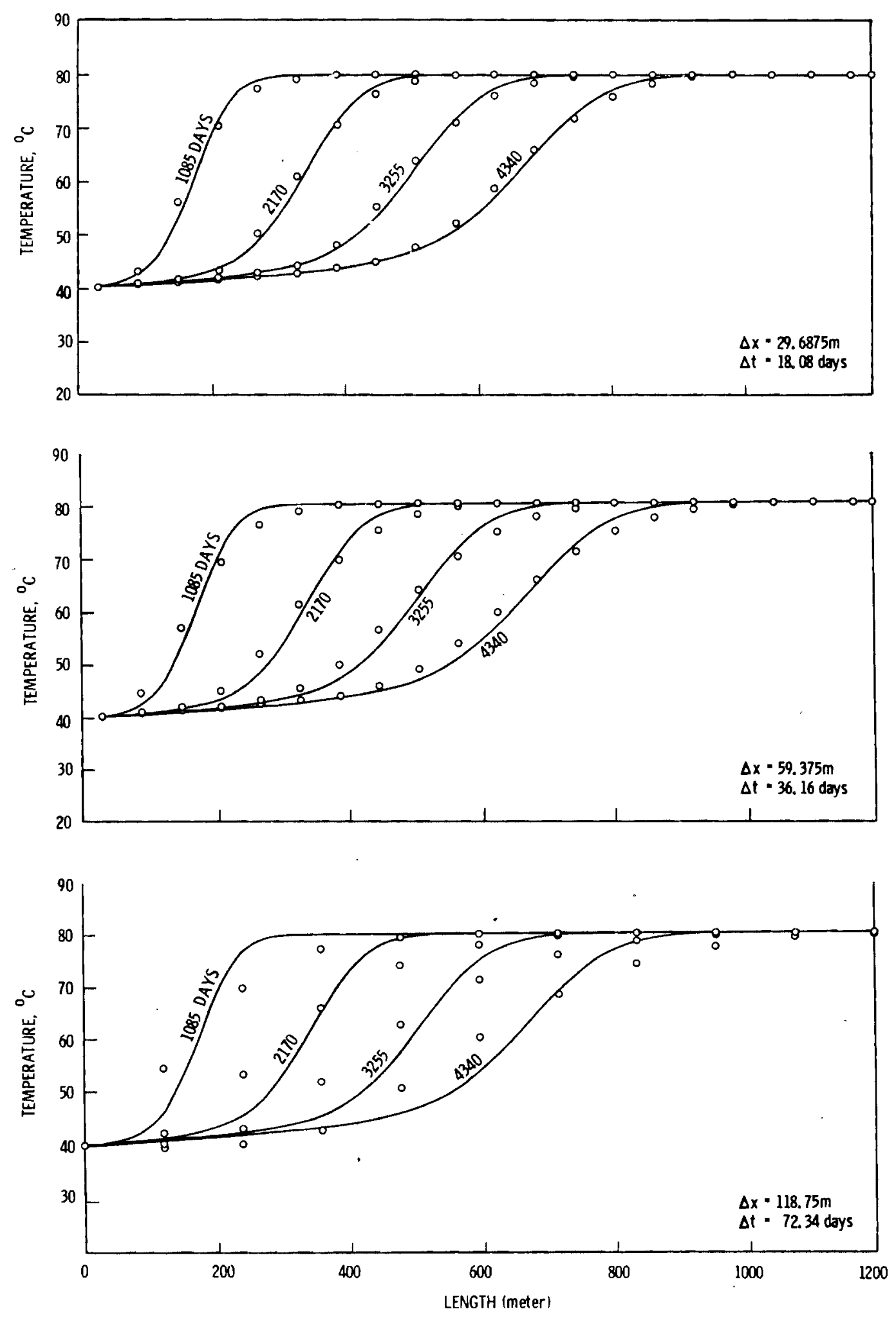

FIGURE 4.24. Comparison of Analytical and CFEST Results for the Linear Avdonin Problem 


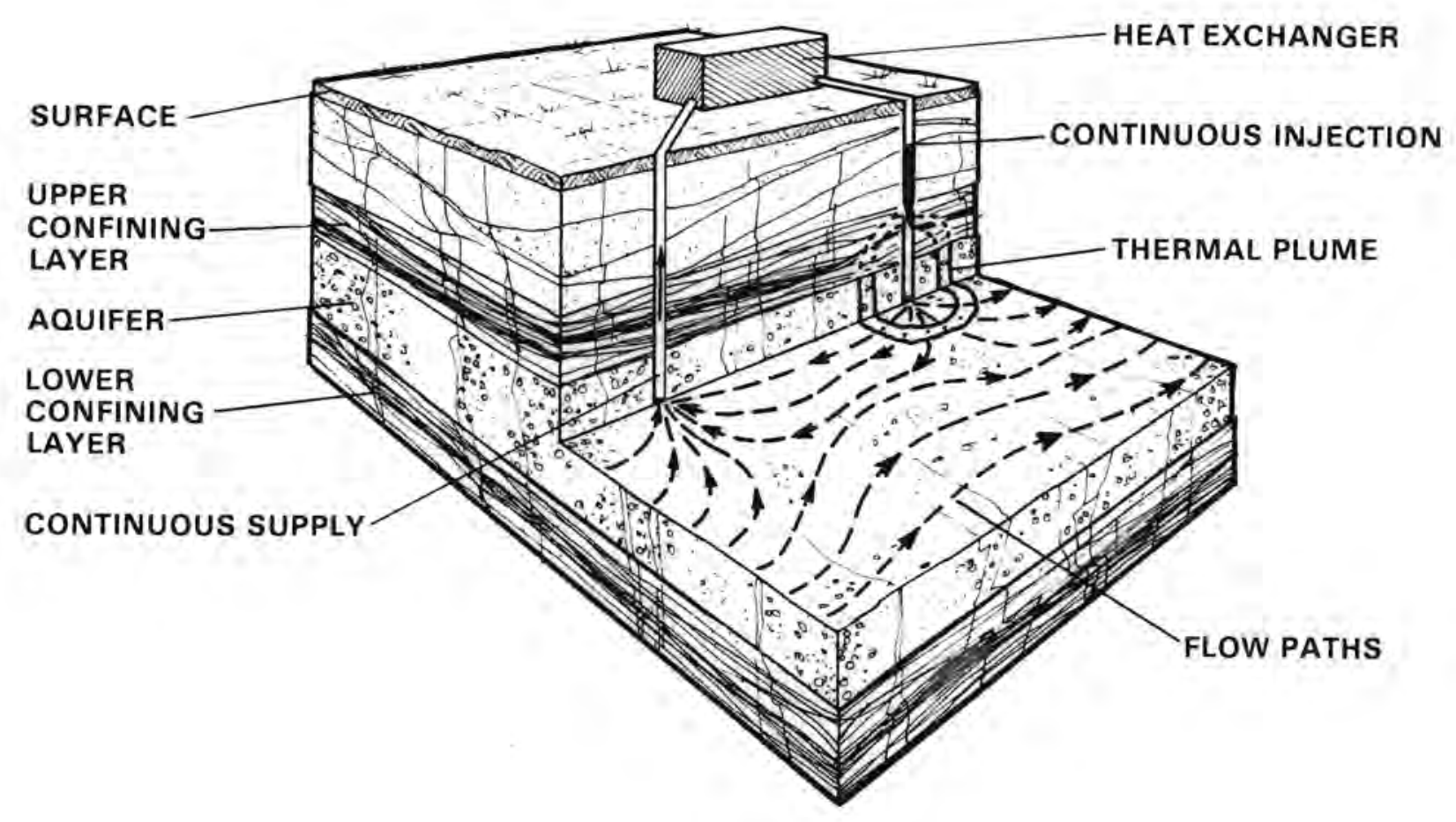

FIGURE 4.25. Schematic Diagram of Doublet Problem Posed by Gringarten and Sauty (1975)

The principle difference between this problem and aquifer thermal energy storage (ATES) is the use of a seasonally reversed system for ATES. This particular problem studies the evolution of a thermal plume for a heat pump application which pumps and injects continuously rather than seasonally. Eventually, the thermal plume shown in Figure 4.25 will approach and breakthrough into the pumped we11. Gringarten and Sauty sought to define the degradation in pumped water quality that could be expected when the distance separating the two wells was limited.

Within their paper Gringarten and Sauty (1975) define several nondimensional parameters useful in presenting their numerical results. They include a nondimensional discharge, $\mathrm{Q}_{D}$; temperature, $\mathrm{T}_{W D}$; time, $\mathrm{t}_{D}$; and thermal exchange, $\lambda$. Note that as $\lambda$ goes to infinity there is less energy exchange between the confining zones and the aquifer. Specific definitions for these parameters are: 


$$
\begin{aligned}
Q_{D} & =\frac{Q}{\left(B D V_{0}\right)} \\
\lambda & =\frac{\left(\rho C_{p}\right)_{W}\left(\rho C_{p}\right)_{A}}{E_{r}\left(\rho C_{p}\right)_{r}} \frac{Q B}{D^{2}} \\
T_{W D} & =\frac{T_{0}-T_{W}}{T_{0}-T_{i}} \\
t_{D} & =\frac{\left(\rho C_{p}\right)_{W}}{\left(\rho C_{p}\right)_{A}} \frac{Q t}{D^{2} B}
\end{aligned}
$$

where

$$
\begin{aligned}
& Q=\text { rate of injection/production } L^{3} t^{-1} \\
& B=\text { thickness of aquifer, } L \\
& D=\text { distance between the production and injection wells, } L \text {. } \\
& \mathrm{V}_{0}=\text { regional ground-water flow, } \mathrm{L} \mathrm{t}^{-1} \\
& T_{0}=\text { initial temperature, } T \\
& T_{W}=\text { temperature at production we11, } T \\
& E_{r}^{W}=\text { vertical heat conductivity of confining rock, } E L^{-1} t^{-1} \\
& \text { and }\left({ } C_{p}\right)_{w},\left({ } C_{p}\right)_{A},\left({ }_{\rho} C_{p}\right)_{r} \text { are the heat capacity of water, aquifer }
\end{aligned}
$$
and rock per unit volume.

As part of their results, Gringarten and Sauty present a set of characteristic curves portraying the production temperature at the pumped well as a function of time and $\lambda$ for discharges of a significant magnitude $\left(Q_{D}>\right.$ $10^{4}$ ). For the purpose of verifying CFEST two simulations have been completed. Lambda values of six and infinity were selected for these simulations. The aquifer, confining rock and fluid properties employed for the lamda equal six case are given in Table 4.7. Lambda equals infinity is obtained by setting the confining rock thermal conductivity to zero; thus creating an insulating boundary. No regional flow was prescribed for the CFEST simulation. The fluid 
TABLE 4.7. Aquifer, Rock and Fluid Properties Used for Doublet Analysis Aquifer (confined)

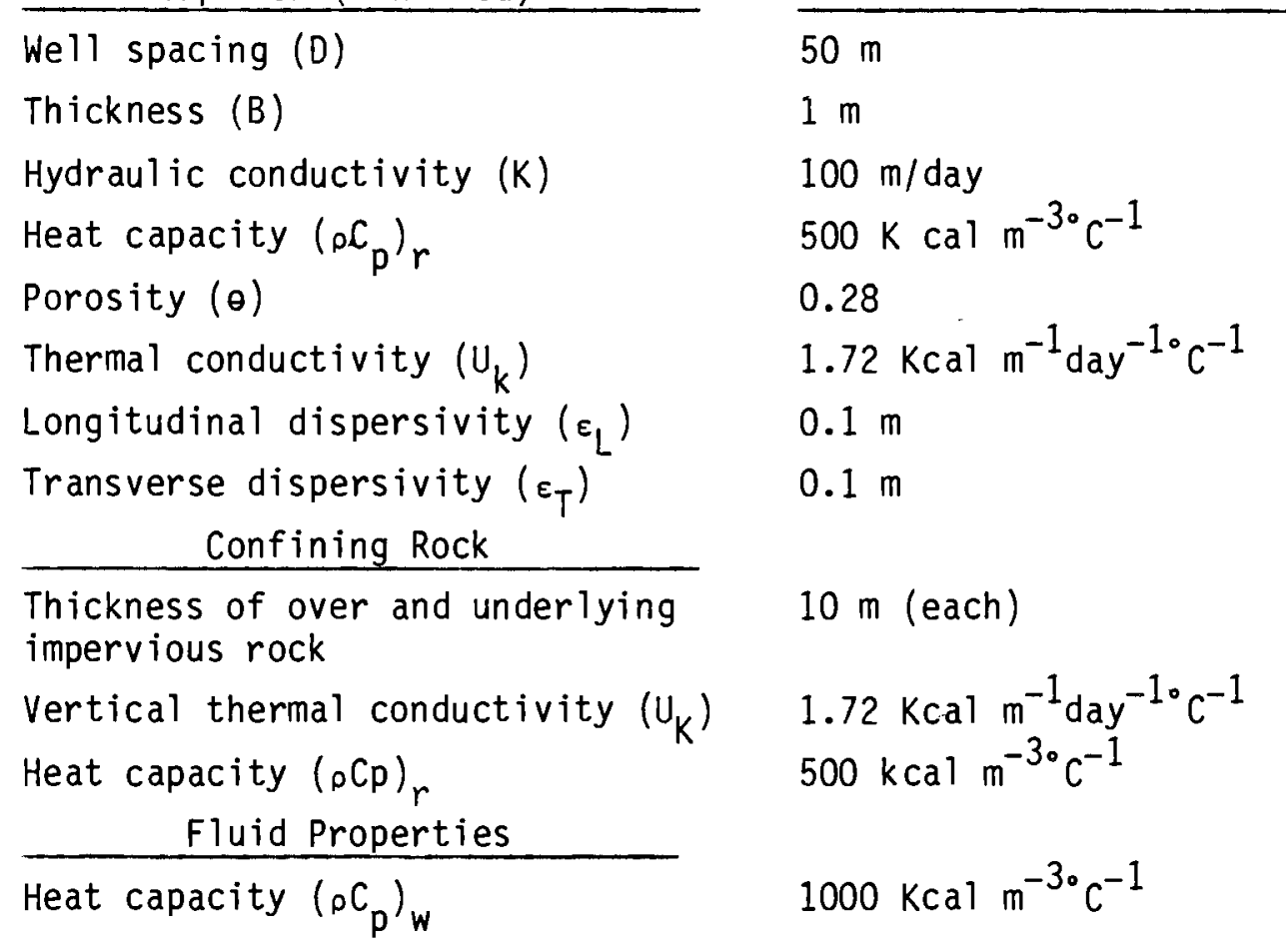

flow was considered steady state. Therefore, parameters such as the compressibility of fluid and medium, viscosity as a function of temperature and density, and variations in density due to temperature were not prescribed. The injection/production rate was $20.156 \mathrm{~m}^{3} /$ day. Initial temperature of the native system was $10^{\circ} \mathrm{C}$ and a $30^{\circ} \mathrm{C}$ injection temperature was employed.

Comparison of the published result and that obtained by CFEST is given in Figure 4.26. Of particular interest is the irregularity of the CFEST result for $\lambda=\infty$. The CFEST code provides a convection-dispersion model of energy transport. With respect to the horizontal, the Gringarten and Sauty model is strictly convective. Thus, a fundamental difference exists and to obtain CFEST solutions a value for longitudinal dispersivity and horizontal thermal conductivity were necessary. For conductive confining rock $(\lambda=6)$ the CFEST results are in good agreement. This is due to the dampening effects of energy transport to the confining media. With insulated confining rocks $(\lambda=\infty)$ the CFEST results slightly overpredict the published result and require reduced time 


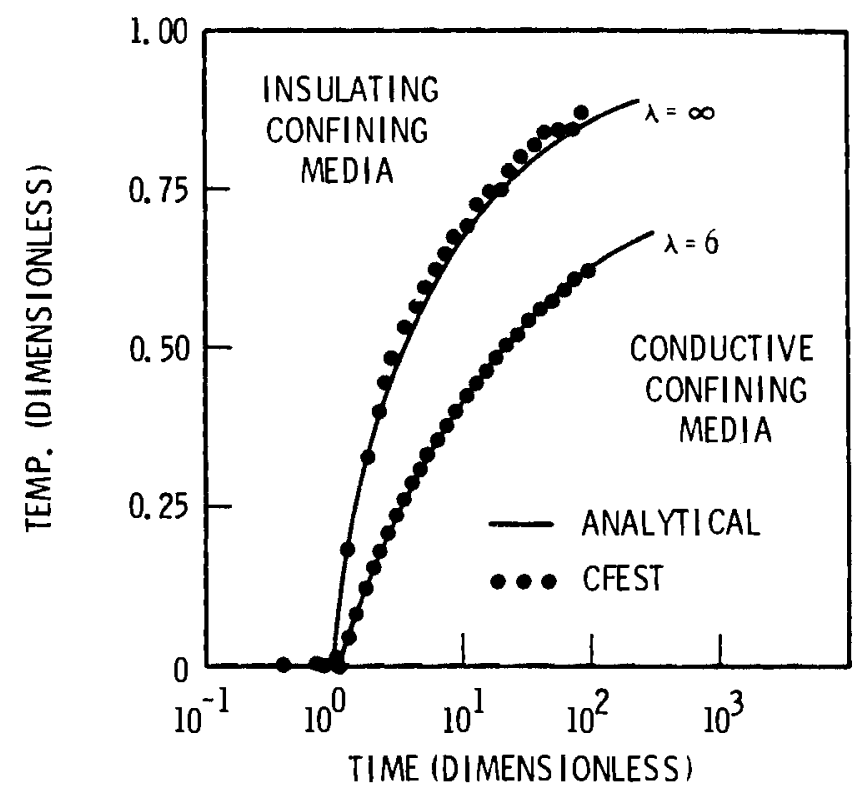

FIGURE 4.26. Comparison of CFEST Results with the Semianalytical Solution of Gringartin-Sauty (1975) for Temperature at the Production Well as a Function of $\lambda$ and time

steps as time advances. This apparent difficulty can be attributed to the inclusion of a small dispersive component in the CFEST analys is where Gringarten and Sauty include none. The results with respect to $\lambda=\infty$ must be judged in light of real phenomena. The confining materials in aquifer systems are not fully insulating, and dispersive phenomena are not negligible. Therefore, the posed problem is a limiting case and CFEST achieves a reasonable solution. 


\section{REFERENCES}

Avdonin, N. A. 1964. "Some Formulas for Calculating the Temperature Field of a Formation During Thermal Injection." Neft i Gaz. Vol. 7, No. 3, pp. $37-41$.

Bear, J. 1979. Hydraulics of Groundwater, McGraw-Hill Inc., 567 p.

Coats, K. H. and D. B. Smith. 1964. Dead-End Pore Volume and Dispersion in Porous Media, S.P.E.J., pp. 73-84.

Faust, C. R. and J. W. Mercer. 1976. An Analysis of Finite-Difference and Finite Element Techniques for Geothermal Reservoir Simulation, Prepared for the Fourth Symposium of Numerical Simulation of Reservoir Performance of the Society of Petroleum Engineers of AIME, SPE 5742, pp. 337-347.

Gringarten, A. C., and J. P. Sauty. 1975. "A Theoretical Study of Heat Extraction for Aquifers with Uniform Regional Flow." Journal of Geophysical Research. 80(35):4956-4962.

Gupta, S. K., C. R. Cole and F. W. Bond. September 1979. Methodology for Release Consequences Analys is - Part III, Finite-Element Three-Dimensional Ground-Water (FE3DWG) Flow Mode1. PNL-2939, Pacific Northwest Laboratory.

Hantush, M. S. 1959. "Nonsteady Flow to Flowing Wells in Leaky Aquifers," Journal of Geophysical Research, Vol. 64, No. 8, pp. 1043, 1052.

Hoopes, J. A. and D. R. Harleman. 1967. "Dispersion in Radial Flow from a Recharge We11, J. Geophys. Res., p. 72.

Hubbert, M. K. 1940. The Theory of Groundwater Motion, J. Geol., Vol. 48, pp. 785-944.

INTERCOMP Resource Development and Engineering, Inc. 1976. A Model for Calculating Effects of Liquid Waste Disposal in Deep Saline Aquifers: U.S. Geological Survey Water-Resources Investigations 76-61, PB 256903, 253 p.

Nelson, R. W. and J. A. Schur. 1978. A Preliminary Evaluation Capability for Some Two-Dimensional Ground-Water Contamination Problems, BCSR-38, Boeing Computer Services, Richland, Washington. (Reissued with minor modification as Paths Groundwater Hydrologic Mode1, PNL-3162, Pacific Northwest Laboratory, Richland, Washington.)

Pinder, G. F. and W. G. Gray. 1977. Finite Element Simulation in Surface and Subsurface Hydrology, Academic Press, $295 \mathrm{p}$.

Scheidegger, A. E. 1961. General Theory of Dispersion in Porous Media. J. Geophys. Res., 66(10), pp. 3273-3278. 
Theis, C. V. 1935. The Relation Between the Lowering of the Piezometric Surface and the Rate and Duration of Discharge of a Wel1 Using Groundwater Storage, Transactions, American Geophysical Union 2:519-524.

Zienkiewicz, 0. C. 1971. The Finite Element Method, McGraw-Hill (UK) Limited, $787 \mathrm{p}$. 
PNL- 4260

UC- $94 \mathrm{e}$

DISTRIBUTION

No. of

Copies

OFFSITE

John J. Brogan

DOE Office of Energy Systems Research

Forrestal Bldg. (MS 6B-025)

1000 Independence Ave. SW

Washington, DC 20585

5 R. Shivers

DOE Office of Energy Systems Research

Forrestal B1dg. (MS 6B-025)

1000 Independence Ave. SW

Washington, DC 20585

J. H. Swisher

DOE Office of Energy Systems Research

Forrestal B1dg. (MS 6B-025)

1000 Independence Ave. SW

Washington, DC 20585

I. Gyuk

DOE Office of Energy Systems Research

Forrestal B1dg. (MS 6B-025)

1000 Independence Ave. SW

Washington, DC 20585

27 Technical Information Center

Fred J. Molz

School of Engineering

Auburn University

Auburn, AL 368630

Charles F. Meyer

1141 Cima Linda Lane

Santa Barbara, CA 93108
No. of

Copies

Chin Fu Tsang

Bldg. 90, Room 1012-H

University of California

Lawrence Berkeley Laboratory

1 Cyclotron Road

Berkeley, CA 94720

Victor E. Hampe 1

Integrated Information Systems

Computation Dept., L-275

University of California

Lawrence Livermore Laboratory

P. 0. Box 808

Livermore, CA 94550

Matt Walton

Minnesota Geological Survey

319 15th Avenue S.E.

Minneapolis, MN 55455

National Aeronautic and Space Administration

Asst. Adm. for Energy Programs

Washington, DC 20546

National Science Foundation

Division of Advanced Energy

Research and Technology

Room 1140

1800 G Street, NW

Washington, DC 20550

Director

New York State Energy Research and Development Agency

Rockefeller Plaza

Albany, NY 11223

J. F. Martin

Oak Ridge National Laboratory

P. 0. Box $Y$

Oak Ridge, TN 37830 
No. of

Copies

Douglas D. Huxtable, Director Energy R\&D

Rocket Research Company

York Center

Redmond, WA 98052

L. B. Katter

Rocket Research

York Center

Redmond, WA 98052

L. Radosevich

Sandia Laboratories, Livermore

P. 0. Box 969

Livermore, CA 94550

W. G. Wilson

Sandia Laboratories, Livermore

P. 0. Box 969

Livermore, CA 94550

Sandia Laboratories

Technical Library Div. 3141

Albuquerque, NM 87185

Charles Wyman

Solar Energy Research Institute

1536 Cole Blvd.

Golden, C0 80401

Allan Michaels

Solar Thermal Storage Programs

Argonne National Laboratory

Building 362

9700 S. Cass Avenue

Argonne, IL 60439

Craig Cooley

Terra Tek

University Research Park

400 Wakara Way

Salt Lake City, UT 84108

U.S. Army Corps of Engineers

Attn: Library

P. 0. Box 59

Louisville, KY 40202
No. of

Copies

U.S. Department of Energy

Attn: Chief, APMBR

Division of Energy Storage Systems

Washington, DC 20545

U.S. Department of Energy

Attn: Director, Policy and Planning

Office of Conservation and

Solar Applications

Washington, DC 20545

U.S. Department of Interior

Attn: Natural Resources Library

Serials Branch (G/E)

Washington, DC 20240

Kevin Billings, Legislative Assistant

Office of Congressman

Sid Morrison

1330 Longworth Bldg.

Washington, DC 20515

Union Carbide Corporation

Nuclear Division

Attn: Library

Y-12 Plant

P. 0. Box $Y$

Oak Ridge, TN 37830

W. E. Soderberg

Program Director, ATES

University of Minnesota

Physical Plant Operations

200 Shops Bldg.

319 15th Avenue S.E.

Minneapolis, MN 55455

J. W. Mercer

GeoTrans Inc.

P. 0. Box 2550

Reston, VA 22090 
No. of

Copies

1 Stuart W. Childs Department of Soil Science Oregon State University Corvallis, OR 97331

5 Sumant K. Gupta ONWI

Battelle Memorial Institute 505 King Avenue

Columbus, Ohio 43201

ONSITE

DOE Richland Operations Office

H. E. Ransom

57 Pacific Northwest Laboratory

D. Blahnik

C. H. Bloomster
No of

Copies

D. B. Cear lock

C. R. Cole (2)

D. E. Deonigi

F. H. Dove (2)

C. T. Kincaid (10)

L. D. Kannberg

K. M. Krupka

W. W. Laity

W. V. Loscutoff

R. P. Marshall

P. R. Meyer (2)

D. A. Myers

C. A. Newbill (2)

J. R. Raymond

J. A. Stottlemyre STES Library (20)

Technical Information (5)

Publishing Coordination $\mathrm{BE}(2)$ 
